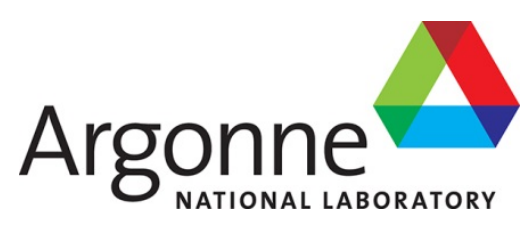

ANL-15/13

\title{
Argonne Engine Friction Study Phase 2 Final Report
}

\author{
Energy Systems Division
}




\section{About Argonne National Laboratory}

Argonne is a U.S. Department of Energy laboratory managed by UChicago Argonne, LLC under contract DE-AC02-06CH11357. The Laboratory's main facility is outside Chicago, at 9700 South Cass Avenue, Argonne, Illinois 60439. For information about Argonne and its pioneering science and technology programs, see www.anl.gov.

\section{DOCUMENT AVAILABILITY}

Online Access: U.S. Department of Energy (DOE) reports produced after 1991 and a growing number of pre-1991 documents are available free via DOE's SciTech Connect (http://www.osti.gov/scitech/)

\section{Reports not in digital format may be purchased by the public from the} National Technical Information Service (NTIS):

U.S. Department of Commerce

National Technical Information Service

5301 Shawnee Rd

Alexandria, VA 22312

www.ntis.gov

Phone: (800) 553-NTIS (6847) or (703) 605-6000

Fax: (703) 605-6900

Email: orders@ntis.gov

Reports not in digital format are available to DOE and DOE contractors from the Office of Scientific and Technical Information (OSTI):

U.S. Department of Energy

Office of Scientific and Technical Information

P.O. Box 62

Oak Ridge, TN 37831-0062

www.osti.gov

Phone: (865) 576-8401

Fax: (865) 576-5728

Email: reports@osti.gov

\section{Disclaimer}

This report was prepared as an account of work sponsored by an agency of the United States Government. Neither the United States Government nor any agency thereof, nor UChicago Argonne, LLC, nor any of their employees or officers, makes any warranty, express or implied, or assumes any legal liability or responsibility for the accuracy, completeness, or usefulness of any information, apparatus, product, or process disclosed, or represents that its use would not infringe privately owned rights. Reference herein to any specific commercial product, process, or service by trade name, trademark, manufacturer, or otherwise, does not necessarily constitute or imply its endorsement, recommendation, or favoring by the United States Government or any agency thereof. The views and opinions of document authors expressed herein do not necessarily state or reflect those of the United States Government or any agency thereof, Argonne National Laboratory, or UChicago Argonne, LLC. 
ANL-15/13

\section{Argonne Engine Friction Study Phase 2 Final Report}

prepared by:

Isaac Fox with contributions by Isaac Fox, Troy Torbeck, and Bill Brogdon Ricardo, Inc.

Prepared for:

Argonne National Laboratory (POC - George Fenske)

ANL Contract \# 1F-01849

Date: January 2002 


\section{Argonne Engine Friction Study Phase 2 Final Report}

Ricardo Inc.

7850 Grant Street

Burr Ridge, IL 60527-5852

TEL: (630) 789-0003

FAX: (630) 789-0127

Prepared for: $\quad$ Argonne National Laboratory

9700 S. Cass Ave.

Argonne, IL 60439-4838

Project: G0908

Archive: RD.03/69702

Date: 10-Jul-03

Author:

Isaac Fox

Contributors:

Isaac Fox

Troy Torbeck

Bill Brogdon

Technical Approval:

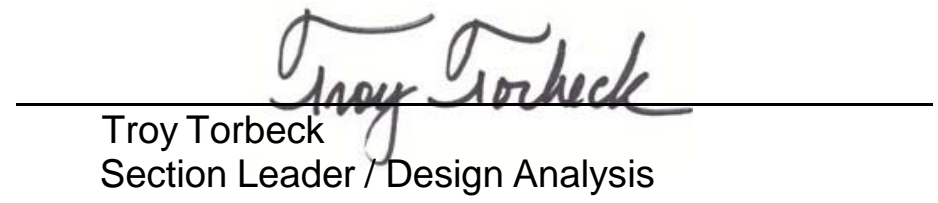




\section{ARGONNE ENGINE FRICTION STUDY PHASE 2}

\section{FINAL REPORT}

\section{EXECUTIVE SUMMARY}

Argonne National Laboratory (ANL) has developed a process for making near frictionless carbon (NFC) coatings and depositing them on metal substrates. Friction reductions approaching an order of magnitude have been measured in laboratory tests. While there are many potential applications for such coatings, friction reduction in internal combustion engines is of particular interest due to the apparent fuel savings potential. Ricardo has performed a program of work to estimate potential fuel economy improvements due to the application of such a coating at key interfaces within a diesel engine typical of those found in large trucks. In the first phase of this work, fuel economy improvements due to the application of coatings without changes to the lubricant were calculated. In the second phase of this work, the combined effects of changes in lubricant viscosity and application of a low-friction coating were calculated.

Piston, ring pack, journal bearing, and valvetrain simulations have been performed, using existing models of representative engines, with various degrees of friction reduction applied at important interfaces, for several lubricant viscosity grades. The simulations were run at 8 specific operating points to allow approximation of engine performance over the FTP test cycle. Changes in fuel consumption and predicted metal-to-metal contact severity were calculated for each case.

Results from the first phase of the work showed that application of a friction-reducing surface treatment, like the NFC coatings, at the piston rings and skirt, and at key interfaces within the valvetrain, is expected to result in a reduction in fuel consumption of $0.43 \%$ to $0.81 \%$ over the FTP heavy duty test cycle, with no changes to the engine lubricant.

Results from the second phase of the work showed that the combination of reduced lubricant viscosity and reduced asperity friction coefficient can result in fuel economy improvements of nearly 5\% over the FTP HD cycle. Metal-to-metal contact severity is substantially increased, and wear-reducing surface treatments or other design changes would be required to prevent premature engine failure. 


\section{TABLE OF CONTENTS}

\section{Page}

EXECUTIVE SUMMARY

2. OBJECTIVES

3. TECHNICAL APPROACH

3.1 Engine Type

3.2 Mean Effective Pressures

3.3 Ricardo 8-Mode FTP Simulation

3.4 Interfaces Considered

3.5 Friction Reductions

3.6 PISDYN

3.7 RINGPAK

3.8 ORBIT

3.9 VALDYN

3.10 Calculation of Fuel Savings

4. RESULTS 


\section{LIST OF TABLES}

$\underline{\text { Page }}$

1. Summary of Load/Speed Cases 15

2. Friction Coefficients at each Interface 15

3. Predicted FMEP Changes by Interface, 0\% Asperity Friction Reduction 16

4. Predicted FMEP Changes by Interface, 30\% Asperity Friction Reduction 17

5. Predicted FMEP Changes by Interface, 60\% Asperity Friction Reduction 18

6. Predicted FMEP Changes by Interface, 90\% Asperity Friction Reduction 19

7. Summary of Overall Fuel Consumption Results, $0 \%$ Asperity Friction Reduction 20

8. Summary of Overall Fuel Consumption Results, 30\% Asperity Friction Reduction 21

9. Summary of Overall Fuel Consumption Results, $60 \%$ Asperity Friction Reduction 22

10. Summary of Overall Fuel Consumption Results, 90\% Asperity Friction Reduction 23 


\section{LIST OF FIGURES}

$\underline{\text { PAGE }}$

1. Diagram of Overall Approach $\quad 24$

2. Significant Friction Sources 25

3. Piston Assembly Motoring Friction vs. Mean Piston Speed 26

4. Total Valvetrain Motoring Friction vs. Mean Piston Speed 27

5. Predicted Piston Skirt Friction Contributions (No Treatment, SAE40) 28

6. Piston Skirt Friction Contributions (30\% Reduction in Asperity Friction, SAE40) 28

7. Piston Skirt Friction Contributions (60\% Reduction in Asperity Friction, SAE40) 29

8. Piston Skirt Friction Contributions (90\% Reduction in Asperity Friction, SAE40) 29

9. Changes in Piston Skirt Average FMEP over FTP Cycle 30

10. Changes in Piston Skirt Contact Severity over FTP Cycle 30

11. Illustration of Metal-to-Metal Contact Regions on Skirt and Liner vs. Viscosity 31

12. Predicted Ring Pack Friction Contributions (No Treatment, SAE40) 32

13. Ring Pack Friction Contributions (30\% Reduction in Asperity Friction, SAE40) 32

14. Ring Pack Friction Contributions (60\% Reduction in Asperity Friction, SAE40) 33

15. Ring Pack Friction Contributions (90\% Reduction in Asperity Friction, SAE40) 33

16. Changes in Ring Pack Average FMEP over FTP Cycle 34

17. Changes in Ring Pack Contact Severity over FTP Cycle 34

18. Changes in Main Bearing Average FMEP over FTP Cycle 35

19. Changes in Main Bearing Contact Severity over FTP Cycle 35

20. Changes in Connecting Rod Large-End Bearing Average FMEP over FTP Cycle 36

21. Changes in Connecting Rod Large-End Bearing Contact Severity over FTP Cycle36

22. Changes in Connecting Rod Small-End Bearing Average FMEP over FTP Cycle 37

23. Changes in Connecting Rod Small-End Bearing Contact Severity over FTP Cycle37

24-29. Predicted FMEP Contributions by Component, 0\% Asperity Friction Reduction38

30-35. Predicted FMEP Contributions by Component, 30\% Asperity Friction Reduction

36-41. Predicted FMEP Contributions by Component, 60\% Asperity Friction Reduction

42-47. Predicted FMEP Contributions by Component, 90\% Asperity Friction Reduction

48-53. Predicted Change in FMEP by Component, 0\% Asperity Friction Reduction

54-59. Predicted Change in FMEP by Component, 30\% Asperity Friction Reduction

60-65. Predicted Change in FMEP by Component, 60\% Asperity Friction Reduction

66-71. Predicted Change in FMEP by Component, 90\% Asperity Friction Reduction

72. Changes in Average FMEP over FTP Cycle

73. Changes in Fuel Consumption over FTP Cycle 


\section{INTRODUCTION}

Argonne National Laboratory (ANL) has developed a process for making near frictionless carbon (NFC) coatings and depositing them on metal substrates. The amorphous carbon coatings exhibit properties comparable to diamond. Friction reductions approaching an order of magnitude have been measured in laboratory tests, and substantial increases in wear resistance have been shown. While there are many potential applications for such coatings, friction reduction in internal combustion engines is of particular interest due to the apparent fuel savings potential.

The U.S. Department of Energy's (DOE) Office of Heavy Vehicle Technology (OHVT) has estimated energy loss due to friction in various vehicles and specific engine components (pistons, rings, and connecting rods). For example, for heavy duty (HD) vehicles the estimated energy loss is equivalent to 160 million barrels of diesel fuel per year. It is assumed that this loss could be reduced through the selective use of NFC coatings on engine components, but there is relatively little guidance available on where to employ such coatings in a manner that is both practical and effective. To properly assess the potential value of Argonne's NFC coatings, their impact on engine friction needs to be quantified and their effect on engine design, production, and durability issues needs to be assessed.

Ricardo has performed a program of work to assess the potential for fuel savings through friction reduction at key engine interfaces combined with lubricant viscosity reduction. This program of work is outlined in Ricardo Statement of Work G0908, and the results of this work are presented in the sections below.

\section{OBJECTIVES}

The objectives of this work were:

Y To estimate the potential for reduction in fuel consumption due to the application of friction-reducing surface treatments and changes to lubricant viscosity

$Y$ To calculate the effects on metal-to-metal contact severity that may result from these changes

\section{TECHNICALAPPROACH}

A schematic representation of the overall technical approach is shown in Figure 1. The following paragraphs summarize the methodology.

\subsection{Engine Type}

The engine type studied was a diesel typical of those found in large trucks. In a valvetrain system typical of these engines, each cam lobe is contacted by the rolling portion of a roller follower. The other end of the roller follower moves a pushrod, which actuates a rocker arm. The rocker arm pivots upon a rocker shaft, with the other end of the arm pressing against a valve bridge. Each valve bridge, and thus each cam lobe, operates two valves. Figure 2 shows an engine with a similar valvetrain layout, but 
without the roller follower and valve bridge. The engine type studied would typically use an articulated piston, comprised of a separate skirt and crown, with two compression rings to seal gases within the cylinder, and one oil retention ring to assist in the removal of excess oil from the cylinder wall.

\subsection{Mean Effective Pressures}

To compare the performance of engines of various sizes, it is common to use mean effective pressure, or MEP. Mean effective pressure is independent of engine size or speed. MEP is a representative pressure that is required within an engine, during the expansion stroke, to produce a particular power output at a particular speed. Cylinder pressure over the remaining strokes is assumed to be zero for this theoretical cycle. In other words, MEP is work per cycle divided by the volume displaced during the cycle. Several different types of MEP were used in the course of this study to simplify comparisons between engines:

$\mathrm{Y}$ Indicated mean effective pressure (IMEP) is based on the cylinder pressure and volume throughout the cycle. It is directly related to the maximum amount of work that could be produced by an engine with no mechanical losses.

Y Brake mean effective pressure (BMEP) is based on the work output of an engine, and takes into account any mechanical losses within the engine. BMEP is a value that is often used to describe how highly rated an engine is, or how heavily it is loaded at a particular operating condition.

$Y$ Friction mean effective pressure (FMEP) is based on the difference between IMEP and BMEP, and represents the mechanical losses within the engine.

\subsection{Ricardo 8-Mode FTP Simulation}

For estimates of fuel savings to be useful, they need to be representative of what can be achieved in real-world operation. The FTP heavy-duty transient test cycle is a test used for emissions testing of engines in the USA. The test is intended to be representative of the load conditions that the engine in a heavy-duty vehicle, such as a truck or bus, would see in operation. The cycle includes both city and highway segments. A cold start segment, periods of acceleration and deceleration, idling, and motoring are incorporated into the test. Typical engine loads are $20-25 \%$ of the available power at a given speed, and there are few periods of steady operation.

Testing an engine on the FTP heavy-duty transient test cycle requires special equipment and calibration, and is thus expensive to perform. Ricardo has developed a test procedure to allow the evaluation of engine performance over the FTP cycle using more conventional test equipment. The Ricardo 8-Mode FTP simulation is a steady-state, nonmotored, test procedure consisting of eight modes designed to represent key regimes of the FTP cycle. Emissions and fuel consumption at each mode are multiplied by a weighting factor, and the results are summed to give an overall outcome. The results of the 8-mode simulation closely correlate with results of the FTP cycle, making the 8-mode simulation a comparatively inexpensive way to gage engine performance over the FTP cycle. 
The detailed nature of the FTP heavy-duty transient test cycle makes it impractical to model the cycle directly for this study. Instead, simulations have been performed at 8 different load/speed points consistent with the Ricardo 8-Mode test. The predicted reduction in FMEP at each operating point was then considered together with measured data from an 8-Mode engine test to predict changes in fuel consumption. Table 1 summarizes the load and speed conditions used. Predicted increases in contact severity at each interface were multiplied by the same weighting factors to give cycleaveraged contact severity increases for the interfaces considered.

\subsection{Interfaces Considered}

The engine interfaces analyzed for this study were the following:

Y Piston skirt to cylinder liner

$Y$ Piston rings to cylinder liner

Y Cam to cam bearings

Y Cam to follower

Y Pushrod to rocker arm

Y Rocker arm to valve bridge

Y Connecting rod small-end bearings

$Y$ Connecting rod large-end bearings

$Y$ Crankshaft main bearings

The interfaces were chosen because of the expected significance of their contributions to engine friction, as well as the existence of appropriate models from previous engine analyses. Figure 2 shows similar components.

\subsection{Friction Reductions}

The effects of a surface treatment on real-world friction at an internal engine interface are very difficult to predict through laboratory or analytical methods alone. Thus, for this study, varying degrees of friction reduction were considered, to bracket the potential for real-world improvement. Friction reductions for each interface were based on consideration of laboratory friction test results, expected conditions at the interface, and experience with motoring friction measurements of existing engines. Table 2 shows a summary of the typical friction coefficients that Ricardo would apply at each interface. The asperity friction coefficients for non-valvetrain interfaces were reduced by $90 \%$, $60 \%$, and $30 \%$. Based on friction reduction results observed at Argonne, real-world asperity friction reductions due to application of the NFC coatings are expected to fall within this range. The valvetrain friction was assumed to follow the trend observed in the other interfaces, and predicted friction for each case was scaled down by the average reduction seen in the other interfaces.

\subsection{PISDYN}

The Ricardo software PISDYN was used to simulate the friction behavior of the piston skirt as it travels up and down the cylinder liner. PISDYN is a time-domain simulation of 
piston secondary dynamic motion, that uses detailed models to represent hydrodynamic and boundary lubrication at the skirt-liner interface and the wrist pin bearings. Elasticity of the skirt and/or cylinder liner are considered. An elasto-hydrodynamic lubrication $(E H L)$ module predicts oil film pressure and bearing clearance, using a mass-conserving solution of the Reynolds Equation, at each node of a matrix covering the surface of the piston skirt. When skirt-liner clearances are small, a Greenwood-Tripp model is used to evaluate the asperity contact pressures, and asperity friction is calculated using a friction coefficient and contact pressures across the skirt matrix. Wrist pin bearing lubrication and friction are calculated used a method similar to that described above.

For this study, an existing PISDYN model from a previous analysis of a heavy-duty diesel engine (Engine "A") was used. Engine "A" has an inline 6 cylinder configuration. It incorporates an articulated piston design and has an overall displaced volume of 10 liters. A baseline series of runs, representative of the Ricardo 8-Mode test, was executed, using the friction coefficient that Ricardo would typically apply. The asperity friction coefficient was reduced, in separate cases, by $90 \%, 60 \%$, and $30 \%$. Lubricant viscosity grades of SAE5, SAE10, SAE20, SAE30, SAE40, and SAE50 were simulated. Predicted reduction in power loss due to piston skirt friction was tabulated, for simulations at each of the 8-modes of the Ricardo 8-mode FTP cycle simulation, for each of the 4 friction coefficient cases, with each of the lubricant viscosity grades. Changes in predicted contact severity for each case were tabulated.

\section{7 $\quad$ RINGPAK}

The Ricardo software RINGPAK was used to calculate the friction between the rings and liner. RINGPAK is a time-domain simulation of ring motion, and addresses both hydrodynamic and boundary lubrication at the ring-liner interfaces. Lubricant pressures at these interfaces are obtained through the implementation of a mass-conserving scheme to solve the Reynolds Equation. When ring-liner clearances are small, a Greenwood-Tripp model is used to evaluate the asperity contact pressures. Hydrodynamic losses are calculated for the lubricant, and ring asperity friction is calculated using contact pressures and a friction coefficient.

For this study, an existing RINGPAK model from a previous analysis of a heavy-duty diesel engine (Engine "A") was used. Engine " $A$ " has an inline 6 cylinder configuration. It incorporates an articulated piston design and has an overall displaced volume of 10 liters. A baseline series of RINGPAK runs, representative of the Ricardo 8-Mode test, was executed, using the ring-liner asperity friction coefficient that Ricardo typically applies. The asperity friction coefficient was reduced, in separate cases, by $90 \%, 60 \%$, and $30 \%$. Predicted reductions in power loss due to ring friction were tabulated, for simulations at each of the 8-modes of the Ricardo 8-mode FTP cycle simulation, for each of the 4 friction coefficient cases, with each of the lubricant viscosity grades. Changes in predicted contact severity for each case were tabulated.

\section{$3.8 \underline{\text { ORBIT }}$}

The Ricardo software ORBIT was used to calculate the friction within the journal bearings in the engine. ORBIT is a time-domain simulation of bearing motion, and 
addresses both hydrodynamic and boundary lubrication at the bearing surfaces. Lubricant pressures between the bearing surfaces are obtained through the implementation of a mass-conserving scheme to solve the Reynolds Equation. When bearing clearances are small, a Greenwood-Tripp model is used to evaluate the asperity contact pressures. Hydrodynamic losses are calculated for the lubricant, and asperity friction is calculated using contact pressures and a friction coefficient.

To generate oil supply pressure conditions for ORBIT, a MATLAB simulation of the lubricant circuit was used. For each engine operating speed and lubricant viscosity, the simulation calculated an average oil supply pressure at each journal bearing. Iterative thermal balance calculations were performed using a rigid bearing model within ORBIT to generate representative oil temperatures for use in the simulations.

ORBIT models representing bearing geometry within a heavy-duty diesel engine (Engine "D") were generated. Engine "D" has an inline 6 cylinder configuration. It incorporates an articulated piston design and has an overall displaced volume of 14.6 liters. Elasticity of the bearing housings was considered for the main bearings and large-end bearings. The asperity friction coefficient was reduced, in separate cases, by $90 \%, 60 \%$, and $30 \%$. Predicted reductions in power loss due to bearing friction were tabulated, for simulations at each of the 8-modes of the Ricardo 8-mode FTP cycle simulation, for each of the 4 friction coefficient cases, with each of the lubricant viscosity grades. Changes in predicted contact severity for each case were tabulated.

\section{$3.9 \quad$ VALDYN}

The Ricardo software VALDYN was used to calculate the friction at key interfaces within the valvetrain. VALDYN is a time-domain simulation of valvetrain dynamics. Friction is addressed in VALDYN via simple friction coefficients and calculated normal forces.

An existing VALDYN model from an analysis of a heavy-duty diesel engine (Engine "B") was used for this study. Engine "B" has an inline 6-cylinder configuration, and has an overall displaced volume of 9 liters. The valvetrain employs a roller-follower, and each cam lobe operates two valves. Exhaust gas pressure was applied at the exhaust valves to provide an accurate representation of valvetrain loading. Friction power losses within the valvetrain were reduced by the average reduction seen at the non-valvetrain interfaces, for the same set of simulations run at the other interfaces. Cam drive power was tabulated for each case.

\subsection{Calculation of Fuel Savings}

Reductions in FMEP were calculated based on the predicted friction power reductions from the PISDYN, RINGPAK, ORBIT, and VALDYN simulations. IMEP plus change in FMEP, divided by IMEP, for each of the 8 modes, gives a scaling factor for fuel consumption at each mode. Data from a previous test of a heavy-duty diesel engine (Engine "C") was used as a baseline. Engine " $\mathrm{C}$ " has an overall displacement of 11 liters. The valvetrain employs a roller-follower, and each cam lobe operates two valves. The engine incorporates an articulated piston design. The fuel consumption of Engine "C," at each test point, was scaled by the aforementioned scaling factor, to give 
Client Name: Argonne National Laboratory

Project No:: G0908

Archive: RD.03/69702

estimated fuel consumption for the engine with NFC coatings. Application of the weighting factors allows a calculation of estimated change in overall fuel consumption for the FTP cycle.

\subsection{RESULTS}

The friction power losses predicted for the baseline PISDYN, RINGPAK, and VALDYN cases fall in line with experimental measurements of motoring friction. See Figures 3 and 4 for a comparison of predicted friction losses versus previously measured motoring friction data.

The predicted contributions of hydrodynamic and boundary friction to FMEP at the piston skirt, for the baseline lubricant viscosity grade, are shown in Figures 5-8. Hydrodynamic friction tends to increase with increased piston speed. Asperity friction is dramatically increased in the high-load cases. The particular piston skirt analyzed had a larger-thandesired amount of skirt contact and wear in the high load cases, but the design is in use in production engines, and such contact is not atypical. The reductions in friction coefficient were of increasing importance as lubricant viscosity was reduced, and as engine load was increased. Figure 9 shows the expected changes in average FMEP over the FTP HD cycle for each combination of lubricant viscosity and asperity friction reduction, considering the piston skirt to cylinder liner interface alone. For each level of asperity friction coefficient reduction, there was a corresponding oil viscosity grade that gave the largest improvement in average FMEP over the cycle. With no change in asperity friction coefficient, SAE40 oil gave the lowest average FMEP over the FTP cycle. If asperity friction coefficient were reduced by $90 \%$, a viscosity grade lower than SAE05 would offer the lowest average FMEP over the cycle. Figure 10 shows the FTPcycle-averaged change in contact severity at the piston skirt to cylinder liner interface, relative to the baseline case, for each of the lubricant viscosity grades considered. The results show that to run successfully with SAE05 oil, the piston skirt to liner interface would need to be made approximately four times as resistant to wear as in the baseline case. Figure 11 shows the predicted growth of the regions of metal-to-metal contact on the skirt and liner as lubricant viscosity is reduced from SAE50 to SAE05. PISDYN can be used to assist in the design of a skirt profile that results in substantially lower wear, but such work was beyond the scope of this study.

The contributions of hydrodynamic and boundary friction to average FMEP at the ringliner interfaces, for the baseline case, are shown in Figures 12-15. Hydrodynamic friction increased with increased piston speed, and with increased engine load. Asperity friction was reduced at higher piston speeds due to increased oil film thickness. Figure 16 shows the expected reductions in average FMEP over the FTP HD cycle for each combination of lubricant viscosity and asperity friction reduction, considering the ringliner interfaces alone. The total friction at the piston rings was dominated by hydrodynamic losses, and thus the lowest total friction was predicted for the case with the lowest lubricant viscosity. Figure 17 shows the FTP-cycle-averaged change in contact severity at the ring-liner interfaces, relative to the baseline case, for each of the lubricant viscosity grades considered. The results are similar to those for the piston skirt; the contact severity using SAE05 oil is about four times that with SAE40 oil. To 
Client Name: Argonne National Laboratory

Project No:: G0908

Archive: $\quad$ RD.03/69702

achieve the same level of wear using SAE05 oil, the ring-liner interfaces would have to be approximately four times as resistant to wear as in the baseline case.

Predicted changes in average FMEP over the FTP cycle, for the crankshaft main bearings, for each combination of lubricant viscosity and asperity friction reduction, are shown in Figure 18. No metal-to-metal contact was predicted for oil viscosity grades above SAE20, and as a result there was no predicted asperity friction for these cases. In the cases where metal-to-metal contact was predicted, the predicted asperity friction was of a substantially lower magnitude than the hydrodynamic friction. As a result, the main bearings are predicted to have the lowest average FMEP when SAE05 oil is used. The FMEP curves in Figure 18 suggest that viscosity grades lower than SAE05 could yield even lower FMEP, but SAE05 was the lowest viscosity grade considered in this study. Figure 19 shows the relative change in FTP-cycle-averaged contact severity at the main bearings. The baseline case showed no predicted metal-to-metal contact, so the contact severity for the main bearings has been normalized by the baseline value for the connecting rod large end bearings. The magnitude of the predicted contact at the main bearings is considerably smaller than that predicted at the large-end bearings, but it is worth noting that contact is predicted to occur in the low viscosity cases, while no contact is predicted for grades above SAE20.

Predicted changes in average FMEP over the FTP cycle, for the connecting rod largeend bearings, are shown in Figure 20. Predicted asperity friction at the large-end bearings was greater than that predicted at the main bearings, but the magnitude of the asperity friction is substantially less than that of the hydrodynamic friction. The large end bearings are predicted to have the lowest average FMEP when SAE05 oil is used. The FMEP curves in Figure 20 suggest that viscosity grades lower than SAE05 could yield even lower FMEP, but SAE05 was the lowest viscosity grade considered in this study. Figure 21 shows the relative change in FTP-cycle-averaged contact severity at the connecting rod large-end bearings. Contact severity is increased more than $17 x$ when SAE05 oil is used in place of SAE40 oil. To maintain the same level of wear, with the same bearing geometry, the large-end bearings would have to be made more than $17 x$ as resistant to wear as in the baseline case. An alternative would be to change the bearing geometry to provide greater oil film thicknesses, but space constraints may not allow such changes.

Predicted changes in average FMEP over the FTP cycle, for the connecting rod smallend bearings, are shown in Figure 22. Predicted asperity friction at the small-end bearings was about one third of the total friction. In contrast to the trends seen at all of the other journal bearings, hydrodynamic friction at the small-end bearings increased as lubricant viscosity was reduced. This is because the small-end bearings act primarily as squeeze bearings, rather than rotating bearings, and pressure losses are, accordingly, of greater importance than shear losses. The lowest average FMEP at the small end bearings was achieved with SAE50 oil. Figure 23 shows the change in FTP-cycleaveraged contact severity at the connecting rod small-end bearings. Predicted contact severity is increased about 2.5x when SAE05 oil is used in place of SAE40 oil.

Tables 3-6 summarize the predicted FMEP changes at each interface for each case. Tables 7-10 summarize the predicted total changes in fuel consumption for each case. 
Client Name: Argonne National Laboratory

Project No:: G0908

Archive: RD.03/69702

Figures 24-37 compare the FMEP contributions at each interface, for each simulation mode, oil viscosity grade, and asperity friction reduction percentage. In the baseline case, the piston rings are the largest contributor to engine friction, followed by the piston skirt. Because of the relatively large amount of asperity friction seen at the piston skirt, it becomes the dominant contributor for low-viscosity cases, if the asperity friction coefficient is not reduced. Figures 38-71 compare the changes in FMEP at each interface, for each simulation mode, oil viscosity grade, and asperity friction coefficient. Asperity friction at the piston skirt to liner interface was largest in low-speed, high-load cases, and as a result, these cases show the largest improvements due to asperity friction reduction. Overall, the piston skirt and rings are the interfaces where reducing asperity friction will have the largest impact on total fuel consumption.

Figure 72 shows the predicted overall changes in average FMEP over the FTP cycle due to changes in oil viscosity and asperity friction coefficient at the interfaces studied. Figure 73 shows the estimated change in fuel consumption over the FTP cycle due to these changes. If a $30 \%$ reduction in asperity friction can be achieved at each of the above interfaces, then using a SAE10 oil is predicted to result in a fuel savings of approximately $1.75 \%$ over the FTP cycle. Using a SAE05 oil in conjunction with a surface treatment that reduces asperity friction by $90 \%$ is predicted to result in fuel savings of nearly $5 \%$ over the FTP cycle.

\subsection{CONCLUSIONS ANDRECOMMENDATIONS}

Application of a friction-reducing surface treatment, like the NFC coatings, at the piston rings and skirt, within the engine journal bearings, and at key interfaces within the valvetrain, is expected to result in a reduction in fuel consumption of $1 \%$ to $4.8 \%$ over the FTP heavy-duty test cycle. The piston skirt and rings are the components which are predicted to show the greatest improvement due to asperity friction reduction. The amount by which fuel consumption is improved is heavily dependent upon the lubricant viscosity chosen. The oil viscosity that yields the best fuel consumption over the FTP HD test cycle depends on what level of asperity friction reduction can be achieved in practice with a given surface treatment.

Metal-to-metal contact severity is substantially increased when lubricant viscosity is reduced. If the use of a lower viscosity lubricant is desired, then changes to the geometry of affected bearings, or improvements in wear resistance at the lubricated interfaces will be necessary. For application of reduced lubricant viscosity to be viable, the surface treatments must provide a sustained increase in wear resistance approximately equal to the increase in contact severity. Hence, the minimum viscosity that can be used, and the maximum fuel savings that can be achieved in practice, will depend on the wear behavior of the treated interfaces.

To make the coatings more commercially attractive, it would be useful to have physical confirmation of their benefits in terms of both friction and wear within an engine. As coating and testing a complete engine would likely be too expensive, rig tests intended to approximate running conditions within an engine may be an attractive alternative. Argonne, certain heavy-duty engine manufacturers, and others have test rigs that can simulate conditions seen at some of the critical engine interfaces, such as piston-liner, 
ring-liner, and the journal bearings. Ricardo suggests performing tests on these test rigs to determine wear and friction effects of the NFC coatings. Operating conditions for the tests should be chosen based upon conditions seen within running engines. The results of these tests can be used in conjunction with the existing simulation decks to estimate the real-world effects that the coatings would have on fuel consumption and wear over a particular engine operating cycle, such as the FTP HD cycle. To facilitate the extraction of asperity friction coefficients from the test results, the test conditions should be duplicated as closely as possible with additional simulation runs, to give predicted contact severity and asperity pressure values corresponding to the test conditions. 


\begin{tabular}{|lcccccccc|}
\hline \multicolumn{2}{l}{ Table 1: Summary of Load/Speed Cases } \\
\begin{tabular}{|lccccccccc}
\hline \\
FTP Simulation Mode
\end{tabular} & 1 & 2 & 3 & 4 & 5 & 6 & 7 & 8 \\
Engine Speed (rpm) & 750 & 960 & 1170 & 1590 & 1590 & 1800 & 1800 & 1800 \\
Fuel Mass $(\mathrm{kg})$ & 1.766 & 28.084 & 48.419 & 28.793 & 58.144 & 10.224 & 31.094 & 57.313 \\
IMEP $(\mathrm{kPa})$ & 104 & 1683 & 1683 & 983 & 1683 & 325 & 983 & 1683 \\
BMEP $(\mathrm{kPa})$ & 0 & 1565 & 1565 & 783 & 1565 & 157 & 783 & 1565 \\
FMEP $(\mathrm{kPa})$ & 104 & 118 & 118 & 200 & 118 & 168 & 200 & 118 \\
Weightings & 0.52 & 0.03 & 0.04 & 0.15 & 0.08 & 0.06 & 0.08 & 0.05 \\
\hline
\end{tabular}

\begin{tabular}{|cccc|}
\hline Table 2: Baseline Friction Coefficients at each Interface & & \\
\hline Interface & Baseline Friction Coefficient & Simulation Program Used & Friction Model \\
Cam-Follower & 0.005 & VALDYN & Simple \\
Cam-Cam Bearing & 0.02 & VALDYN & Simple \\
Rocker Arm - Rocker Support & 0.02 & VALDYN & Simple \\
Pushrod Socket - Pushrod & 0.05 & VALDYN & Simple \\
Rocker Tip - Valve Bridge & 0.05 & VALDYN & Detailed Hydrodynamic and Boundary Lubrication \\
Piston Skirt - Cylinder Liner & 0.08 & PISDYN & Detailed Hydrodynamic and Boundary Lubrication \\
Piston Rings - Cylinder Liner & 0.12 & RINGPAK & Detailed Hydrodynamic and Boundary Lubrication \\
Piston Pin - Piston & 0.08 & PISDYN & Detailed Hydrodynamic and Boundary Lubrication \\
Connecting Rod Small End & 0.12 & ORBIT & Detailed Hydrodynamic and Boundary Lubrication \\
Connecting Rod Large End & 0.12 & ORBIT & Detailed Hydrodynamic and Boundary Lubrication \\
Crankshaft Main Bearing & 0.12 & ORBIT &
\end{tabular}


Client Name: Argonne National Laboratory

Project No: $\quad$ G0908

Archive: RD.03/69702

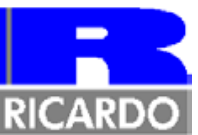

Table 3: Summary of Predicted FMEP Changes at each Interface, 0\% Asperity Friction Reduction

\begin{tabular}{|c|c|c|c|c|c|c|c|c|c|}
\hline FTP Simulation & $\begin{array}{l}\text { Mode } \\
\text { Viscosity } \\
\text { Grade (SAE) }\end{array}$ & 1 & 2 & 3 & $\Delta \mathrm{FM}$ & $\mathrm{kPa})$ & 6 & 7 & 8 \\
\hline \multirow{6}{*}{$\begin{array}{l}\text { Large End } \\
\text { Bearings }\end{array}$} & 5 & -1.61 & 3.18 & -1.20 & -3.62 & -3.93 & -2.95 & -3.23 & -3.55 \\
\hline & 10 & -1.44 & 2.20 & -1.37 & -3.34 & -3.62 & -2.65 & -2.90 & -3.20 \\
\hline & 20 & -0.77 & 0.13 & -1.09 & -1.86 & -2.04 & -1.31 & -1.42 & -1.59 \\
\hline & 30 & -0.38 & -0.08 & -0.65 & -1.18 & -1.27 & -0.57 & -0.60 & -0.68 \\
\hline & 40 & 0.00 & 0.00 & 0.00 & 0.00 & 0.00 & 0.00 & 0.00 & 0.00 \\
\hline & 50 & 0.51 & 0.58 & 0.75 & 0.53 & 0.59 & 1.07 & 1.15 & 1.26 \\
\hline \multirow{7}{*}{$\begin{array}{l}\text { Small End } \\
\text { Bearings }\end{array}$} & & \multicolumn{8}{|c|}{$\triangle$ FMEP $(\mathrm{kPa})$} \\
\hline & 5 & 0.31 & 1.39 & 0.55 & 0.77 & 0.91 & 1.44 & 0.88 & 0.93 \\
\hline & 10 & 0.27 & 1.36 & 0.45 & 0.74 & 0.70 & 0.96 & 0.68 & 0.80 \\
\hline & 20 & 0.12 & 1.16 & 0.18 & 0.27 & 0.29 & 0.36 & 0.21 & 0.28 \\
\hline & 30 & 0.04 & 1.07 & 0.07 & 0.04 & 0.08 & 0.08 & 0.07 & 0.07 \\
\hline & 40 & 0.00 & 0.00 & 0.00 & 0.00 & 0.00 & 0.00 & 0.00 & 0.00 \\
\hline & 50 & -0.06 & 0.87 & -0.07 & -0.09 & -0.09 & -0.19 & -0.07 & -0.15 \\
\hline \multirow{7}{*}{$\begin{array}{c}\text { Crankshaft } \\
\text { Main Bearings }\end{array}$} & & \multicolumn{8}{|c|}{$\triangle F M E P(\mathrm{kPa})$} \\
\hline & 5 & -3.25 & -4.18 & -4.13 & -3.37 & -3.80 & -3.21 & -3.50 & -3.72 \\
\hline & 10 & -2.85 & -3.73 & -3.57 & -2.93 & -3.30 & -2.98 & -3.08 & -3.29 \\
\hline & 20 & -1.41 & -1.82 & -1.65 & -1.54 & -1.66 & -1.51 & -1.43 & -1.70 \\
\hline & 30 & -0.66 & -0.82 & -0.68 & -0.75 & -0.80 & -0.69 & -0.71 & -0.92 \\
\hline & 40 & 0.00 & 0.00 & 0.00 & 0.00 & 0.00 & 0.00 & 0.00 & 0.00 \\
\hline & 50 & 0.88 & 1.11 & 1.17 & 0.80 & 0.81 & 0.72 & 0.76 & 0.78 \\
\hline & & \multicolumn{8}{|c|}{$\triangle$ FMEP $(\mathrm{kPa})$} \\
\hline & 5 & 9.76 & 41.51 & 46.53 & -4.77 & 41.40 & -6.80 & -5.94 & 34.47 \\
\hline & 10 & 6.02 & 35.25 & 39.91 & -5.13 & 35.11 & -6.80 & -6.16 & 28.89 \\
\hline \multirow[t]{7}{*}{ Piston Skirt } & 20 & -0.03 & 16.04 & 18.18 & -3.96 & 14.84 & -4.74 & -4.42 & 11.36 \\
\hline & 30 & -0.49 & 6.87 & 7.92 & -2.08 & 5.77 & -2.49 & -2.25 & 3.88 \\
\hline & 40 & 0.00 & 0.00 & 0.00 & 0.00 & 0.00 & 0.00 & 0.00 & 0.00 \\
\hline & 50 & 1.52 & -8.15 & -8.71 & 3.99 & -6.62 & 4.71 & 4.63 & -4.89 \\
\hline & & \multicolumn{8}{|c|}{$\triangle F M E P(k P a)$} \\
\hline & 5 & -1.30 & -3.20 & -6.15 & -11.28 & -10.62 & -12.29 & -12.76 & -13.19 \\
\hline & 10 & -1.21 & -2.84 & -5.91 & -10.67 & -10.23 & -11.21 & -12.02 & -12.37 \\
\hline \multirow[t]{7}{*}{ Piston Rings } & 20 & -0.37 & -2.18 & -4.18 & -6.94 & -6.28 & -7.14 & -7.87 & -7.91 \\
\hline & 30 & 0.47 & 0.15 & -1.67 & -3.56 & -3.03 & -3.37 & -3.10 & -3.88 \\
\hline & 40 & 0.00 & 0.00 & 0.00 & 0.00 & 0.00 & 0.00 & 0.00 & 0.00 \\
\hline & 50 & 5.12 & 5.82 & 5.85 & 6.85 & 8.12 & 7.76 & 7.76 & 8.53 \\
\hline & & \multicolumn{8}{|c|}{$\triangle$ FMEP $(\mathrm{kPa})$} \\
\hline & 5 & 0.35 & 1.14 & 0.84 & -0.86 & 0.43 & -0.82 & -0.80 & 0.26 \\
\hline & 10 & 0.08 & 1.01 & 0.73 & -0.81 & 0.35 & -0.76 & -0.75 & 0.19 \\
\hline \multirow[t]{4}{*}{ Valvetrain } & 20 & -0.25 & 0.49 & 0.33 & -0.47 & 0.11 & -0.42 & -0.42 & 0.01 \\
\hline & 30 & -0.10 & 0.28 & 0.15 & -0.23 & 0.02 & -0.19 & -0.17 & -0.03 \\
\hline & 40 & 0.00 & 0.00 & 0.00 & 0.00 & 0.00 & 0.00 & 0.00 & 0.00 \\
\hline & 50 & 0.66 & 0.01 & -0.03 & 0.29 & 0.06 & 0.29 & 0.28 & 0.10 \\
\hline
\end{tabular}


Client Name: Argonne National Laboratory

Project No: $\quad$ G0908

Archive: RD.03/69702

Table 4: Summary of Predicted FMEP Changes at each Interface, 30\% Asperity Friction Reduction

FTP Simulation Mode

\begin{tabular}{|c|c|c|c|c|c|c|c|c|c|}
\hline & $\begin{array}{c}\text { Viscosity Grade } \\
\text { (SAE) }\end{array}$ & & & & $\Delta \mathrm{FN}$ & $\mathrm{kPa}$ ) & & & \\
\hline \multirow{6}{*}{$\begin{array}{c}\text { Large End } \\
\text { Bearings }\end{array}$} & 5 & -1.61 & 1.42 & -1.65 & -3.62 & -3.93 & -2.95 & -3.23 & -3.55 \\
\hline & 10 & -1.44 & 0.83 & -1.69 & -3.34 & -3.62 & -2.65 & -2.90 & -3.20 \\
\hline & 20 & -0.77 & -0.35 & -1.13 & -1.86 & -2.04 & -1.31 & -1.42 & -1.59 \\
\hline & 30 & -0.38 & -0.33 & -0.65 & -1.18 & -1.27 & -0.57 & -0.60 & -0.68 \\
\hline & 40 & 0.00 & -0.11 & 0.00 & 0.00 & 0.00 & 0.00 & 0.00 & 0.00 \\
\hline & 50 & 0.51 & 0.55 & 0.75 & 0.53 & 0.59 & 1.07 & 1.15 & 1.26 \\
\hline \multirow{7}{*}{$\begin{array}{c}\text { Small End } \\
\text { Bearings }\end{array}$} & & \multicolumn{8}{|c|}{$\Delta$ FMEP $(\mathrm{kPa})$} \\
\hline & 5 & 0.18 & 1.16 & 0.35 & 0.69 & 0.78 & 1.44 & 0.86 & 0.83 \\
\hline & 10 & 0.15 & 1.13 & 0.26 & 0.66 & 0.58 & 0.96 & 0.67 & 0.71 \\
\hline & 20 & 0.04 & 0.97 & 0.02 & 0.22 & 0.20 & 0.36 & 0.19 & 0.22 \\
\hline & 30 & -0.02 & 0.91 & -0.07 & 0.01 & 0.00 & 0.08 & 0.06 & 0.02 \\
\hline & 40 & -0.05 & 0.00 & -0.12 & -0.03 & -0.06 & 0.00 & -0.01 & -0.04 \\
\hline & 50 & -0.09 & 0.75 & -0.17 & -0.11 & -0.13 & -0.19 & -0.08 & -0.18 \\
\hline \multirow{7}{*}{$\begin{array}{l}\text { Crankshaft Main } \\
\text { Bearings }\end{array}$} & & \multicolumn{8}{|c|}{$\Delta$ FMEP $(\mathrm{kPa})$} \\
\hline & 5 & -3.25 & -4.18 & -4.13 & -3.37 & -3.80 & -3.21 & -3.50 & $\begin{array}{l}-3.72 \\
\end{array}$ \\
\hline & 10 & -2.85 & -3.73 & -3.57 & -2.93 & -3.30 & -2.98 & -3.08 & -3.29 \\
\hline & 20 & -1.41 & -1.82 & -1.65 & -1.54 & -1.66 & -1.51 & -1.43 & -1.70 \\
\hline & 30 & -0.66 & -0.82 & -0.68 & -0.75 & -0.80 & -0.69 & -0.71 & -0.92 \\
\hline & 40 & 0.00 & 0.00 & 0.00 & 0.00 & 0.00 & 0.00 & 0.00 & 0.00 \\
\hline & 50 & 0.88 & 1.11 & 1.17 & 0.80 & 0.81 & 0.72 & 0.76 & 0.78 \\
\hline & & \multicolumn{8}{|c|}{$\triangle$ FMEP $(\mathrm{kPa})$} \\
\hline & 5 & 5.30 & 19.85 & 23.51 & -5.86 & 21.39 & -7.49 & $\begin{array}{l}-6.93 \\
\end{array}$ & 17.91 \\
\hline & 10 & 2.80 & 15.54 & 18.97 & -5.89 & 17.10 & -7.25 & -6.84 & 14.14 \\
\hline \multirow[t]{7}{*}{ Piston Skirt } & 20 & -0.95 & 2.45 & 4.16 & -4.17 & 3.42 & -4.83 & -4.61 & 2.43 \\
\hline & 30 & -0.94 & -3.73 & -2.74 & -2.18 & -2.57 & -2.51 & -2.34 & -2.39 \\
\hline & 40 & -0.24 & -8.29 & -8.01 & -0.05 & -6.23 & 0.00 & -0.03 & -4.69 \\
\hline & 50 & 1.44 & -13.53 & -13.58 & 3.99 & -10.17 & 4.71 & 4.63 & -7.32 \\
\hline & & \multicolumn{8}{|c|}{$\triangle$ FMEP $(\mathrm{kPa})$} \\
\hline & 5 & -6.58 & -8.78 & -11.16 & -15.01 & -14.77 & -15.52 & -16.17 & -16.87 \\
\hline & 10 & -5.98 & -7.85 & -10.26 & -13.75 & -13.64 & -13.87 & -14.77 & -15.36 \\
\hline \multirow[t]{7}{*}{ Piston Rings } & 20 & -3.78 & -5.37 & -6.77 & -8.60 & -8.14 & -8.46 & -9.22 & -9.41 \\
\hline & 30 & -2.08 & -2.28 & -3.48 & -4.58 & -4.15 & -4.15 & -4.01 & -4.81 \\
\hline & 40 & -1.37 & -1.20 & -0.89 & -0.50 & -0.50 & -0.35 & -0.35 & -0.35 \\
\hline & 50 & 3.81 & 4.79 & 5.17 & 6.45 & 7.73 & 7.52 & 7.41 & 8.18 \\
\hline & & \multicolumn{8}{|c|}{$\Delta$ FMEP $(\mathrm{kPa})$} \\
\hline & 5 & -0.54 & 0.28 & 0.16 & -1.04 & -0.01 & -0.95 & -0.94 & -0.09 \\
\hline & 10 & -0.70 & 0.18 & 0.09 & -0.96 & -0.05 & -0.87 & -0.86 & -0.12 \\
\hline \multirow[t]{4}{*}{ Valvetrain } & 20 & -0.70 & -0.15 & -0.16 & -0.54 & -0.17 & -0.46 & -0.46 & -0.20 \\
\hline & 30 & -0.40 & -0.25 & -0.24 & -0.27 & -0.19 & -0.21 & -0.19 & -0.18 \\
\hline & 40 & -0.16 & -0.41 & -0.29 & -0.02 & -0.15 & -0.01 & -0.01 & -0.10 \\
\hline & 50 & 0.55 & -0.27 & -0.22 & 0.28 & -0.03 & 0.29 & 0.28 & 0.05 \\
\hline
\end{tabular}


Client Name: Argonne National Laboratory

Project No: $\quad$ G0908

Archive: RD.03/69702

Table 5: Summary of Predicted FMEP Changes at each Interface, $60 \%$ Asperity Friction Reduction

FTP Simulation Mode 1
23 $\begin{array}{lll}3 & 4 & 5\end{array}$

$\triangle$ FMEP $(\mathrm{kPa})$

Large End

Bearings

Grade (SAE)

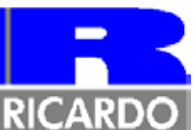

$\underset{\text { RICARDO }}{2}$

RICARDO

$\begin{array}{ccccccccc}5 & -1.61 & -0.33 & -2.09 & -3.62 & -3.93 & -2.95 & -3.23 & -3.55 \\ 10 & -1.44 & -0.54 & -2.01 & -3.34 & -3.62 & -2.65 & -2.90 & -3.20 \\ 20 & -0.77 & -0.82 & -1.17 & -1.86 & -2.04 & -1.31 & -1.42 & -1.59 \\ 30 & -0.38 & -0.57 & -0.66 & -1.18 & -1.27 & -0.57 & -0.60 & -0.68 \\ 40 & 0.00 & -0.23 & 0.00 & 0.00 & 0.00 & 0.00 & 0.00 & 0.00 \\ 50 & 0.51 & 0.53 & 0.75 & 0.53 & 0.59 & 1.07 & 1.15 & 1.26\end{array}$

5

Small End

Bearings

Crankshaft Main

Bearings

Piston Skirt

Piston Rings

Valvetrain

\section{0}

20

30

40

50

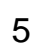

5
10

20

30

40

50

PIston Rings

40
50
5
10

20

30

40

50

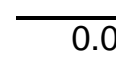

0.03

$-0.04$

$-0.08$

$-0.09$

$-0.12$

0.53

0.75

0.53

0.59

1.07

1.15

1.26

$\triangle$ FMEP $(\mathrm{kPa})$

$\begin{array}{lllll}0.60 & 0.65 & 1.44 & 0.84 & 0.72 \\ 0.59 & 0.46 & 0.96 & 0.65 & 0.61 \\ 0.17 & 0.11 & 0.36 & 0.18 & 0.15 \\ -0.03 & -0.07 & 0.08 & 0.05 & -0.03 \\ -0.06 & -0.13 & 0.00 & -0.02 & -0.08 \\ -0.13 & -0.18 & -0.19 & -0.08 & -0.21\end{array}$

$\triangle$ FMEP $(\mathrm{kPa})$

\begin{tabular}{llllllll}
\hline-3.25 & -4.18 & -4.13 & -3.37 & -3.80 & -3.21 & -3.50 & -3.72 \\
-2.85 & -3.73 & -3.57 & -2.93 & -3.30 & -2.98 & -3.08 & -3.29 \\
-1.41 & -1.82 & -1.65 & -1.54 & -1.66 & -1.51 & -1.43 & -1.70 \\
-0.66 & -0.82 & -0.68 & -0.75 & -0.80 & -0.69 & -0.71 & -0.92 \\
0.00 & 0.00 & 0.00 & 0.00 & 0.00 & 0.00 & 0.00 & 0.00 \\
0.88 & 1.11 & 1.17 & 0.80 & 0.81 & 0.72 & 0.76 & 0.78
\end{tabular}

$\triangle$ FMEP $(\mathrm{kPa})$

$\begin{array}{ccccccccc}5 & 0.83 & -1.80 & 0.49 & -6.95 & 1.39 & -8.19 & -7.91 & 1.36 \\ 10 & -0.43 & -4.17 & -1.98 & -6.65 & -0.91 & -7.71 & -7.51 & -0.62 \\ 20 & -1.88 & -11.15 & -9.85 & -4.39 & -8.00 & -4.92 & -4.81 & -6.49 \\ 30 & -1.39 & -14.32 & -13.40 & -2.29 & -10.91 & -2.52 & -2.43 & -8.67 \\ 40 & -0.49 & -16.58 & -16.02 & -0.09 & -12.45 & 0.00 & -0.05 & -9.39 \\ 50 & 1.37 & -18.92 & -18.45 & 3.98 & -13.72 & 4.71 & 4.62 & -9.75\end{array}$

$\triangle$ FMEP $(\mathrm{kPa})$

$\begin{array}{ccccccccc}5 & -11.86 & -14.37 & -16.17 & -18.74 & -18.92 & -18.74 & -19.58 & -20.56 \\ 10 & -10.76 & -12.87 & -14.61 & -16.83 & -17.05 & -16.54 & -17.51 & -18.35 \\ 20 & -7.19 & -8.55 & -9.37 & -10.26 & -9.99 & -9.79 & -10.57 & -10.91 \\ 30 & -4.62 & -4.70 & -5.29 & -5.61 & -5.27 & -4.93 & -4.92 & -5.74 \\ 40 & -2.74 & -2.40 & -1.79 & -1.00 & -1.00 & -0.70 & -0.70 & -0.70 \\ 50 & 2.49 & 3.77 & 4.49 & 6.06 & 7.33 & 7.29 & 7.06 & 7.83\end{array}$

\begin{tabular}{ccccccccc}
\multicolumn{8}{c}{$\Delta \mathrm{FMEP}(\mathrm{kPa})$} \\
\cline { 2 - 9 } 10 & -1.42 & -0.58 & -0.51 & -1.23 & -0.44 & -1.08 & -1.08 & -0.44 \\
20 & -1.47 & -0.64 & -0.55 & -1.10 & -0.46 & -0.97 & -0.97 & -0.44 \\
30 & -1.15 & -0.80 & -0.64 & -0.60 & -0.46 & -0.51 & -0.51 & -0.40 \\
40 & -0.71 & -0.78 & -0.63 & -0.30 & -0.40 & -0.23 & -0.22 & -0.32 \\
50 & -0.32 & -0.82 & -0.59 & -0.03 & -0.30 & -0.02 & -0.02 & -0.20 \\
& 0.43 & -0.55 & -0.41 & 0.27 & -0.11 & 0.28 & 0.27 & 0.00
\end{tabular}


Client Name: Argonne National Laboratory

Project No: $\quad$ G0908

Archive: RD.03/69702

Table 6: Summary of Predicted FMEP Changes at each Interface, 90\% Asperity Friction Reduction

FTP Simulation Mode

Viscosity

Grade (SAE)

Large End

Bearings

5
10
20
30
40
50

5
10
20
30
40
50

10

20

30

40

50

$\begin{array}{lc} & 5 \\ \text { Small End } & 10 \\ \text { Bearings } & 20 \\ & 30 \\ & 40 \\ & 50\end{array}$

5

$20-0.12$

$30-0.14$

$40-0.14$

$50 \quad-0.15$

0.51

0.69

0.68

0.60

0.58
3

5 $\triangle$ FMEP $(\mathrm{kPa})$

$-3.62 \quad-3.93$

$-2.54$

$-2.33$

$-1.21$

$-0.67$

0.00

0.75

$-1.86$

$-1.18$

0.00

0.53
-3.93
-3.62

$-2.04$

$-1.27$

0.00

0.59

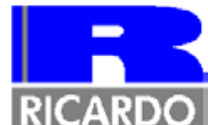

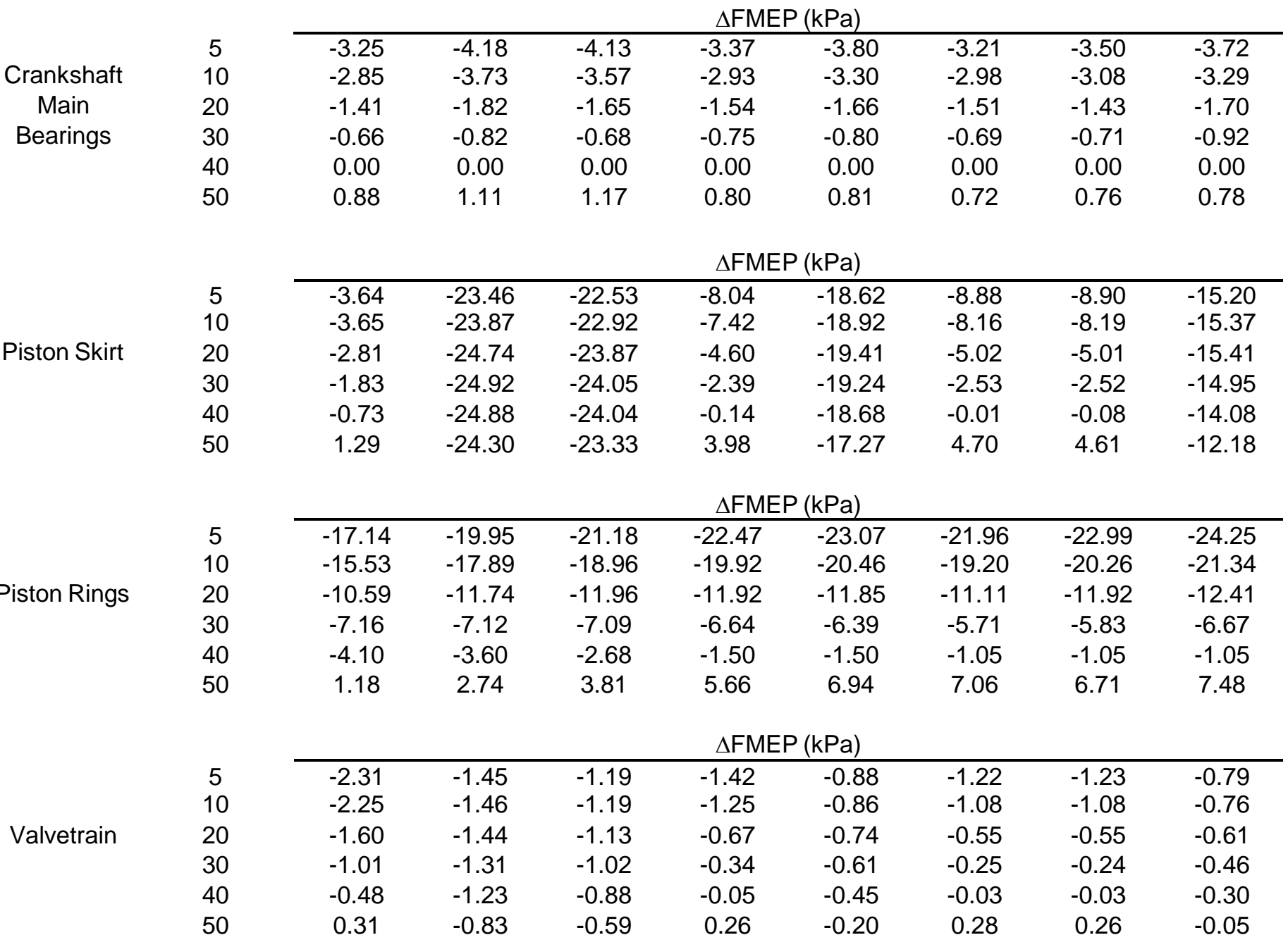

$\triangle$ FMEP $(\mathrm{kPa})$

$\begin{array}{ccccc}0.52 & 0.52 & 1.44 & 0.83 & 0.61 \\ 0.51 & 0.34 & 0.96 & 0.63 & 0.51 \\ 0.12 & 0.02 & 0.36 & 0.17 & 0.08 \\ -0.07 & -0.15 & 0.08 & 0.04 & -0.09 \\ -0.09 & -0.19 & 0.00 & -0.03 & -0.13 \\ -0.14 & -0.23 & -0.19 & -0.09 & -0.24\end{array}$

$\triangle F M E P(\mathrm{kPa})$ 
Client Name: Argonne National Laboratory

Project No:: G0908

Archive: RD.03/69702

Table 7: Summary of Overall Fuel Consumption Results, $0 \%$ Asperity Friction Reduction

FTP Simulation Mode

Engine Speed (rpm)

Fuel Mass (kg)

$\operatorname{IMEP}(\mathrm{kPa})$

$\operatorname{BMEP}(\mathrm{kPa})$

Weightings

Weighted fuel consumption $(\mathrm{kg})$
1

750

1.766

104

0

0.524

0.93

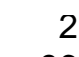

960

28.084

1683

1565

0.03

0.84

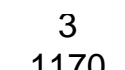

1170

48.419

1683

1565

0.039
4

1590

28.793

983

783

0.149
5

1590

58.144

1683

1565

0.075

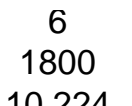

10.224

325

157

0.057
0.58
7
1800

31.094

983

783

0.081

2.52

Total fuel for 1 hour: $17.99 \mathrm{~kg}$

8

1800

57.313

1683

1565

0.045

2.58

\title{
SAE05 - 0\%
}

(IMEP + Delta FMEP) / IMEP

Scaled Fuel Consumption (kg)

\begin{tabular}{cccccccc}
1.04 & 1.02 & 1.02 & 0.98 & 1.01 & 0.92 & 0.97 & 1.01 \\
0.963 & 0.862 & 1.929 & 4.189 & 4.424 & 0.539 & 2.454 & 2.60 \\
\hline & & & & Total fuel for 1 hour: & 17.96 & $\mathrm{kq}$ \\
& & & & & Change & -0.02 & $\mathrm{~kg}$ \\
& & & & & & Change & $-0.1 \%$
\end{tabular}

SAE10 - 0\%

(IMEP + Delta FMEP) / IMEP

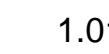

$1.01 \quad 1.02$

1.02

0.98

1.01

0.93

0.98

1.01

Scaled Fuel Consumption $(\mathrm{kg})$

\begin{tabular}{lll}
0.933 & $0.859 \quad 1.92$ \\
\hline
\end{tabular}

$1.922 \quad 4.194$

4.410

0.541

2.457

$\begin{array}{rrr}\text { Total fuel for } 1 \text { hour: } & 17.91 & \mathrm{kq} \\ \text { Change } & -0.08 & \mathrm{~kg} \\ \text { Change } & -0.4 \% & \end{array}$

SAE20 - 0\%

(IMEP + Delta FMEP) / IMEP

Scaled Fuel Consumption (kg)

\begin{tabular}{ccc}
0.97 & 1.01 & 1.0 \\
0.901 & 0.849 & 1 \\
\hline
\end{tabular}

1.01

\begin{abstract}
0.99
\end{abstract}
4.227

1.00

0.95

$4.374 \quad 0.556$

0.98

1.00

1.902

Total fuel

\begin{tabular}{cc}
$2.479 \quad 2.58$ \\
\hline
\end{tabular}

Change

Change

$-0.12$

$-0.12$

$\mathrm{ka}$

$-0.7 \%$

SAE30 - 0\%

(IMEP + Delta FMEP) / IMEP

Scaled Fuel Consumption (kg)

\begin{tabular}{ccc}
0.99 & 1.00 & 1.0 \\
0.915 & 0.846 & 1.80 \\
\hline
\end{tabular}

1.00

0.99
4.256

1.00

4.363

0.98

0.570

0.99

1.00

1.894

$\begin{array}{rrr}\text { Total fuel for 1 hour: } & 17.92 & \mathrm{kq} \\ \text { Change } & -0.07 & \mathrm{~kg} \\ \text { Change } & -0.4 \% & \end{array}$

SAE40 - 0\%

(IMEP + Delta FMEP) / IMEP

Scaled Fuel Consumption (kg)

\begin{tabular}{ccc}
1.00 & 1.00 & 1.0 \\
0.925 & 0.843 & 1.88 \\
\hline
\end{tabular}

1.00

1.00

4.290
1.00 4.361

1.00

0.583

1.00

2.519

1.00

1.888

Total fuel

$\begin{array}{ccc}\text { for 1 hour: } & 17.99 & \mathrm{ka} \\ \text { Change } & 0.00 & \mathrm{~kg} \\ \text { Change } & 0.0 \% & \end{array}$

SAE50 - 0\%

(IMEP + Delta FMEP) / IMEP

1.08

$1.08 \quad 1.00$

1.00

1.00
1.887

1.01
4.344

1.00
4.368

1.04

0.609

1.01

1.00

Total fuel for

$\begin{array}{ccc}\text { for } 1 \text { hour: } & 18.20 & \mathrm{ka} \\ \text { Change } & 0.21 & \mathrm{~kg} \\ \text { Change } & 1.2 \% & \end{array}$


Client Name: Argonne National Laboratory

Project No:: G0908

Archive: $\quad$ RD.03/69702

Table 8: Summary of Overall Fuel Consumption Results, 30\% Asperity Friction Reduction

FTP Simulation Mode

Engine Speed (rpm)

Fuel Mass $(\mathrm{kg})$

IMEP $(\mathrm{kPa})$

$\operatorname{BMEP}(\mathrm{kPa})$

Weightings

Weighted fuel consumption $(\mathrm{kg})$
1

750

1.766

104

0

0.524

0.93

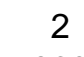

960

28.084

1683

1565

0.03

0.84

\section{3}

1170

48.419

1683

1565

0.039

1.89

\section{4}

1590

28.793

983

783

0.149

4.29
5

1590

58.144

1683

1565

0.075

0.075
6
1800

1800
10.224

325

157

0.057

0.58

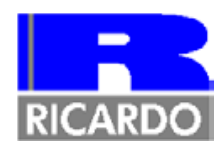

Total fuel for 1 hour: $17.99 \mathrm{~kg}$

\section{SAE05 - 30\%}

(IMEP + Delta FMEP) / IMEP

Scaled Fuel Consumption (kg)

\begin{tabular}{|c|c|c|c|c|c|c|c|}
\hline 0.94 & 1.01 & 1.00 & 0.97 & 1.00 & 0.91 & 0.97 & 1.00 \\
\hline 0.867 & 0.847 & 1.896 & 4.167 & 4.360 & 0.531 & 2.442 & 2.57 \\
\hline & & & & & & $\begin{array}{l}1 \text { hour: } \\
\text { Change }\end{array}$ & $\begin{array}{l}17.68 \\
-0.31\end{array}$ \\
\hline & & & & & & Change & $-1.7 \%$ \\
\hline
\end{tabular}

SAE10 - 30\%

(IMEP + Delta FMEP) / IMEP

\begin{tabular}{cccccccc}
0.92 & 1.00 & 1.00 & 0.97 & 1.00 & 0.92 & 0.97 & 1.00 \\
0.854 & 0.846 & 1.893 & 4.176 & 4.353 & 0.535 & 2.447 & 2.57 \\
\hline & & & & Total fuel for 1 hour: & 17.67 & $\mathrm{ka}$ \\
& & & & Change & -0.32 & $\mathrm{~kg}$ \\
& & & & & Change & $-1.8 \%$
\end{tabular}

SAE20 - 30\%

(IMEP + Delta FMEP) / IMEP

\begin{tabular}{|c|c|c|c|c|c|c|c|}
\hline $\begin{array}{c}0.93 \\
0.858\end{array}$ & $\begin{array}{c}1.00 \\
0.840\end{array}$ & $\begin{array}{c}1.00 \\
1882\end{array}$ & $\begin{array}{c}0.98 \\
4218\end{array}$ & $\begin{array}{c}1.00 \\
4.339\end{array}$ & $\begin{array}{c}0.95 \\
0.554\end{array}$ & $\begin{array}{l}0.98 \\
2475\end{array}$ & $\begin{array}{l}0.99 \\
256\end{array}$ \\
\hline & & & & & Total & $\begin{array}{l}1 \text { hour: } \\
\text { Change }\end{array}$ & $\begin{array}{l}17.73 \\
-0.26\end{array}$ \\
\hline & & & & & & Change & $-1.4 \%$ \\
\hline
\end{tabular}

SAE30 - 30\%

(IMEP + Delta FMEP) / IMEP

\begin{tabular}{cccccccc}
0.96 & 1.00 & 1.00 & 0.99 & 0.99 & 0.98 & 0.99 & 0.99 \\
0.885 & 0.839 & 1.880 & 4.251 & 4.338 & 0.568 & 2.499 & 2.57 \\
\hline & & & & Total fuel for 1 hour: & 17.83 & $\mathrm{kq}$ \\
& & & & & Change & -0.16 & $\mathrm{~kg}$ \\
& & & & & Change & $-0.9 \%$ &
\end{tabular}

SAE40 - 30\%

(IMEP + Delta FMEP) / IMEP

\begin{tabular}{ccccccccc}
0.98 & 0.99 & 0.99 & 1.00 & 1.00 & 1.00 & 1.00 & 1.00 & \\
0.909 & 0.838 & 1.878 & 4.288 & 4.343 & 0.582 & 2.518 & 2.57 \\
\hline & & & & & Total fuel for 1 hour: & 17.93 & $\mathrm{~kg}$ \\
& & & & & & Change & -0.06 & $\mathrm{~kg}$ \\
& & & & & & & Change & $-0.3 \%$
\end{tabular}

SAE50 - 30\%

(IMEP + Delta FMEP) / IMEP

\begin{tabular}{rrrrrrrrr}
1.07 & 1.00 & 1.00 & 1.01 & 1.00 & 1.04 & 1.01 & 1.00 \\
0.988 & 0.839 & 1.881 & 4.342 & 4.358 & 0.608 & 2.555 & 2.58 \\
\hline & & & & & Total fuel for 1 hour: & 18.15 & $\mathrm{~kg}$ \\
& & & & & & Change & 0.17 & $\mathrm{~kg}$ \\
& & & & & & & \\
& & & & & &
\end{tabular}


Client Name: Argonne National Laboratory

Project No:: G0908

Archive: $\quad$ RD.03/69702

Table 9: Summary of Overall Fuel Consumption Results, 60\% Asperity Friction Reduction

FTP Simulation Mode

Engine Speed (rpm)

Fuel Mass $(\mathrm{kg})$

IMEP $(\mathrm{kPa})$

$\operatorname{BMEP}(\mathrm{kPa})$

Weightings

Weighted fuel consumption $(\mathrm{kg})$
1

750

1.766

104

0

0.524

0.93

2
960
28.084
1683
1565
0.03
0.84

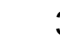

$1170 \quad 1590$

$48.419 \quad 28.793$

1683

1565

0.039

1.89

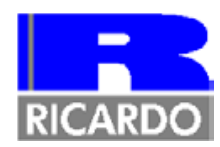

SAE05 - 60\%

(IMEP + Delta FMEP) / IMEP

Scaled Fuel Consumption (kg)

\begin{tabular}{cccccccc}
0.83 & 0.99 & 0.99 & 0.97 & 0.99 & 0.90 & 0.96 & 0.98 \\
0.772 & 0.832 & 1.863 & 4.145 & 4.296 & 0.524 & 2.430 & 2.54 \\
\hline & & & & Total fuel for 1 hour: & 17.40 & $\mathrm{~kg}$ \\
& & & & & Change & -0.59 & $\mathrm{~kg}$ \\
& & & & & Change & $-3.3 \%$
\end{tabular}

SAE10 - 60\%

(IMEP + Delta FMEP) / IMEP

Scaled Fuel Consumption (kg)

\begin{tabular}{cccccccc}
0.84 & 0.99 & 0.99 & 0.97 & 0.99 & 0.91 & 0.97 & 0.98 \\
0.775 & 0.832 & 1.863 & 4.158 & 4.296 & 0.529 & 2.438 & 2.54 \\
\hline & & & & Total fuel for 1 hour: & 17.43 & $\mathrm{ka}$ \\
& & & & & Change & -0.56 & $\mathrm{~kg}$ \\
& & & & & & Change & $-3.1 \%$
\end{tabular}

SAE20 - 60\%

(IMEP + Delta FMEP) / IMEP

Scaled Fuel Consumption (kg)

\begin{tabular}{cccccccc}
0.88 & 0.99 & 0.99 & 0.98 & 0.99 & 0.95 & 0.98 & 0.99 \\
0.815 & 0.831 & 1.863 & 4.210 & 4.304 & 0.551 & 2.471 & 2.55 \\
\hline & & & & Total fuel for 1 hour: & 17.59 & $\mathrm{ka}$ \\
& & & & & Change & -0.40 & $\mathrm{~kg}$ \\
& & & & & & Change & $-2.2 \%$
\end{tabular}

SAE30 - 60\%

(IMEP + Delta FMEP) / IMEP

\begin{tabular}{cccccccc}
0.92 & 0.99 & 0.99 & 0.99 & 0.99 & 0.97 & 0.99 & 0.99 \\
0.856 & 0.832 & 1.865 & 4.246 & 4.312 & 0.567 & 2.496 & 2.55 \\
\hline & & & & Total fuel for 1 hour: & 17.73 & $\mathrm{kq}$ \\
& & & & & Change & -0.26 & $\mathrm{~kg}$ \\
& & & & & Change & $-1.4 \%$
\end{tabular}

SAE40 - 60\%

(IMEP + Delta FMEP) / IMEP

\begin{tabular}{rrrrrrrrr}
0.97 & 0.99 & 0.99 & 1.00 & 0.99 & 1.00 & 1.00 & 0.99 \\
0.893 & 0.832 & 1.867 & 4.285 & 4.325 & 0.581 & 2.517 & 2.56 \\
\hline & & & & Total fuel for 1 hour: & 17.86 & $\mathrm{~kg}$ \\
& & & & Change & -0.12 & $\mathrm{~kg}$ \\
& & & & & Change & $-0.7 \%$ &
\end{tabular}

SAE50 - 60\%

(IMEP + Delta FMEP) / IMEP

\begin{tabular}{|c|c|c|c|c|c|c|c|}
\hline 1.05 & 0.99 & 0.99 & 1.01 & 1.00 & 1.04 & 1.01 & 1.00 \\
\hline 0.975 & 0.836 & 1.874 & 4.340 & 4.347 & 0.608 & 2.554 & 2.58 \\
\hline & & & & & Total fi & $\begin{array}{l}1 \text { hour: } \\
\text { Change }\end{array}$ & $\begin{array}{c}18.11 \\
0.13\end{array}$ \\
\hline
\end{tabular}


Client Name: Argonne National Laboratory

Project No:: G0908

Archive: $\quad$ RD.03/69702

Table 10: Summary of Overall Fuel Consumption Results, 90\% Asperity Friction Reduction

FTP Simulation Mode

Engine Speed (rpm)

Fuel Mass $(\mathrm{kg})$

IMEP $(\mathrm{kPa})$

$\operatorname{BMEP}(\mathrm{kPa})$

Weightings

Weighted fuel consumption $(\mathrm{kg})$
1

750

1.766

104

0

0.524

0.93

\section{2}

960

28.084

1683

1565

0.03

0.84

\section{3}

1170

48.419

1683

1565

0.039

1.89
4

1590

28.793

983

783

0.149

4.29

\section{5}

1590

58.144

1683

1565

0.075

4.36
6

1800

10.224
325

157

0.057

0.58

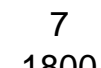

1800

31.094

983

783

0.081

0.081
2.52

2.52

Total fuel for 1 hour:
8

1800

57.313

1683

1565

0.045

2.58

\section{SAE05 - 90\%}

(IMEP + Delta FMEP) / IMEP

Scaled Fuel Consumption (kg)

\begin{tabular}{cccccccc}
0.73 & 0.97 & 0.97 & 0.96 & 0.97 & 0.89 & 0.96 & 0.97 \\
0.676 & 0.817 & 1.830 & 4.123 & 4.232 & 0.517 & 2.419 & 2.51 \\
\hline & & & & Total fuel for 1 hour: & 17.12 & $\mathrm{~kg}$ \\
& & & & & Change & -0.87 & $\mathrm{~kg}$ \\
& & & & & & Change & $-4.8 \%$
\end{tabular}

SAE10 - 90\%

(IMEP + Delta FMEP) / IMEP

Scaled Fuel Consumption (kg)

\begin{tabular}{ccc}
0.75 & 0.97 & 0.9 \\
0.696 & 0.818 & 1.83 \\
\hline
\end{tabular}

0.97

0.97

0.97

0.90

0.96

0.97

$1.833 \quad 4.140$

4.239

0.523

2.429

Total fuel for

$\begin{array}{lll}\text { Change } & -0.80 & \mathrm{~kg} \\ \text { Change } & -4.4 \% & \end{array}$

SAE20 - 90\%

(IMEP + Delta FMEP) / IMEP

Scaled Fuel Consumption (kg)

\begin{tabular}{cccccccc}
0.83 & 0.98 & 0.98 & 0.98 & 0.98 & 0.94 & 0.98 & 0.98 \\
0.771 & 0.822 & 1.843 & 4.201 & 4.268 & 0.548 & 2.467 & 2.53 \\
\hline & & & & Total fuel for 1 hour: & 17.45 & $\mathrm{ka}$ \\
& & & & & Change & -0.54 & $\mathrm{~kg}$ \\
& & & & & & Change & $-3.0 \%$
\end{tabular}

SAE30 - 90\%

(IMEP + Delta FMEP) / IMEP

\begin{tabular}{cccccccc}
0.89 & 0.98 & 0.98 & 0.99 & 0.98 & 0.97 & 0.99 & 0.99 \\
0.826 & 0.825 & 1.850 & 4.241 & 4.287 & 0.565 & 2.493 & 2.54 \\
\hline & & & & Total fuel for 1 hour: & 17.63 & $\mathrm{~kg}$ \\
& & & & Change & -0.36 & $\mathrm{~kg}$ \\
& & & & Change & $-2.0 \%$
\end{tabular}

SAE40 - 90\%

(IMEP + Delta FMEP) / IMEP

\begin{tabular}{rrrrrrrrr}
0.95 & 0.98 & 0.98 & 1.00 & 0.99 & 1.00 & 1.00 & 0.99 \\
0.877 & 0.827 & 1.857 & 4.282 & 4.307 & 0.581 & 2.516 & 2.56 \\
\hline & & & & Total fuel for 1 hour: & 17.80 & $\mathrm{~kg}$ \\
& & & & Change & -0.19 & $\mathrm{~kg}$ \\
& & & & & Change & $-1.0 \%$ &
\end{tabular}

SAE50 - 90\%

(IMEP + Delta FMEP) / IMEP

1.04

$\begin{array}{lll}1.04 & 0.99 & 0.99\end{array}$

1.01

0.99

1.04

1.01

1.00

Scaled Fuel Consumption (kg)

\begin{tabular}{rrrrrrrr}
0.961 & 0.832 & 1.868 & 4.339 & 4.337 & 0.607 & 2.553 & 2.57 \\
\hline & & & Total fuel for 1 hour: & 18.07 & $\mathrm{~kg}$ \\
& & & Change & 0.08 & $\mathrm{~kg}$ \\
& & & Change & $0.5 \%$
\end{tabular}




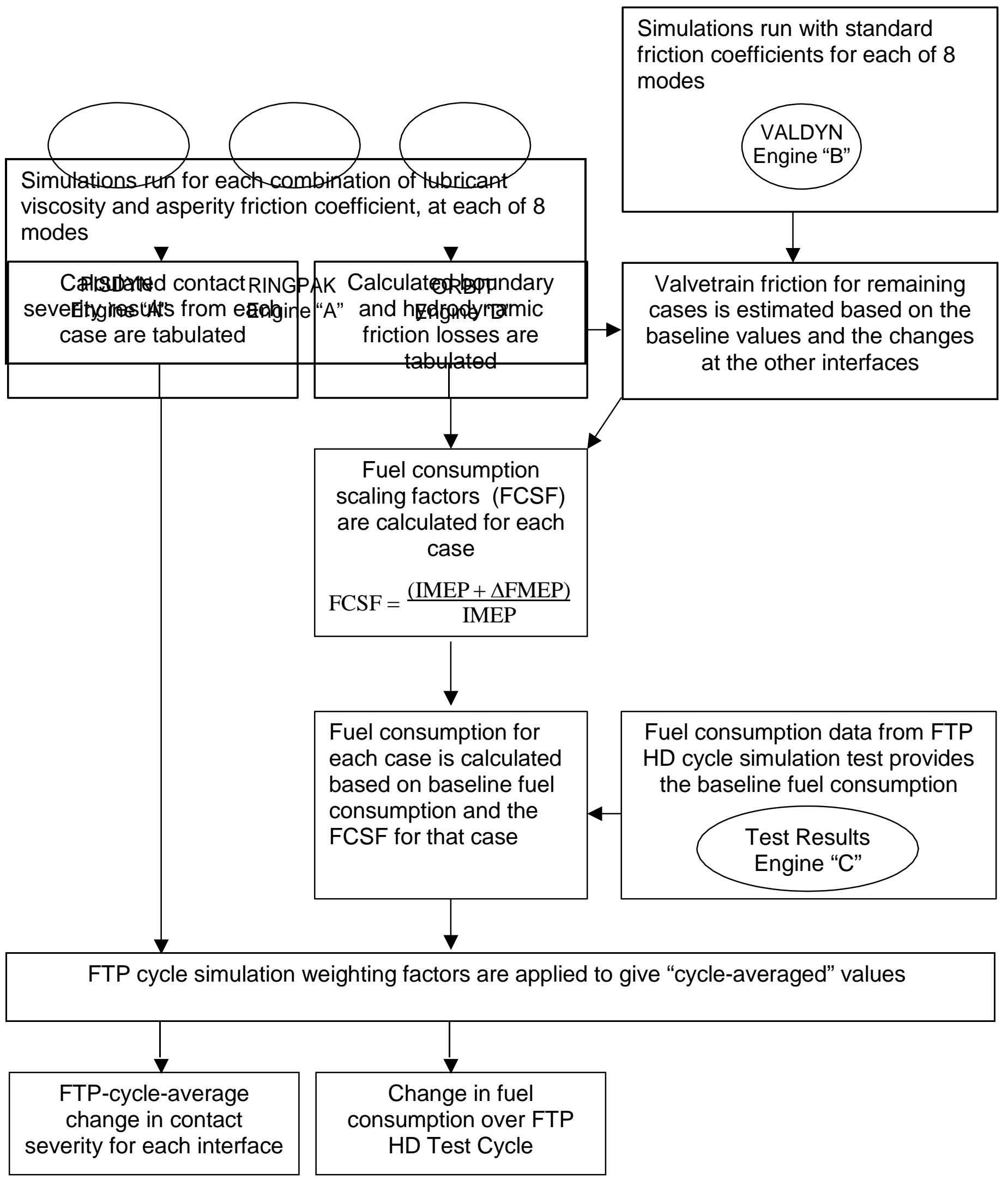

Figure 1: Diagram of Overall Approach 
Client Name: Argonne National Laboratory

Project No:: G0908

Archive:

RD.03/69702 
* interface considered in this study

- Rocker bushing *

- Rocker tip to valve *

- Pushrod to rocker interface *

- Fuel injection system

- Piston Rings *

- Piston Skirt *

rface *

- Crankshaft main bearings *

- Main seals

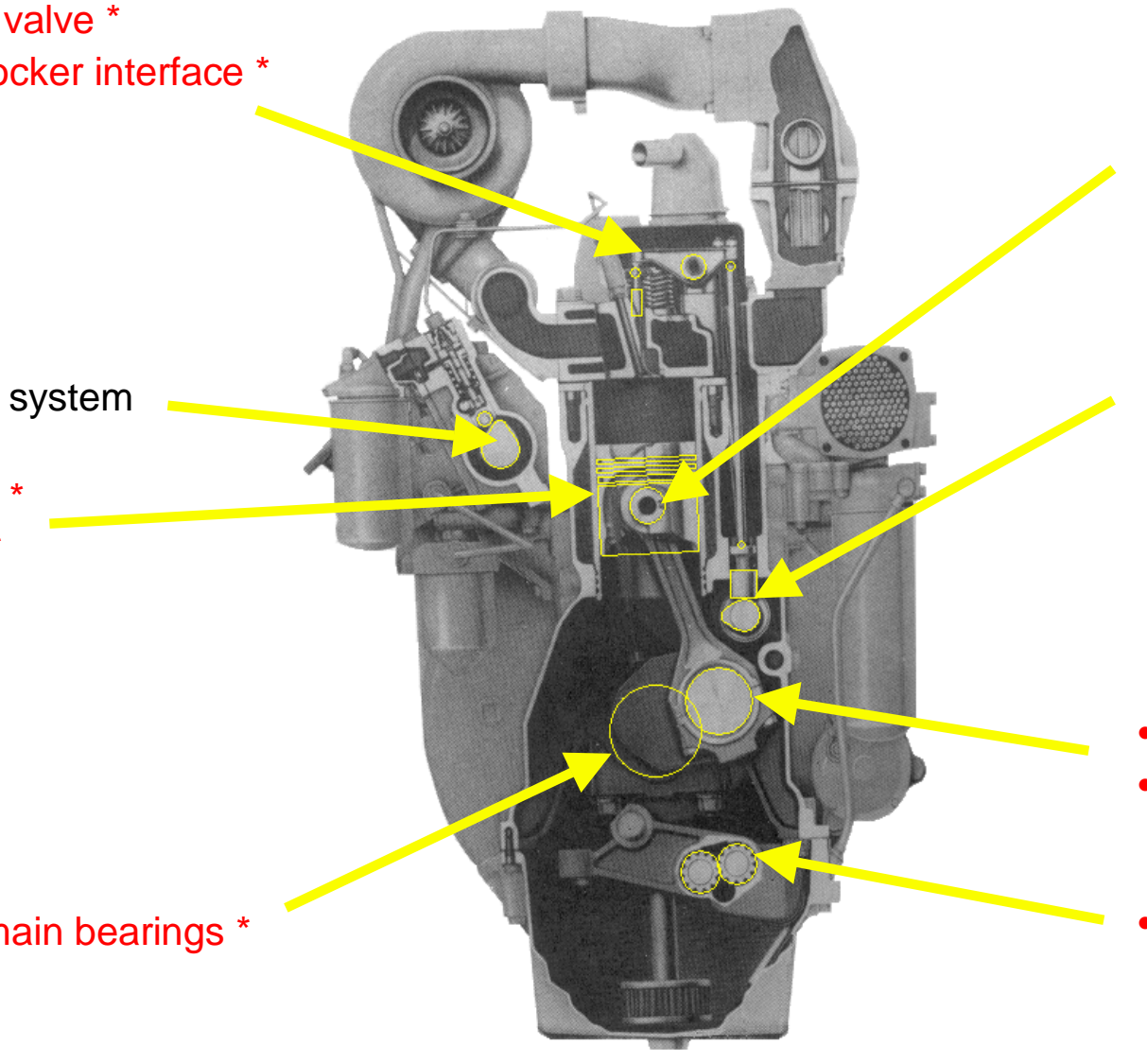

- Connecting Rod Small-End Bearings *

- Piston pin bushings *

- Cam - follower interface *

- Cam bearings *

- Follower - pushrod interface *

- Timing drive

- Connecting Rod Large-End Bearings *

- Crankshaft windage

Figure 2: Significant Friction Sources 
Figure 3: Low-Load Simulation and Measured

Piston Assy Motoring Friction vs. Mean Piston Speed (Diesel Engines)

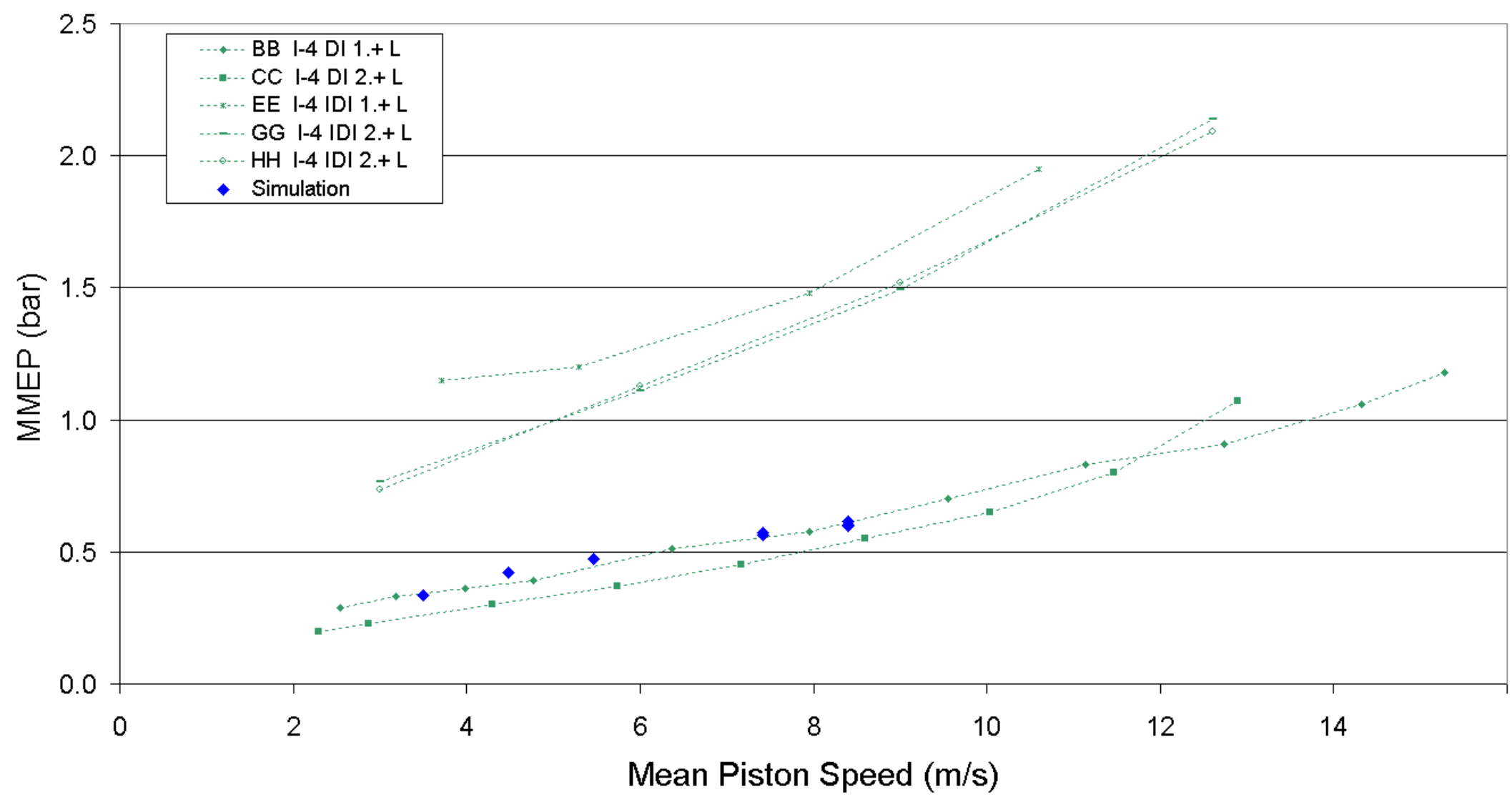


Client Name: Argonne National Laboratory

Figure 4: Low-Load Simulation and Measured Total Valvetrain Motoring Friction vs. Mean Piston Speed (Diesel Engines)

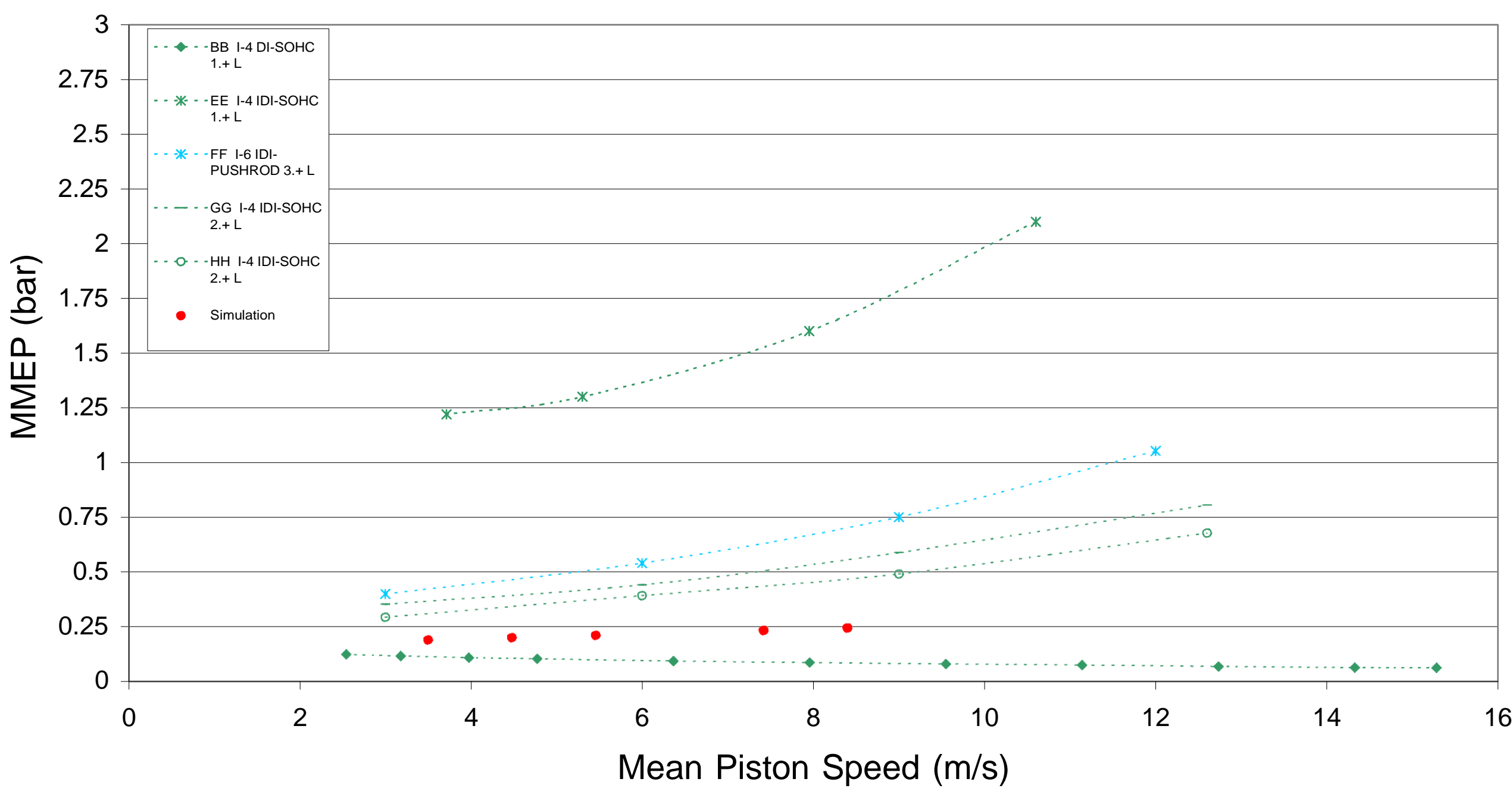


Figure 5: Predicted Piston Skirt Friction Contributions (No Treatment)

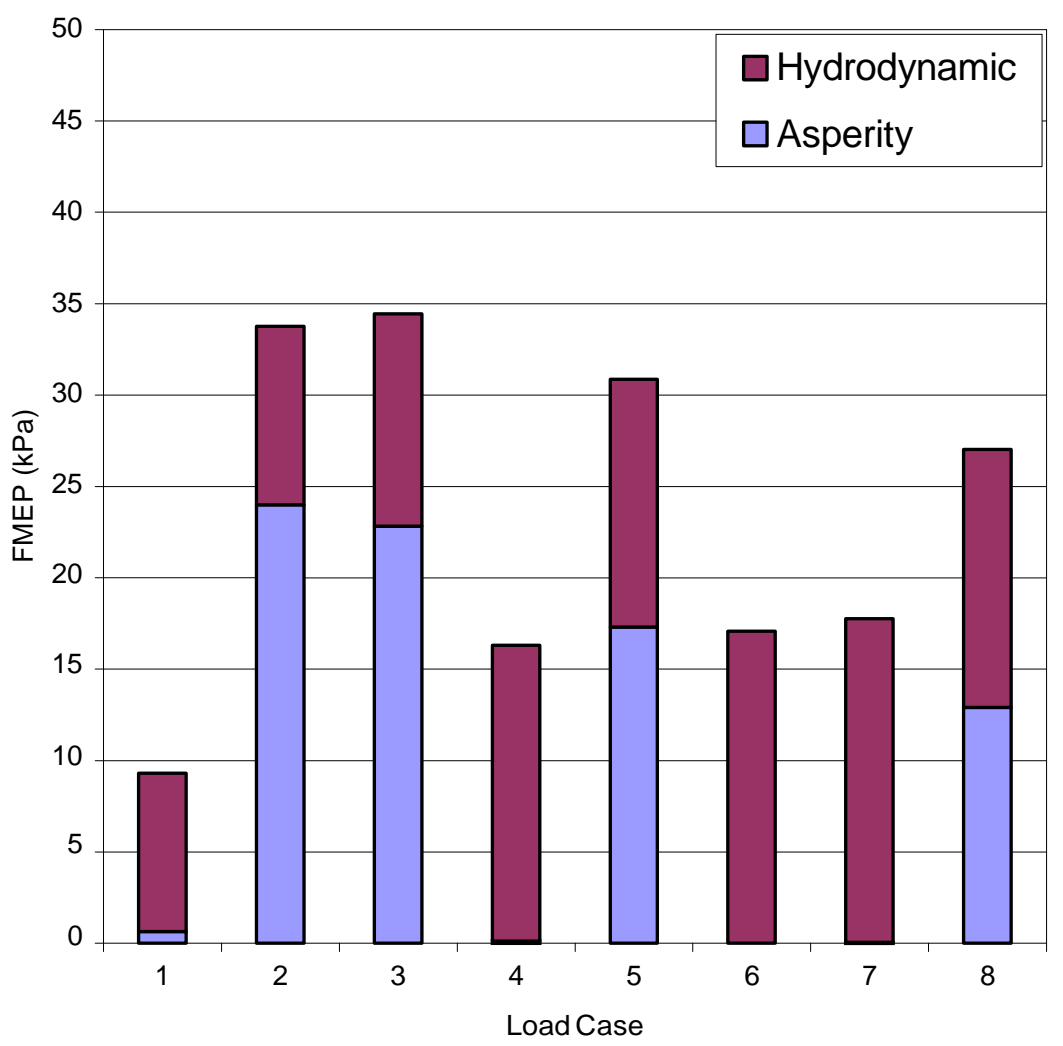

Figure 6: Piston Skirt Friction Contributions (30\% Reduction in Asperity Friction Coefficient)

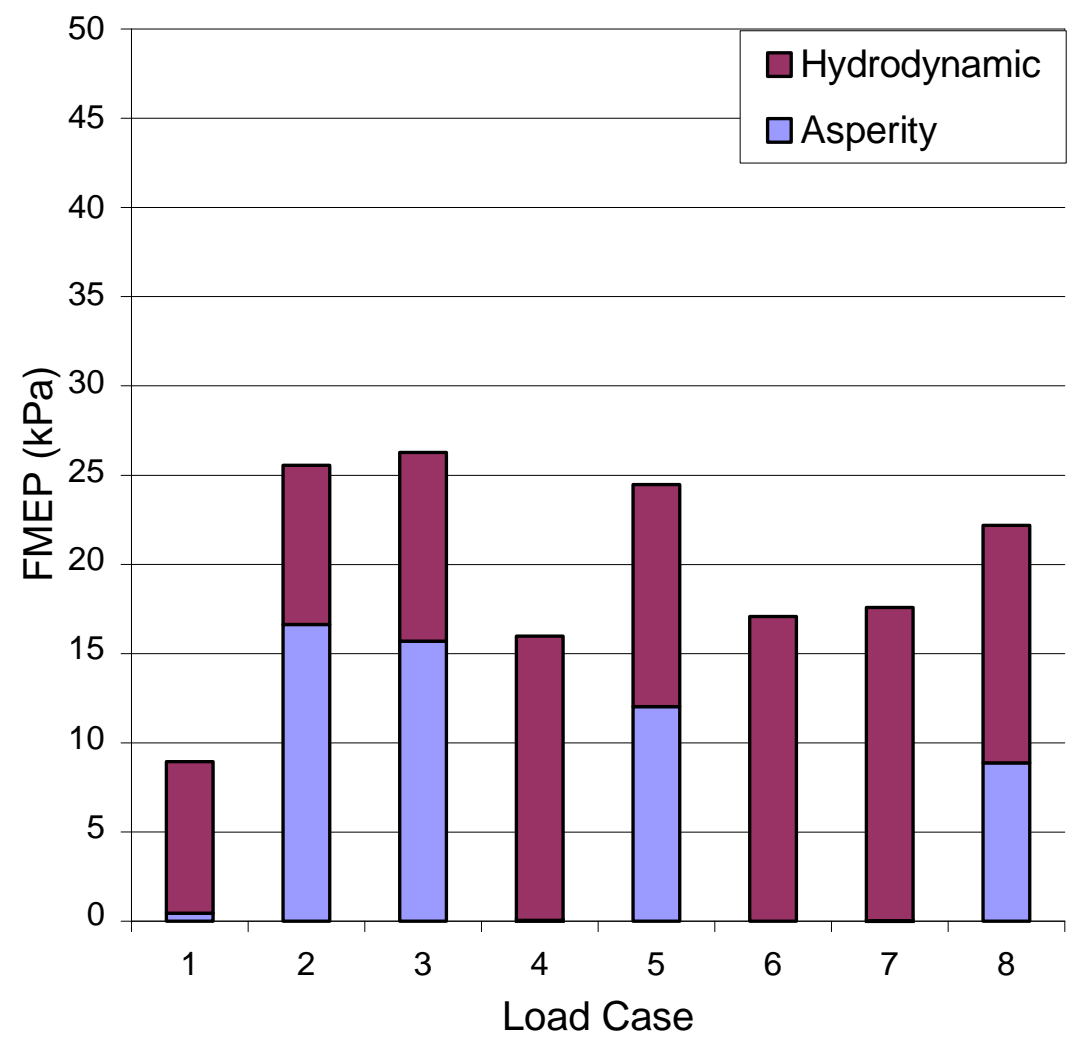


Figure 7: Piston Skirt Friction Contributions (60\% Reduction in Asperity Friction Coefficient)

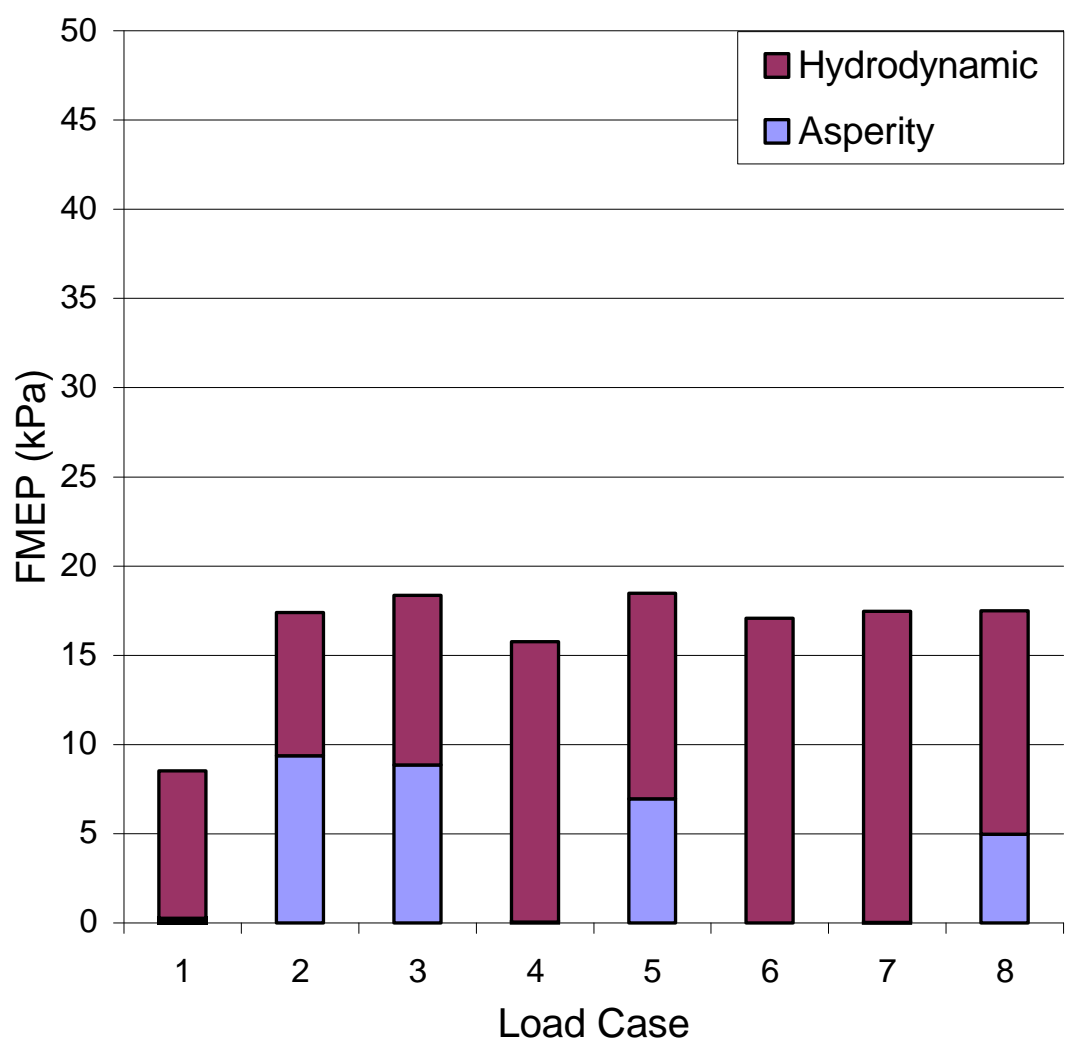

Figure 8: Piston Skirt Friction Contributions (90\% Reduction in Asperity Friction Coefficient)

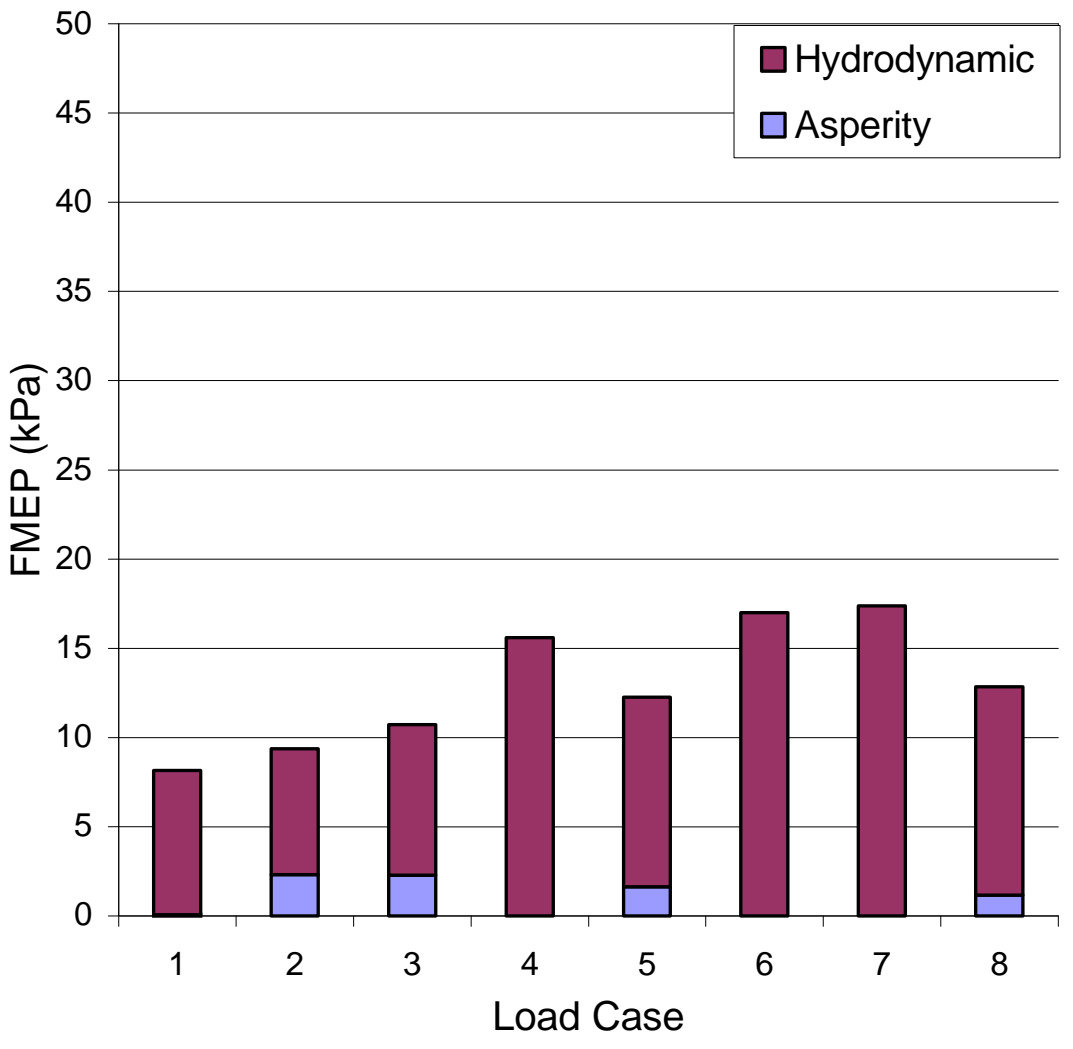


Figure 9: Predicted Changes in Piston Average FMEP Over FTP Cycle versus Viscosity Grade

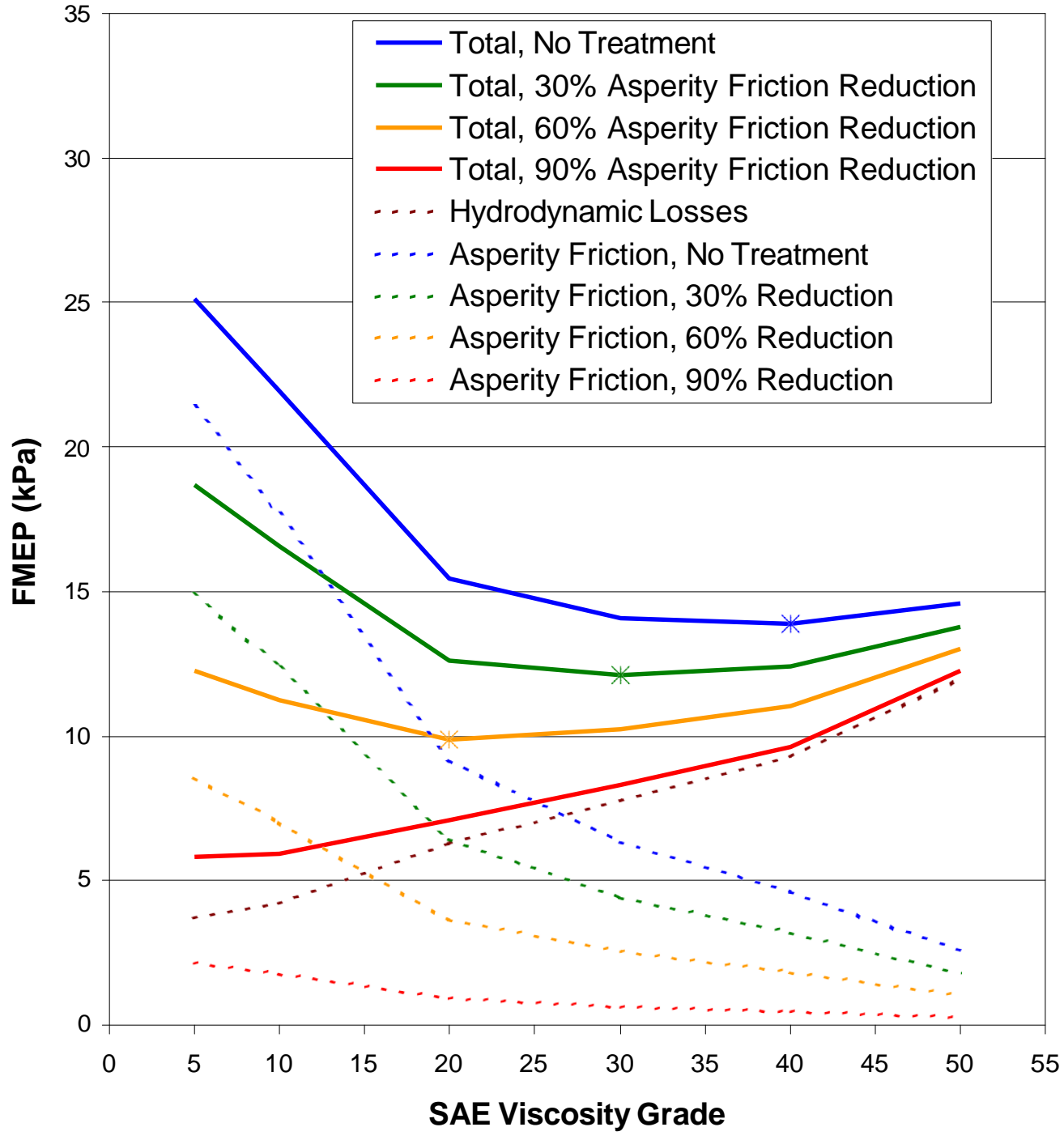

Figure 10: Normalized Predicted Changes in Piston Skirt Contact Severity Over FTP Cycle

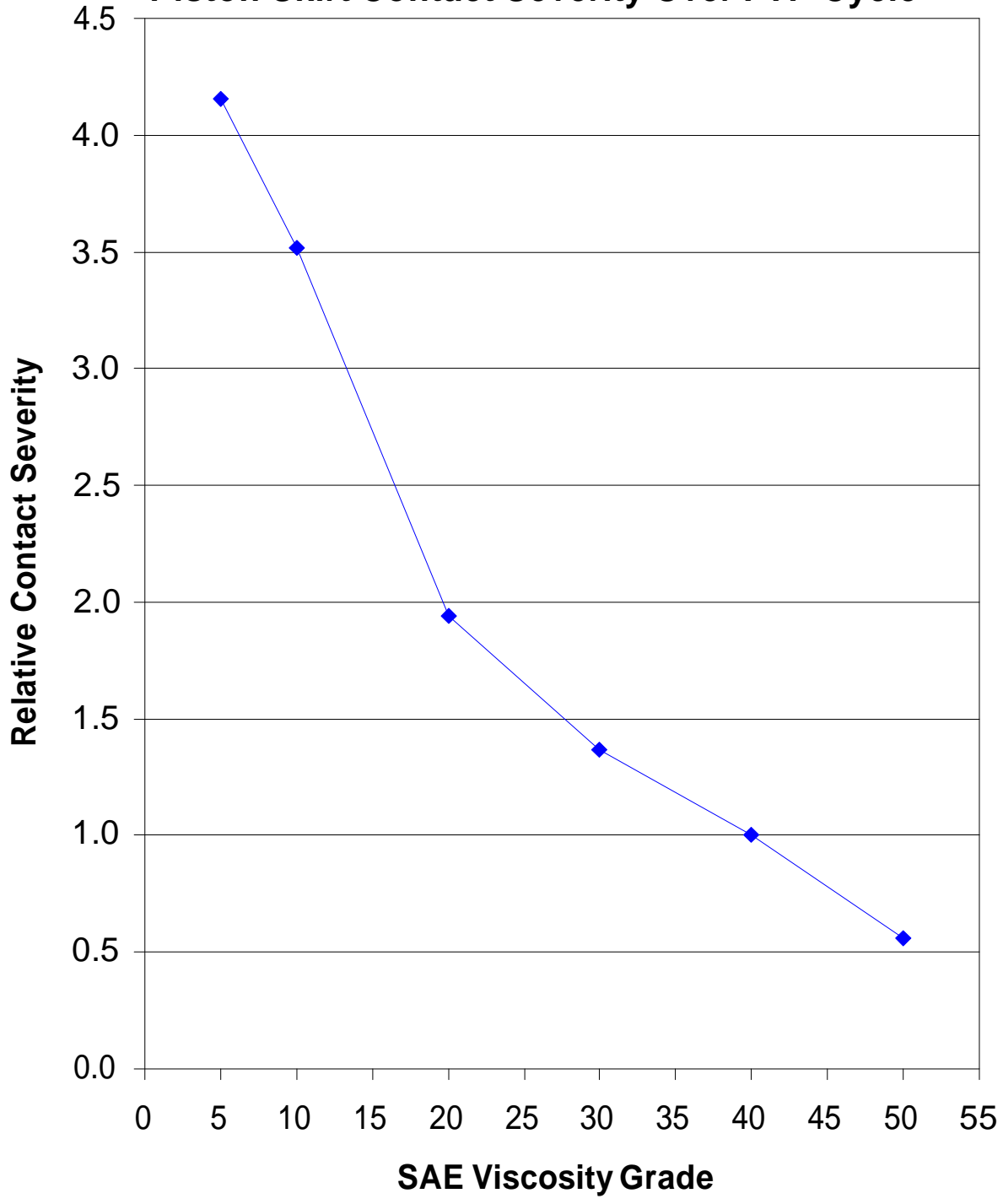

Page 30 of 46 
Figure 11: Illustration of Predicted Piston Skirt to Liner Contact Region Extents vs. Oil Viscosity Grade

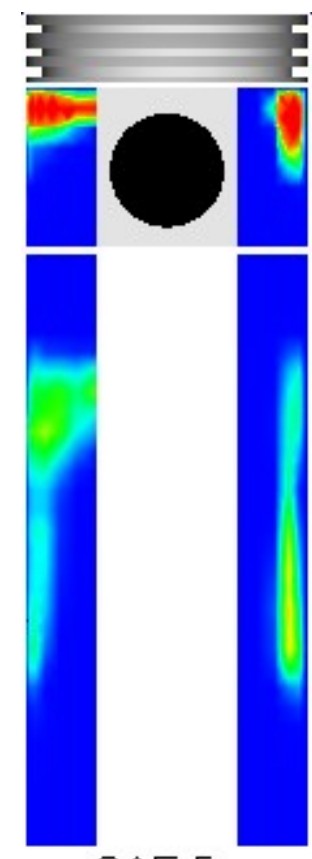

SAE 5

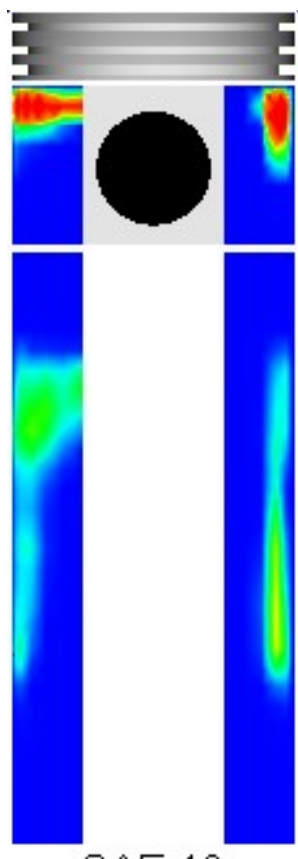

SAE 10

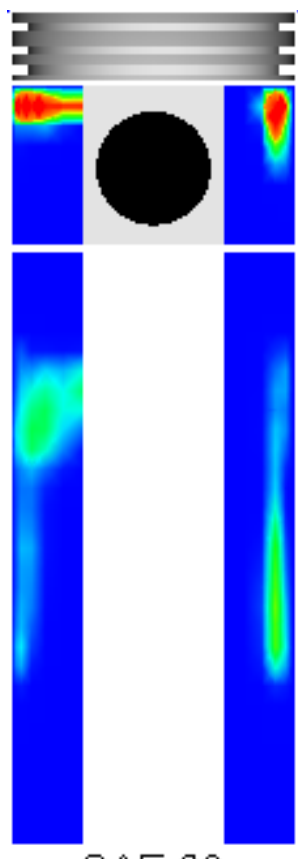

SAE 20

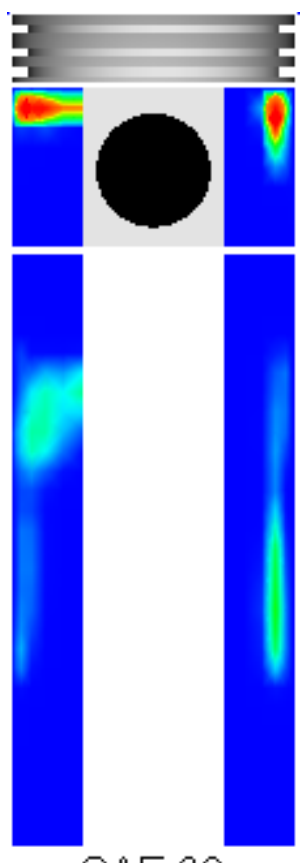

SAE 30

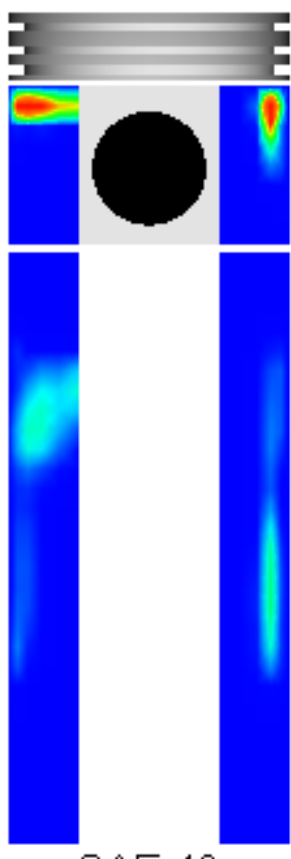

SAE 40

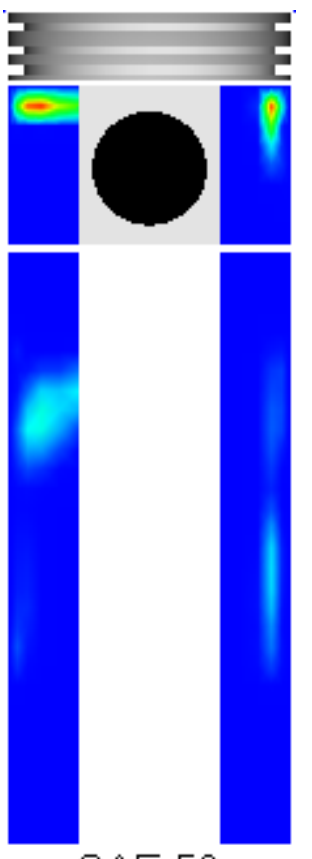

SAE 50 
Figure 12: Predicted Ring Pack Friction

Contributions (No Treatment)

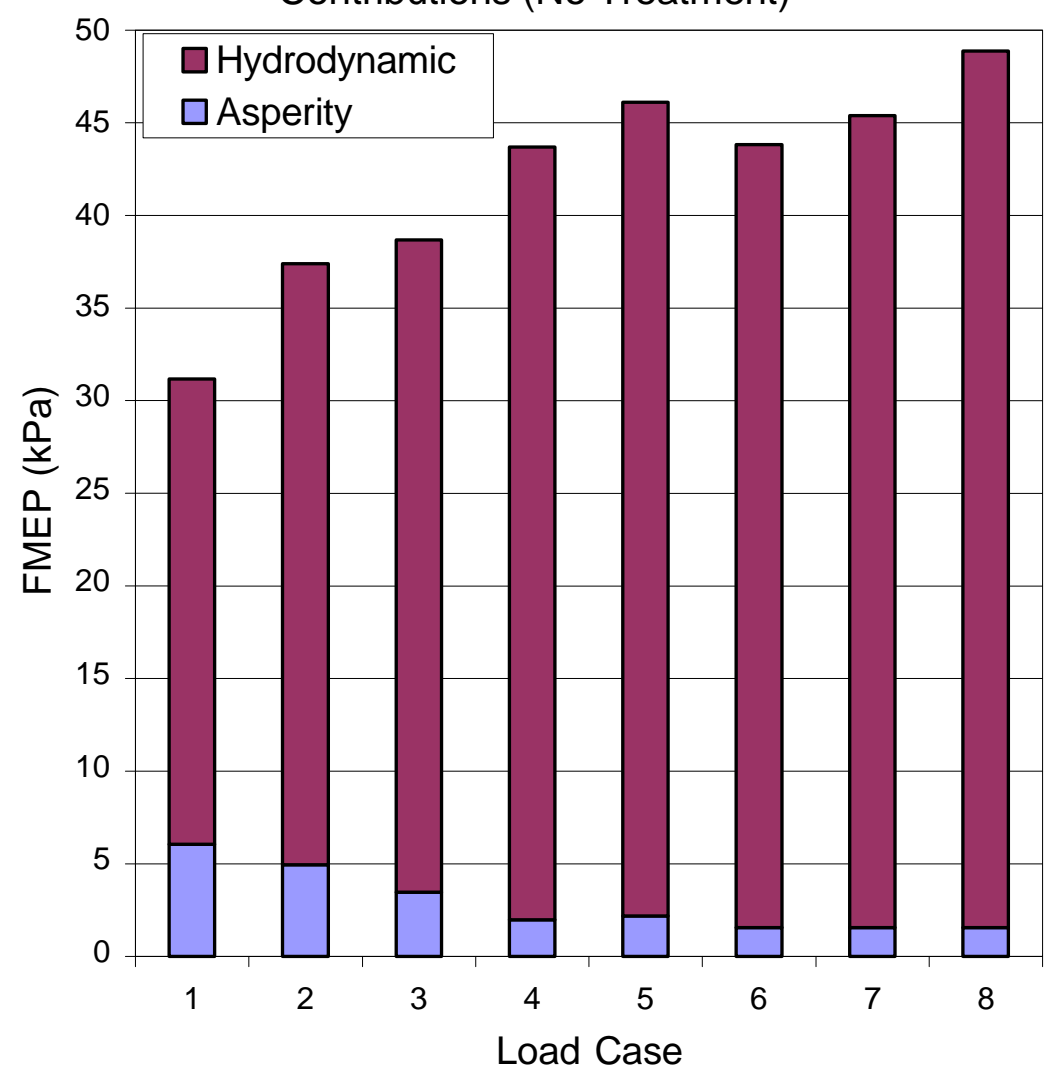

Figure 13: Ring Pack Friction Contributions (30\% Reduction in Asperity Friction Coefficient)

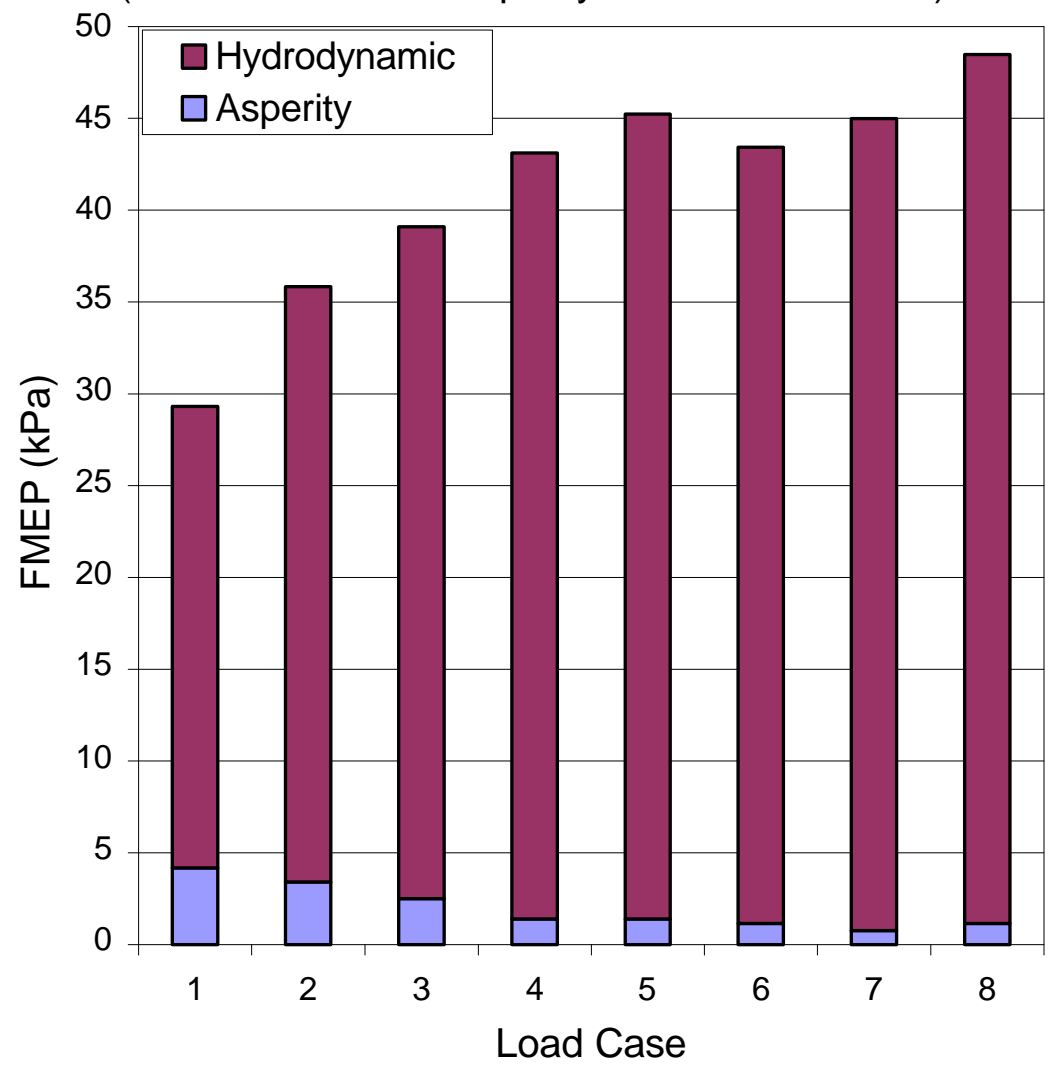


Figure 14: Ring Pack Friction Contributions (60\% Reduction in Asperity Friction Coefficient)

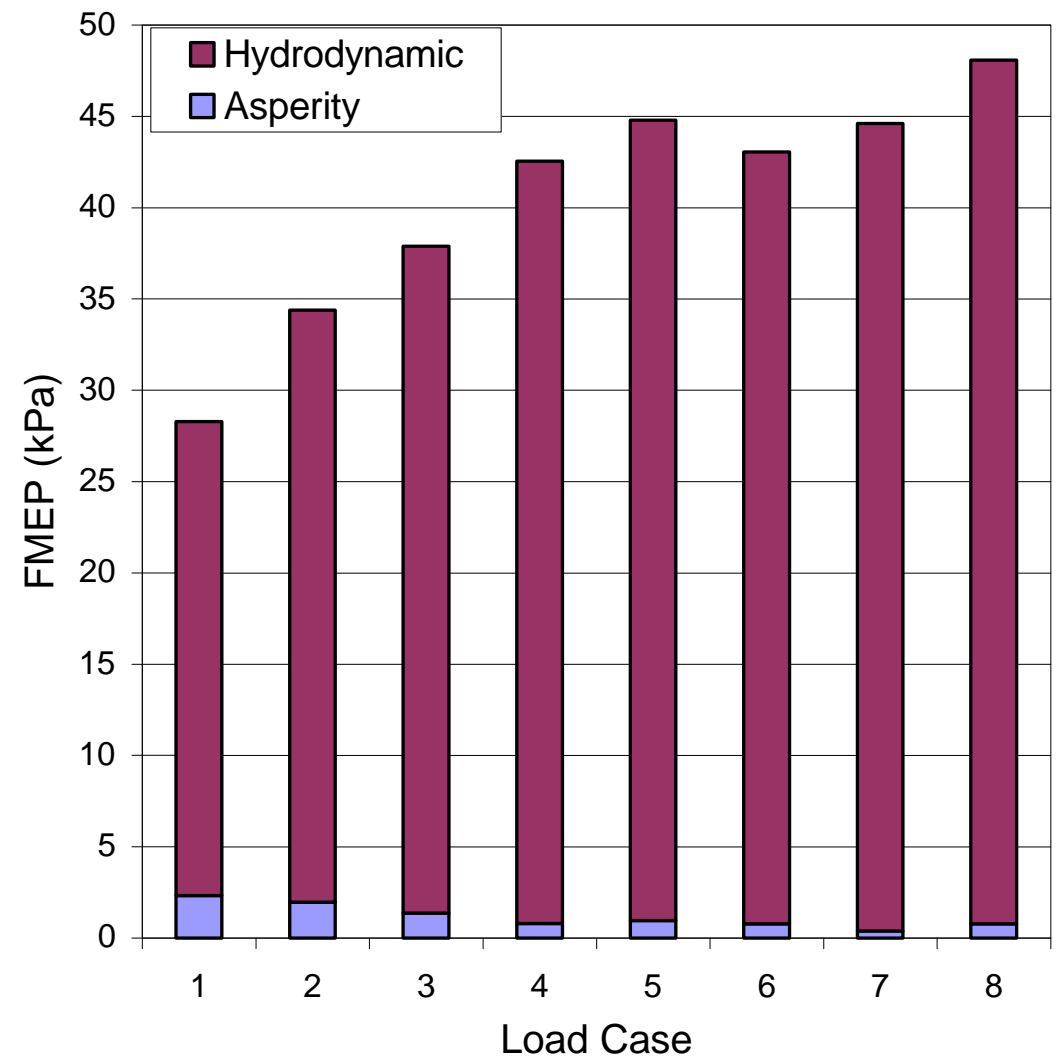

Figure 15: Ring Pack Friction Contributions (90\% Reduction in Asperity Friction Coefficient)

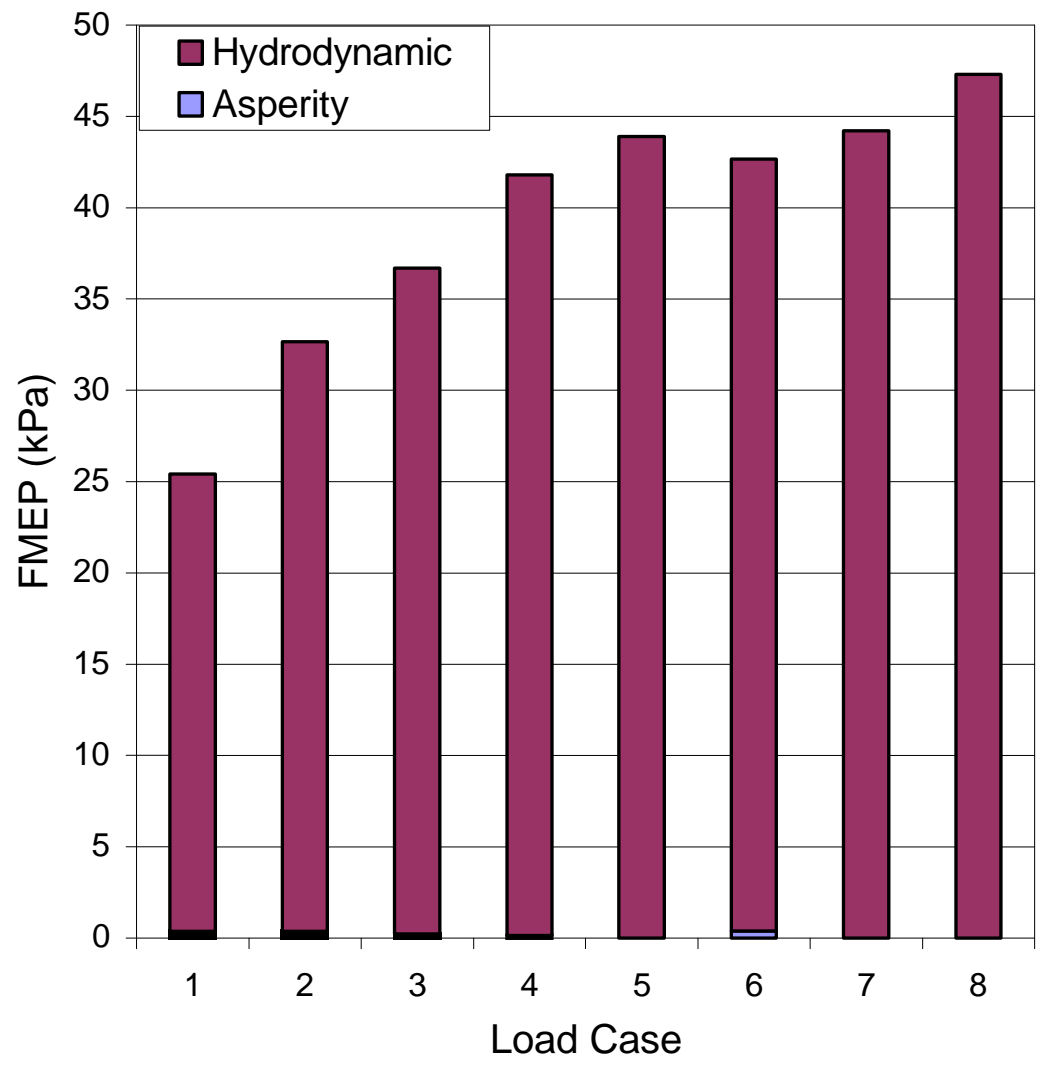




\section{Figure 16: Predicted Changes in Ring} Pack Average FMEP Over FTP Cycle

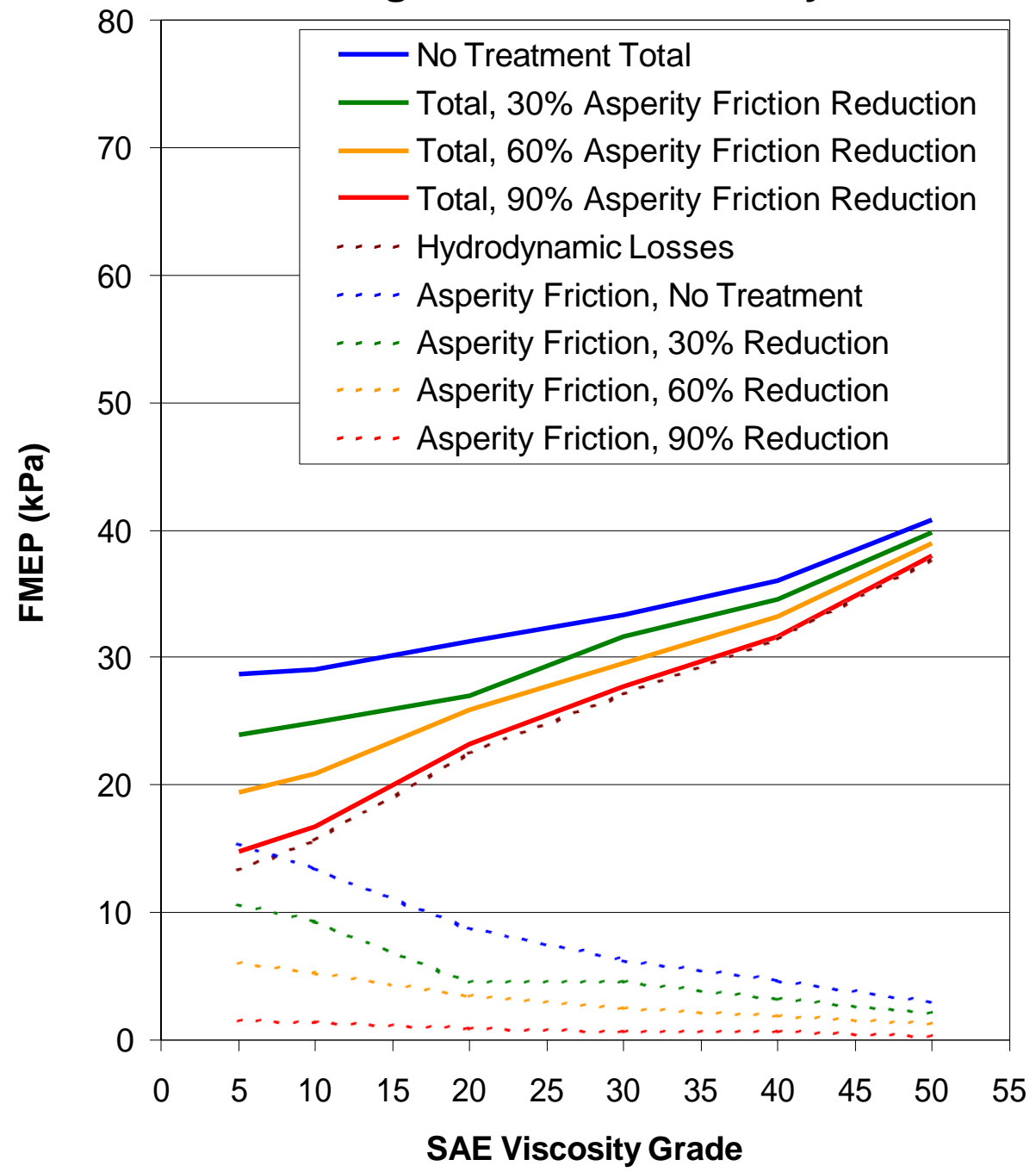

Figure 17: Normalized Predicted Changes in Ring - Liner Contact Severity Over FTP Cycle

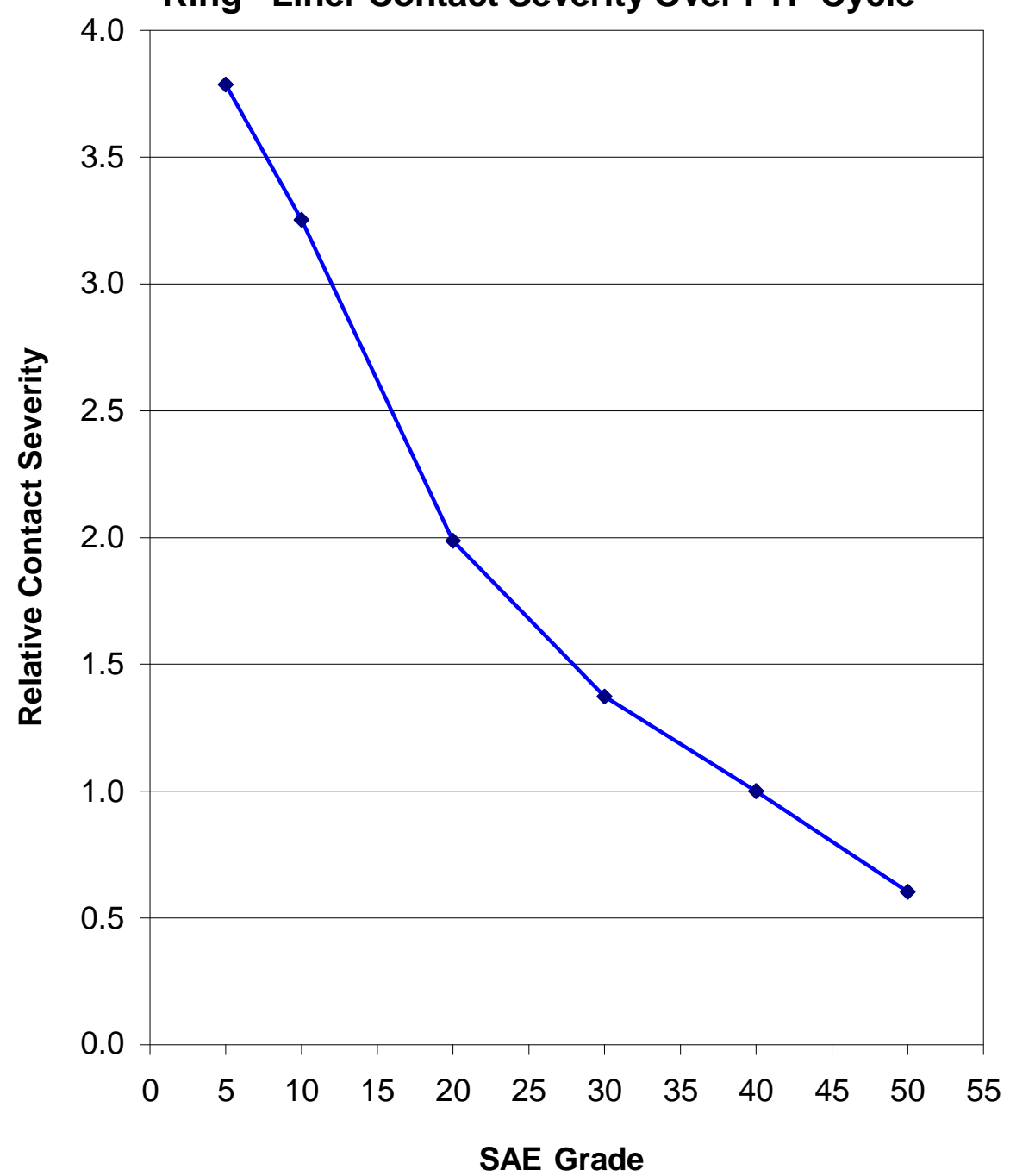


Client Name: Argonne National Laboratory

Project No.: G0908

Archive:

Figure 18: Predicted Changes in Main Bearing Average FMEP Over FTP Cycle

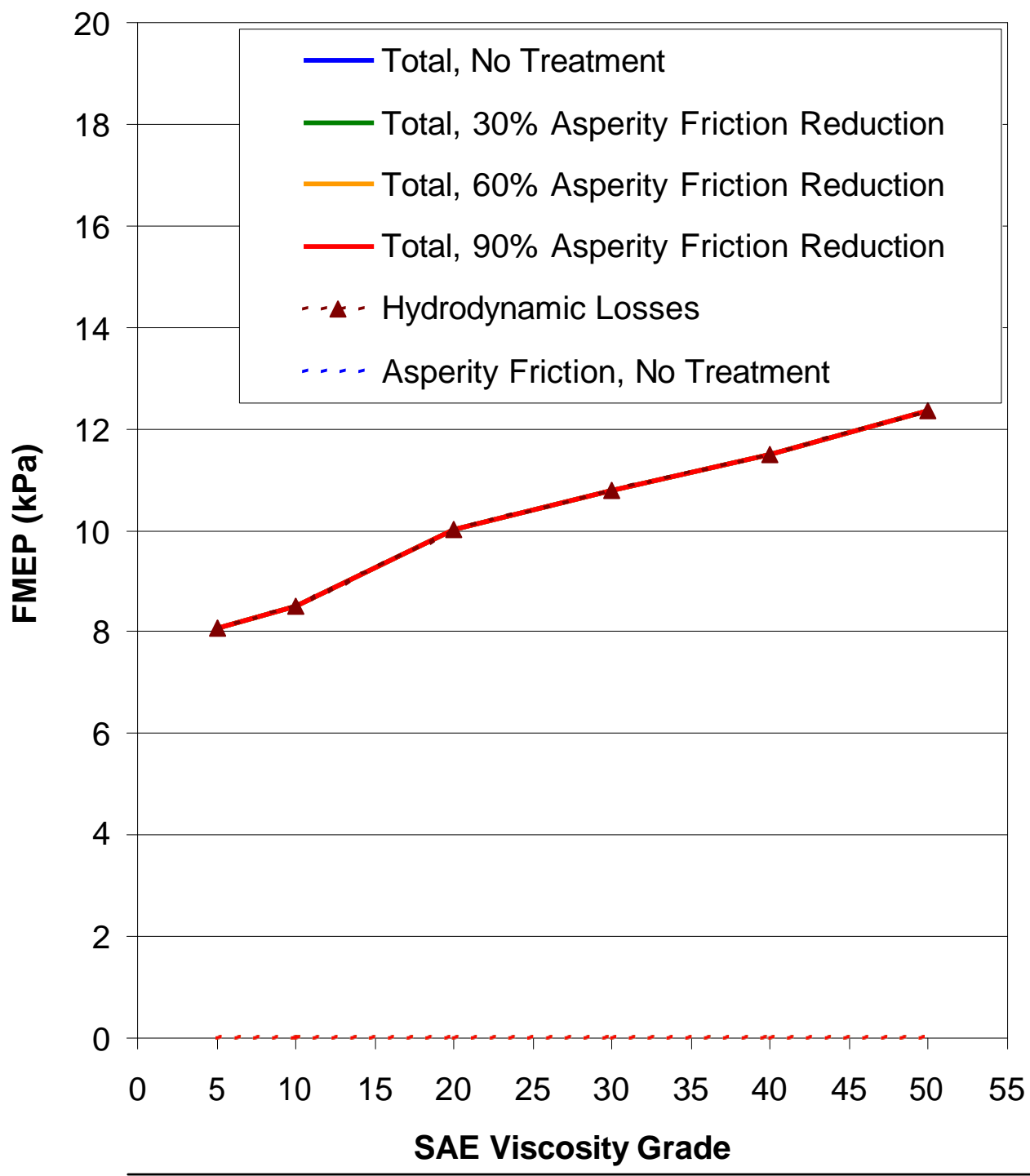

10-Jul-2003
Figure 19: Normalized Predicted Changes in Main Bearing Contact Severity Over FTP Cycle

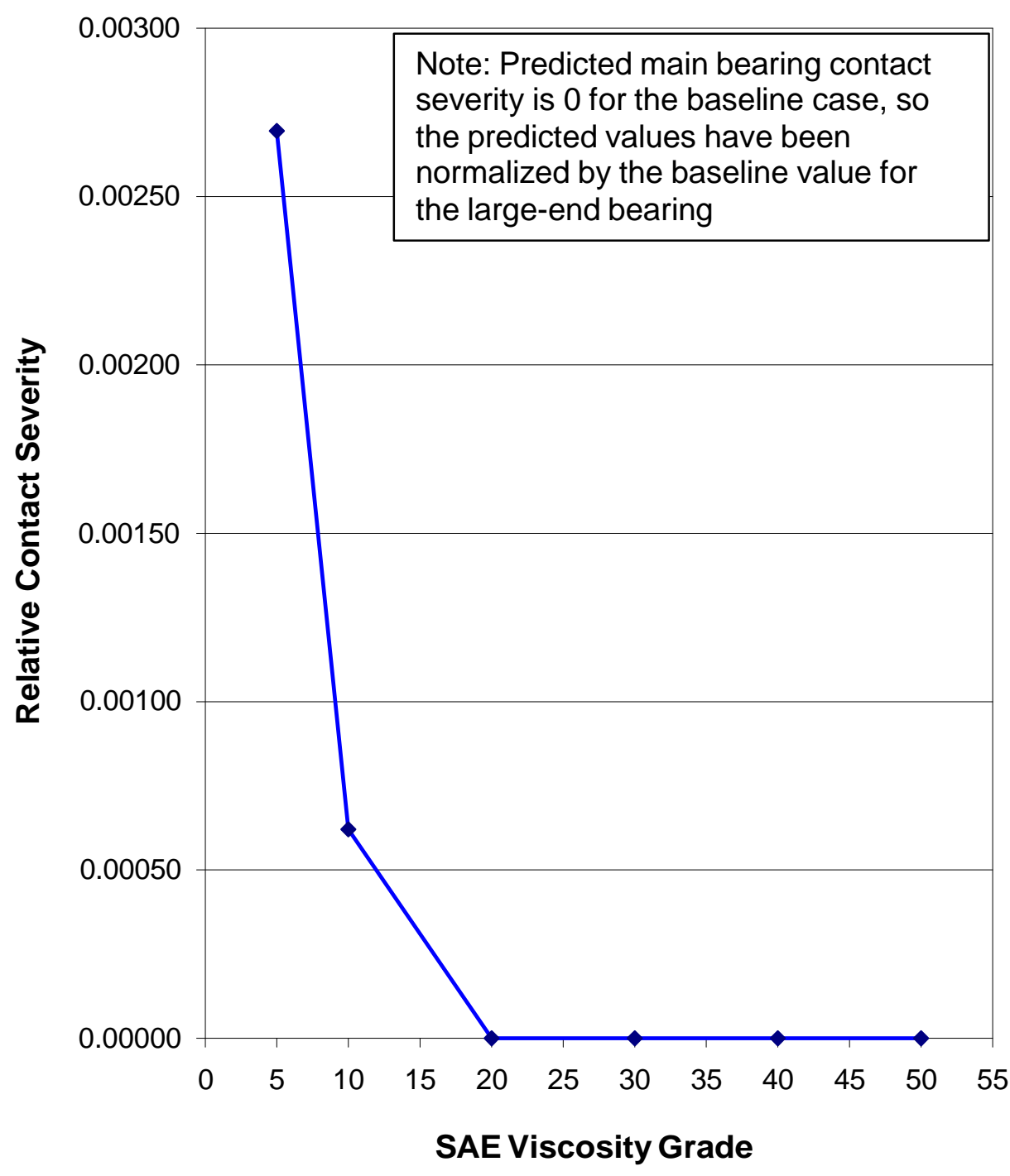

Page 35 of 46 


\section{Figure 20: Predicted Changes in Large- End Average FMEP Over FTP Cycle}

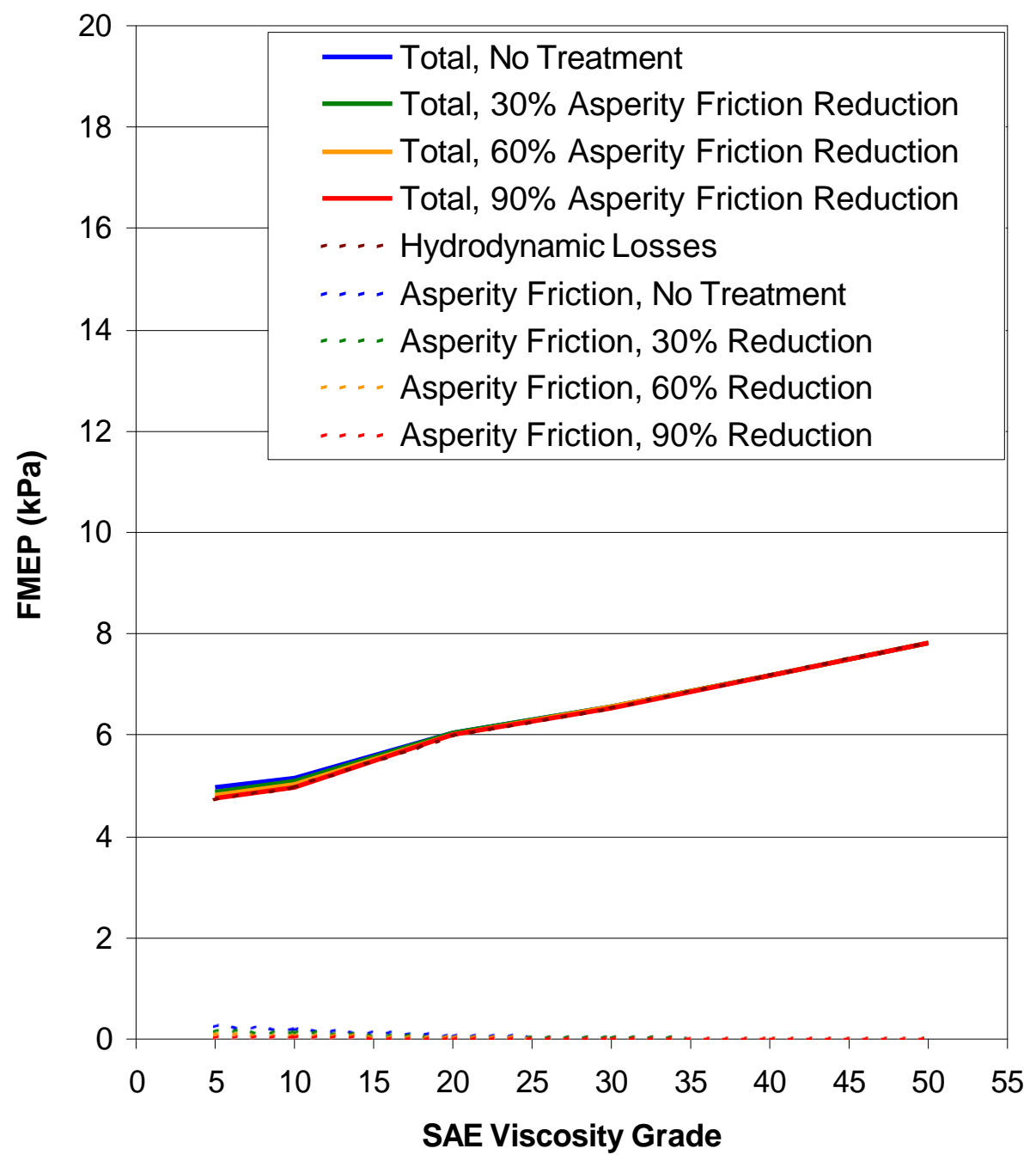

Figure 21: Normalized Predicted Changes in LargeEnd Bearing Contact Severity Over FTP Cycle

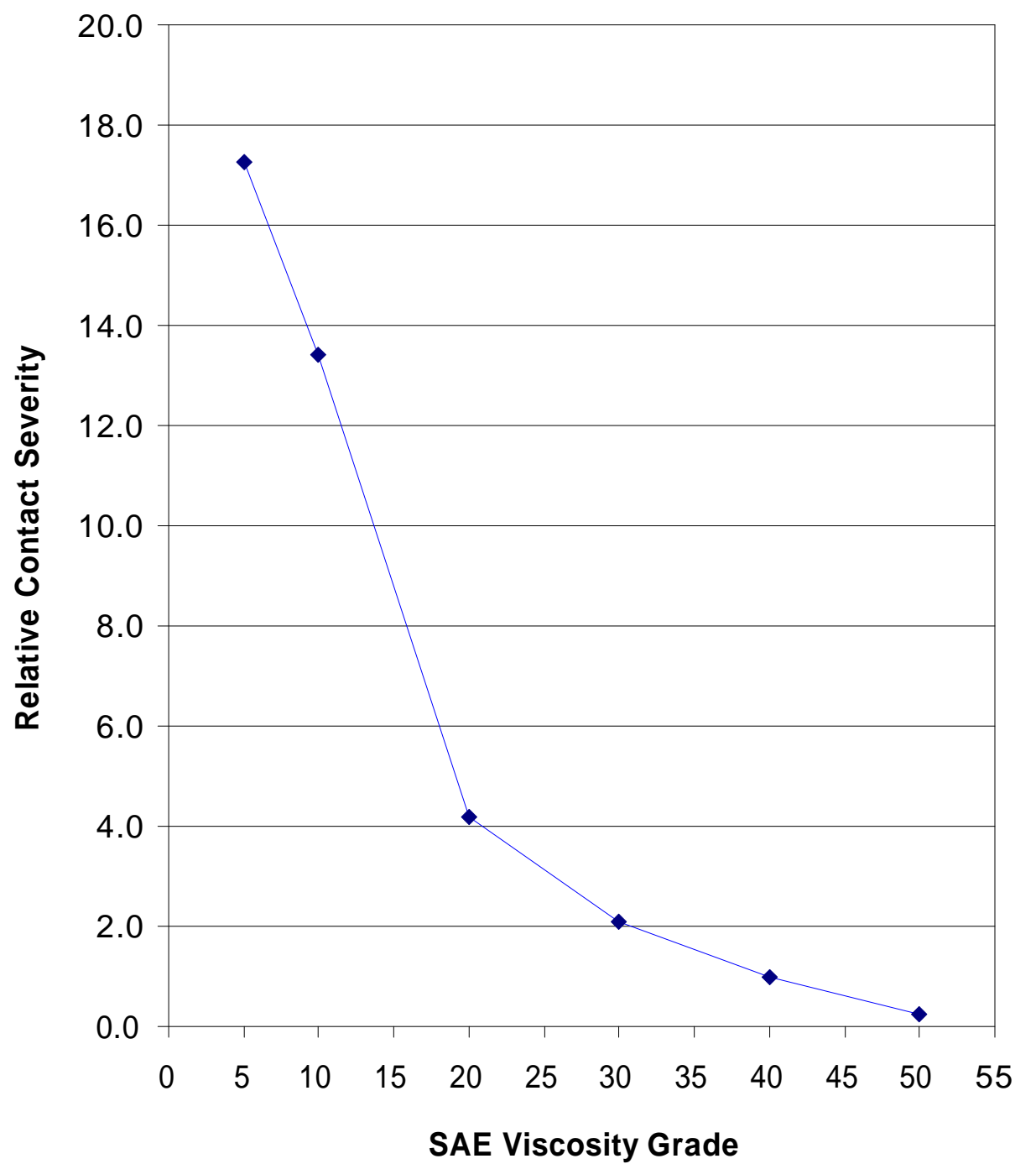

SAE Viscosity Grade 
Figure 22: Predicted Changes in Small-End Bearing Average FMEP over FTP Cycle

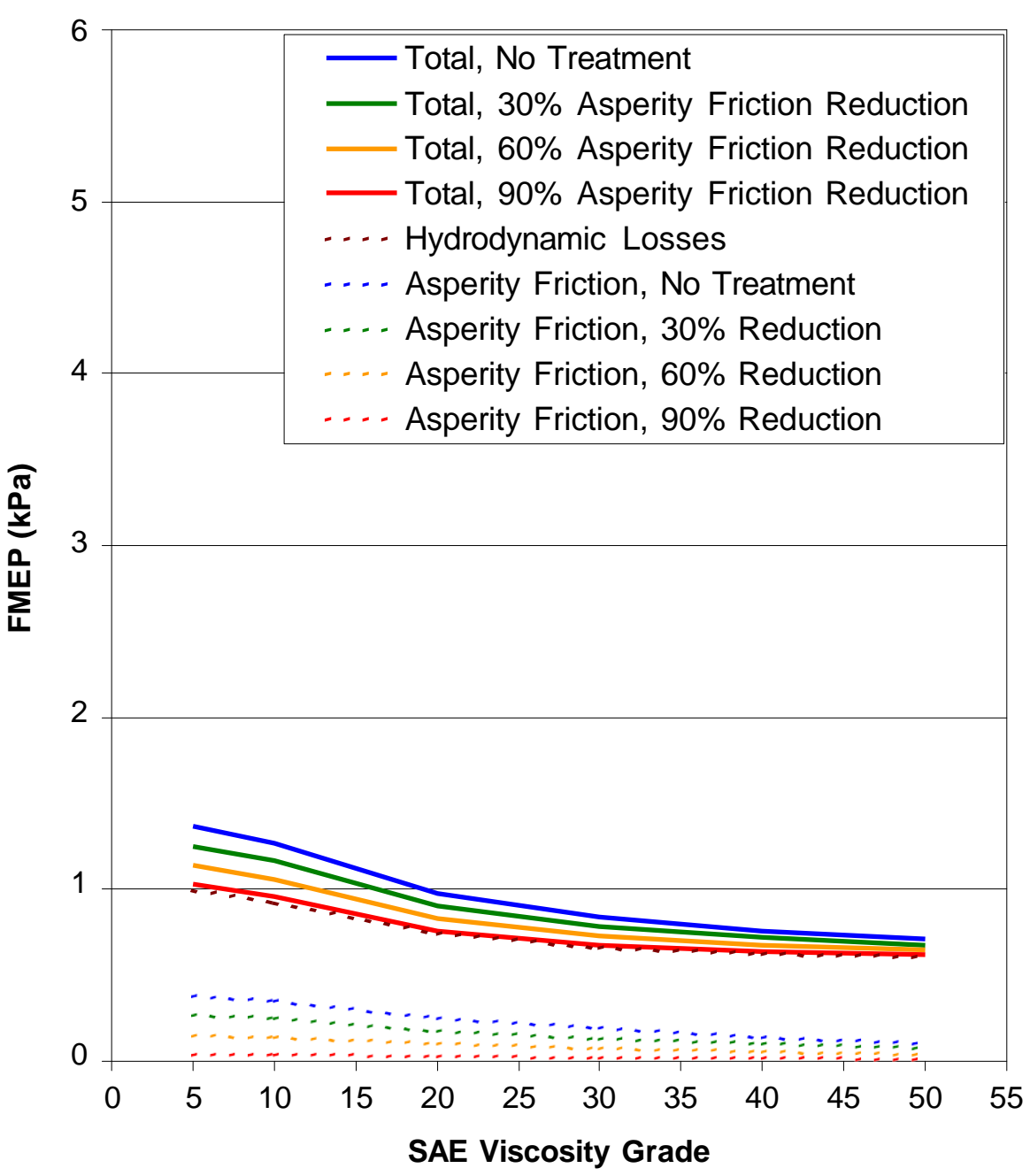

Figure 23: Normalized Predicted Changes in SmallEnd Bearing Contact Severity Over FTP Cycle

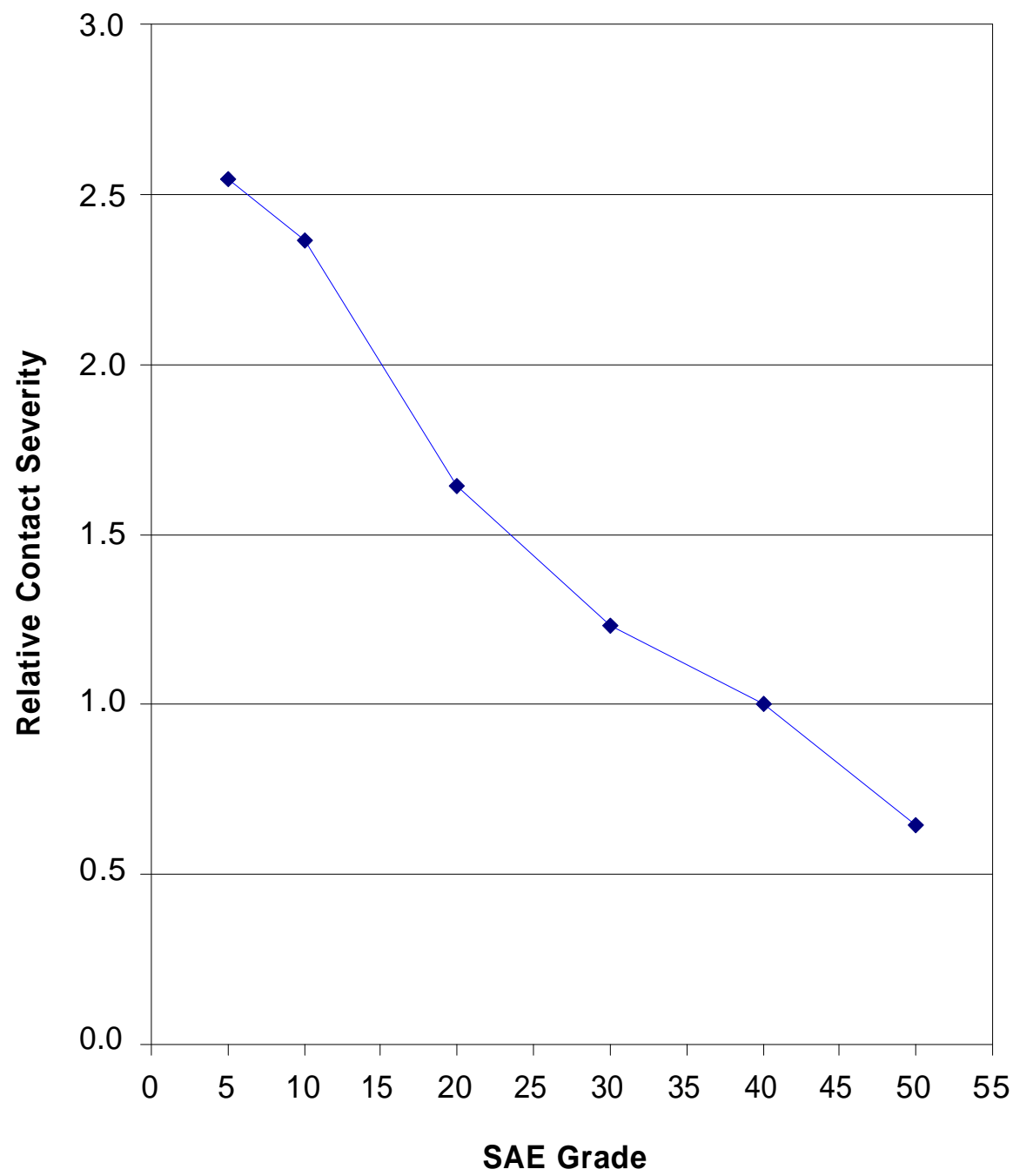


Client Name: Argonne National Laboratory

Project No: $\quad$ G0908
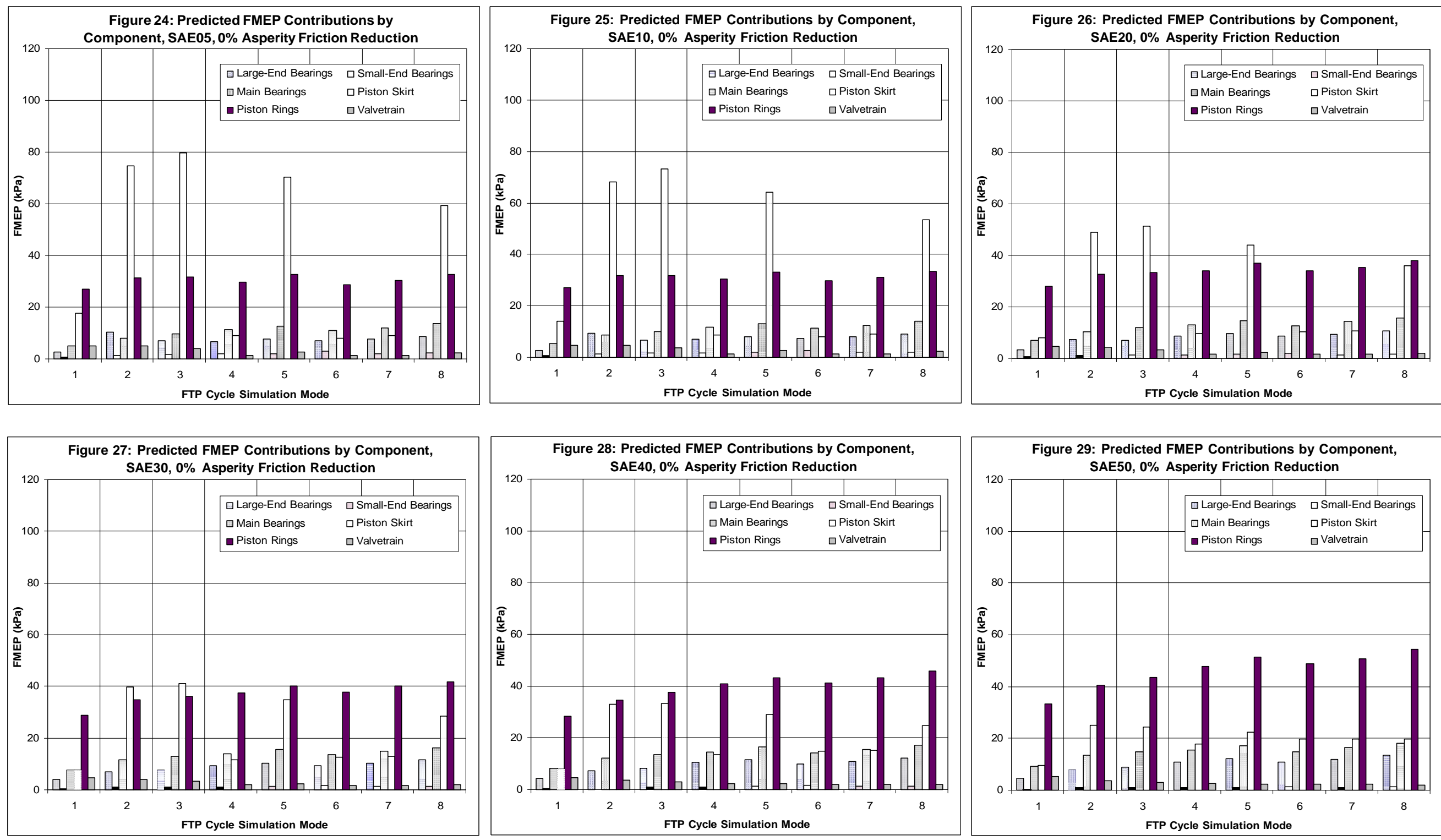
Client Name: Argonne National Laboratory

Project No: $\quad$ G0908
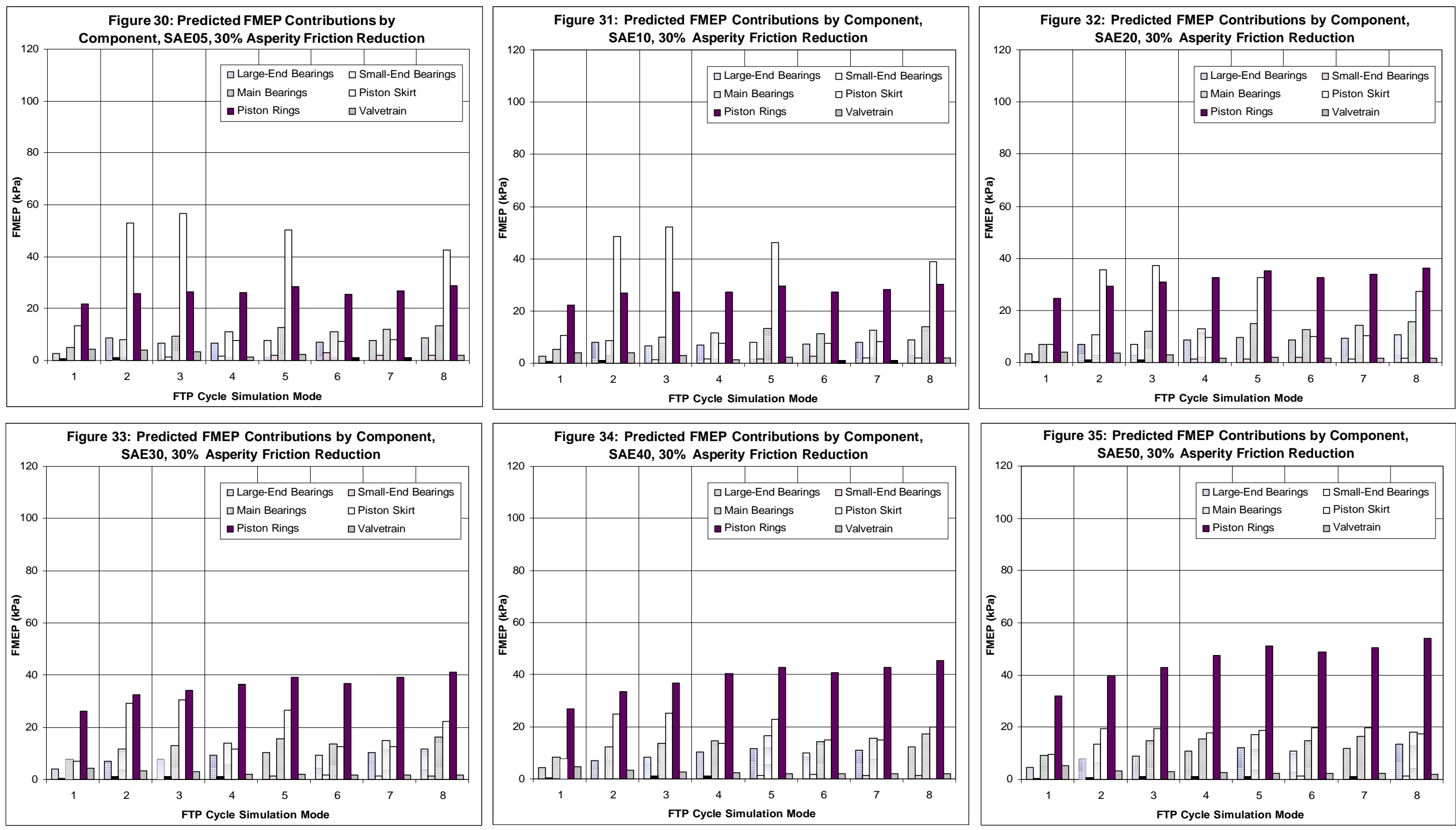
Figure 36: Predicted FMEP Contributions by
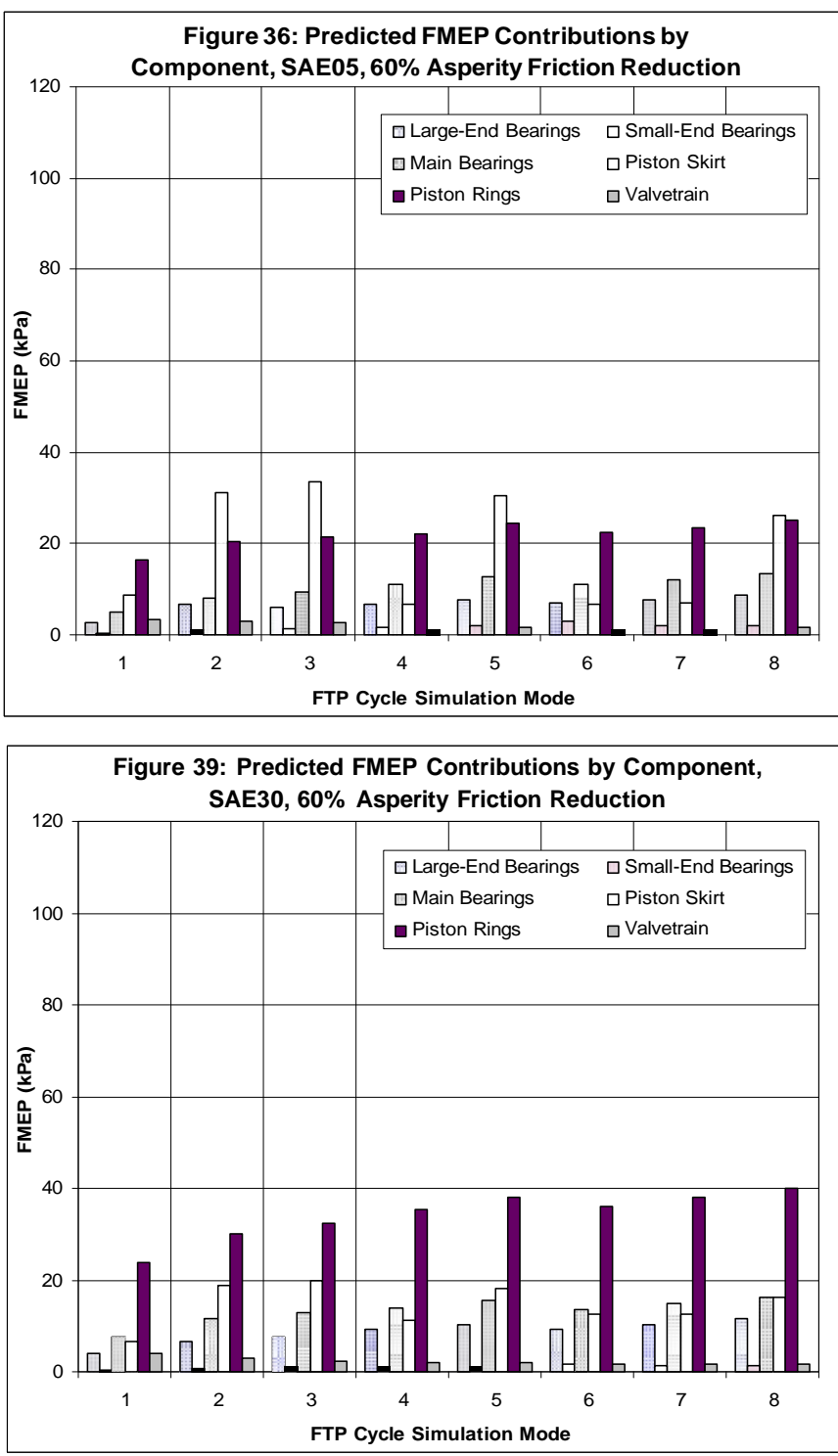

Figure 37: Predicted FMEP Contributions by Component, AE10, 60\% Asperity Friction Reduction
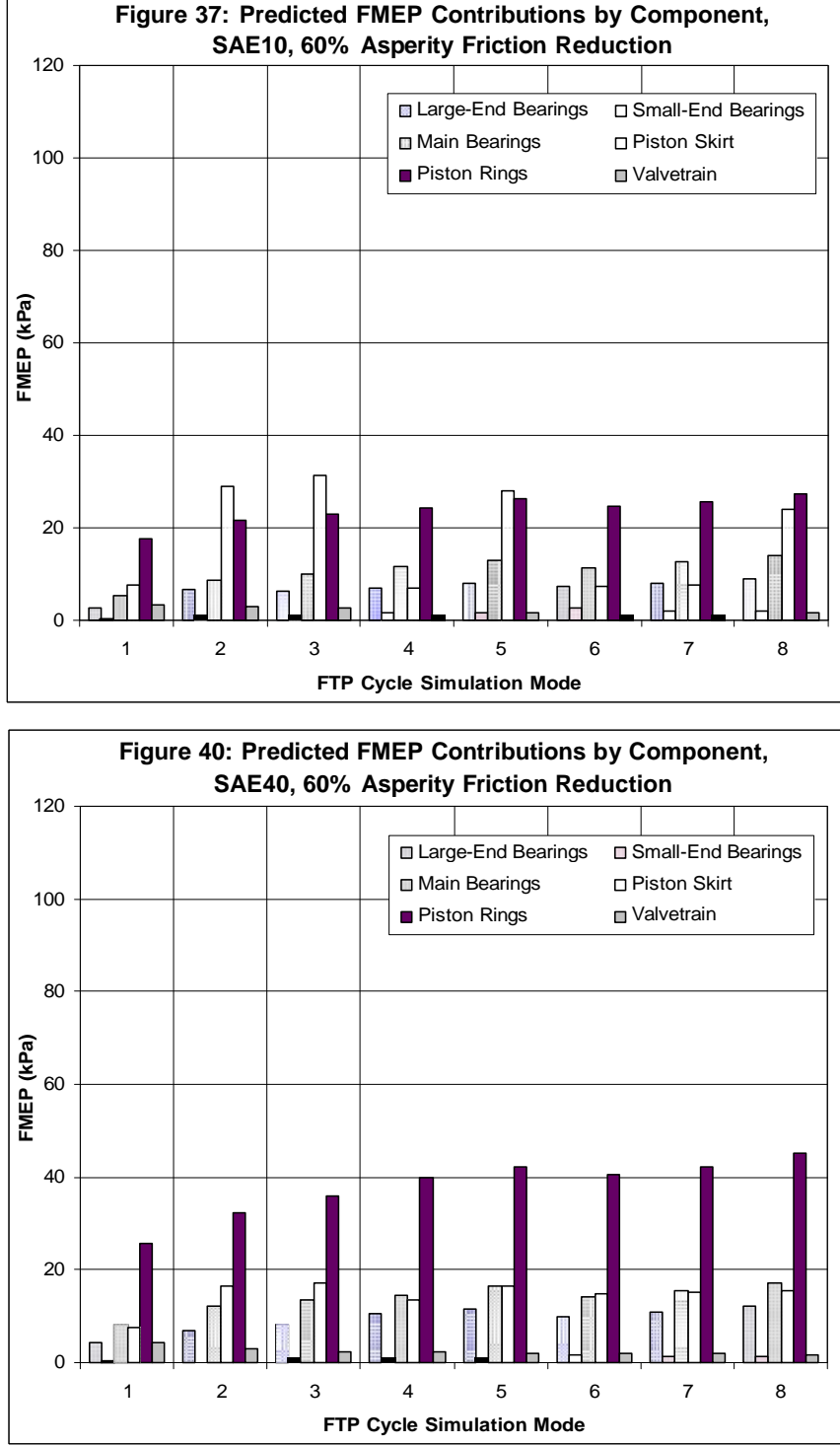

Figure 38: Predicted FMEP Contributions by Component, AE20, 60\% Asperity Friction Reduction
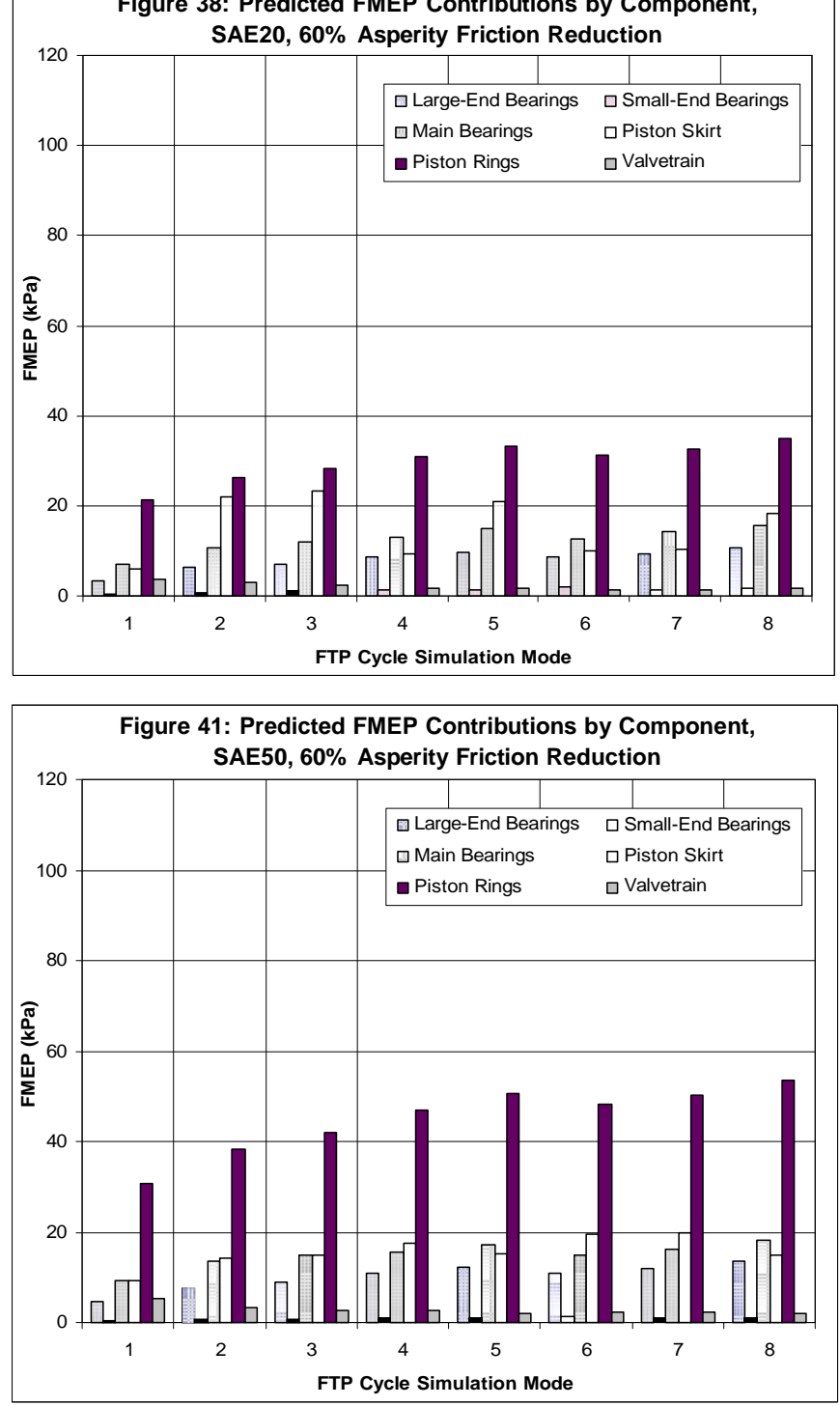
Client Name: Argonne National Laboratory

Project No.: G0908

Archive:

Figure 42: Predicted FMEP Contributions by
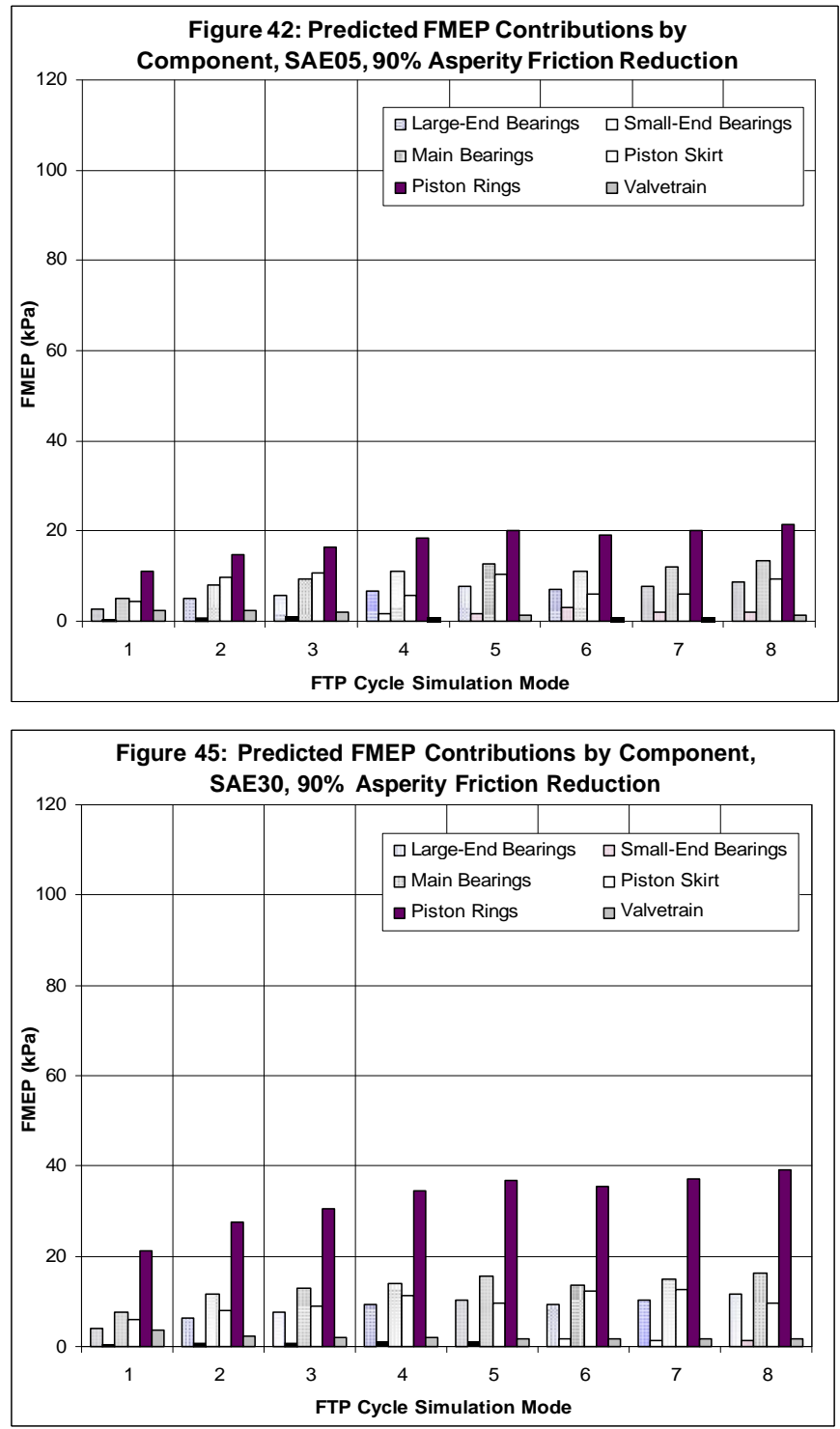

Figure 43: Predicted FMEP Contributions by Component SAE10, 90\% Asperity Friction Reduction
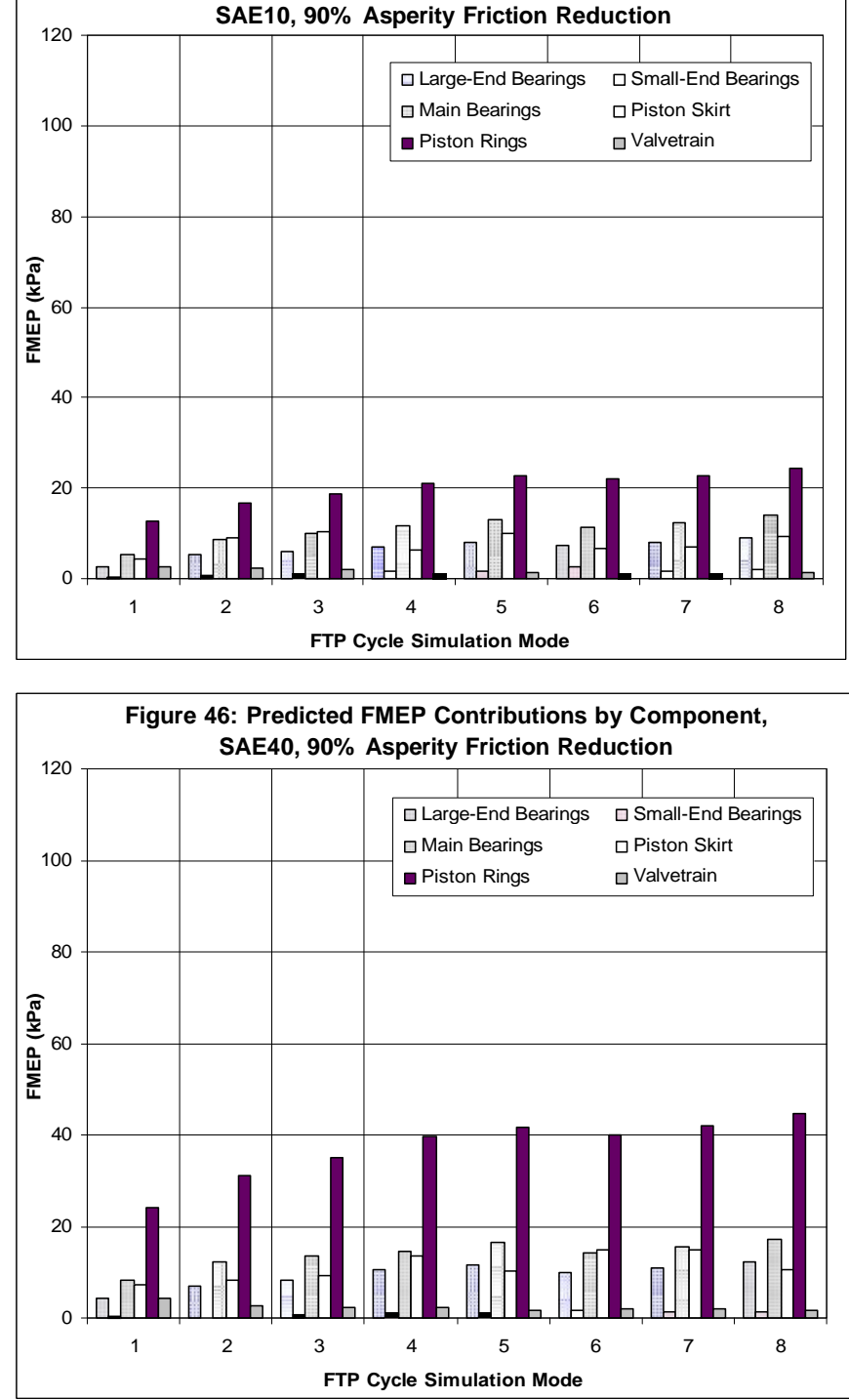

Figure 44: Predicted FMEP Contributions by Component, SAE20, 90\% Asperity Friction Reduction
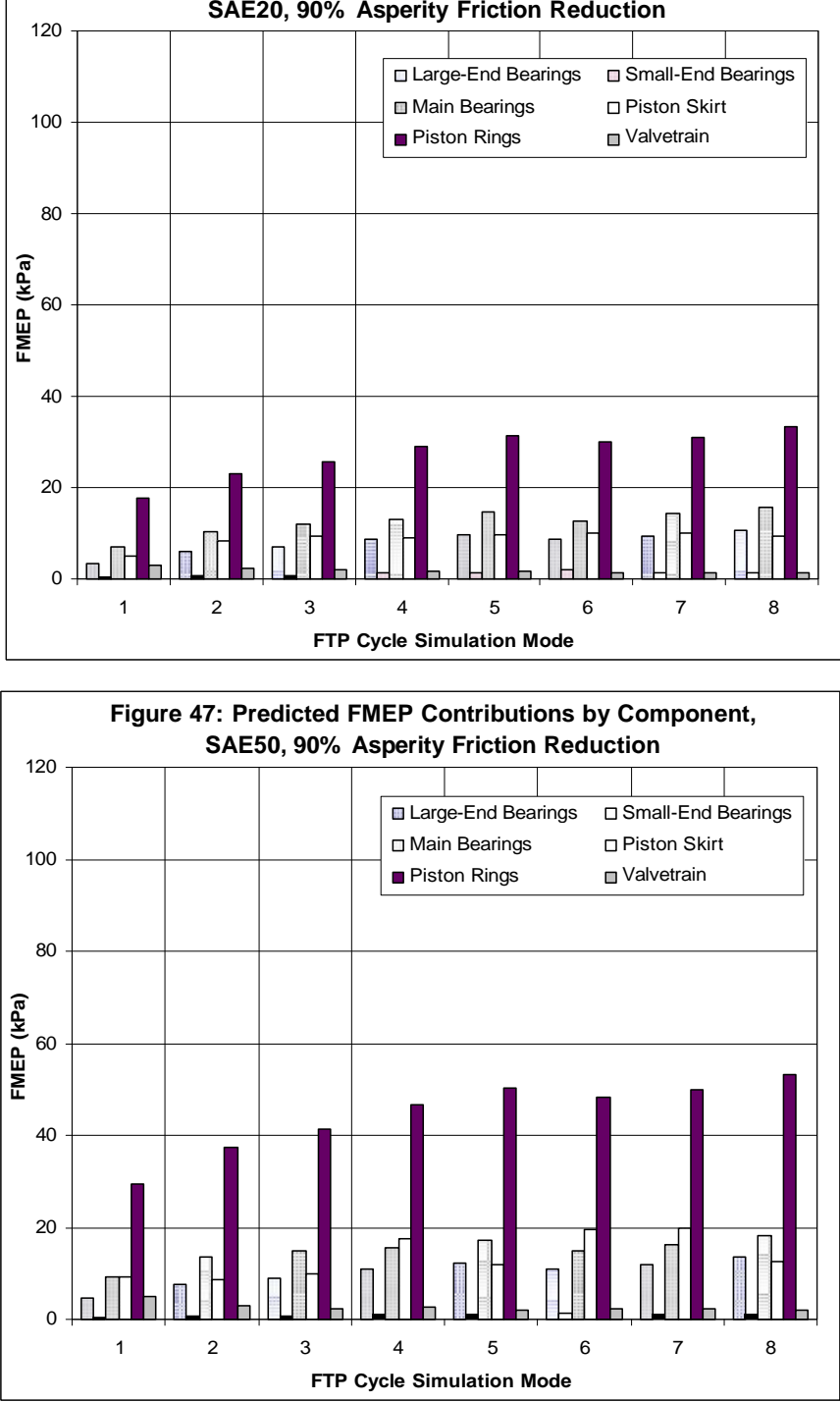
Figure 48: Predicted Change in FMEP by Component SAE05, 0\% Asperity Friction Reduction
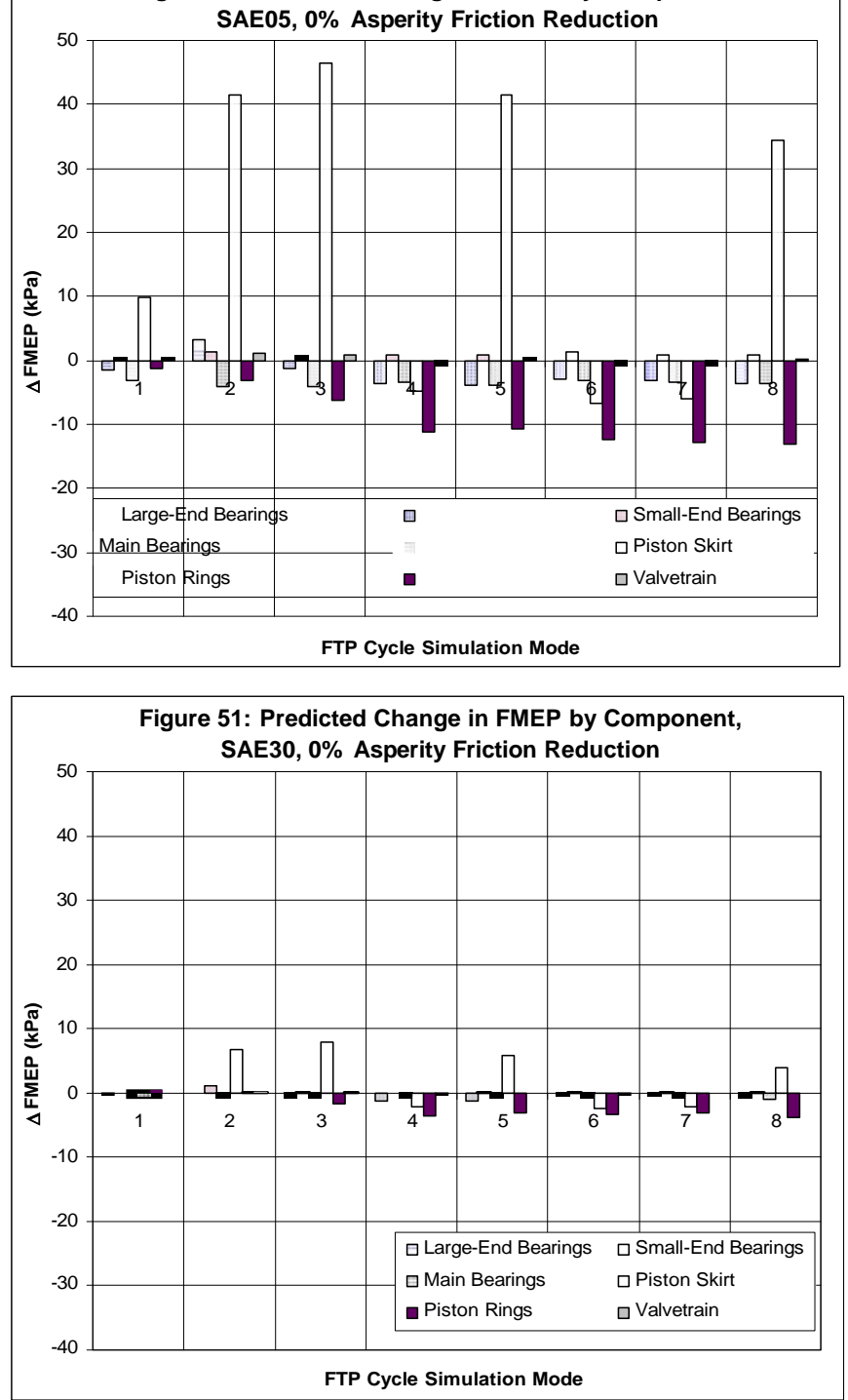

Figure 49: Predicted Change in FMEP by Component,
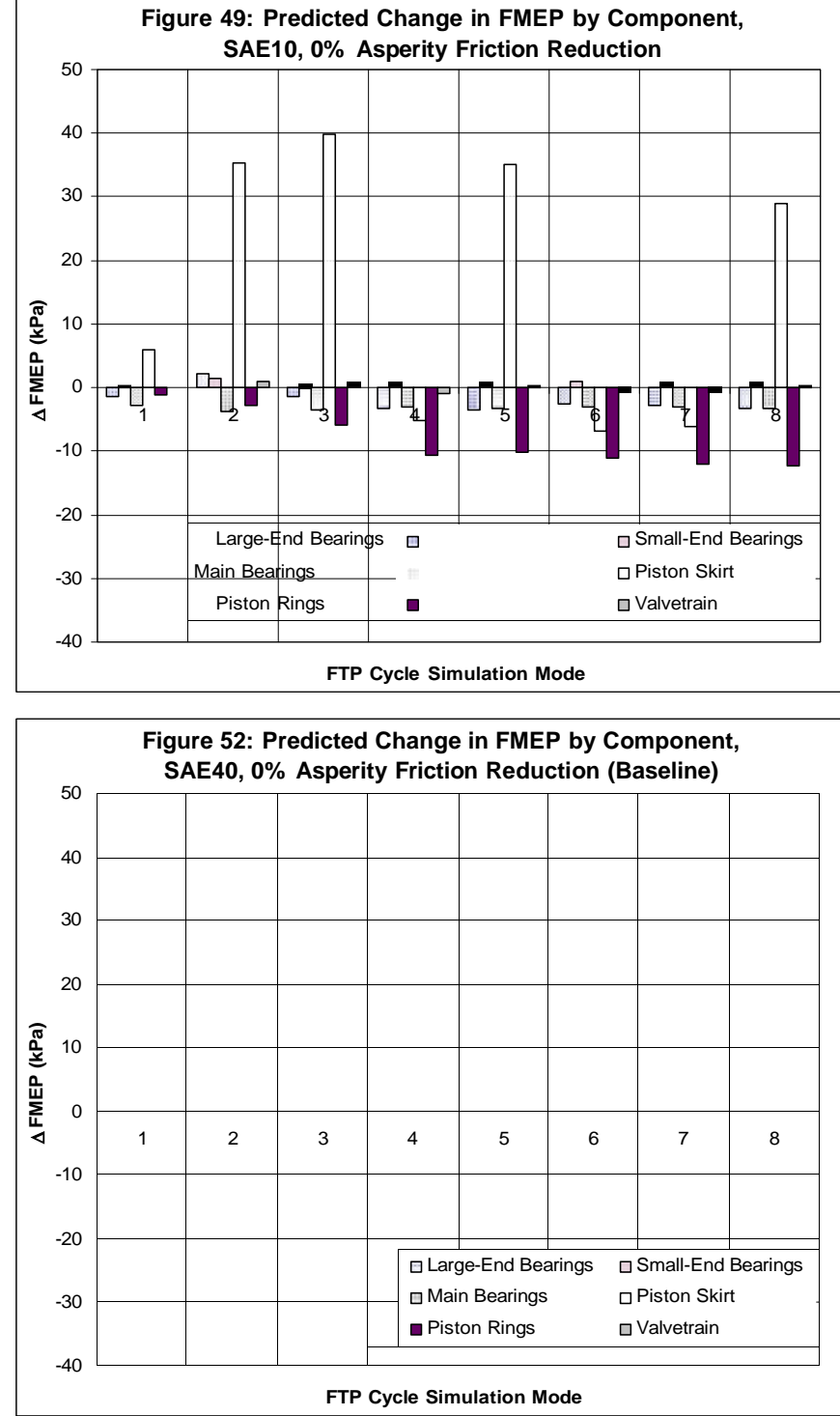

Figure 50: Predicted Change in FMEP by Component, SAE20, 0\% Asperity Friction Reduction

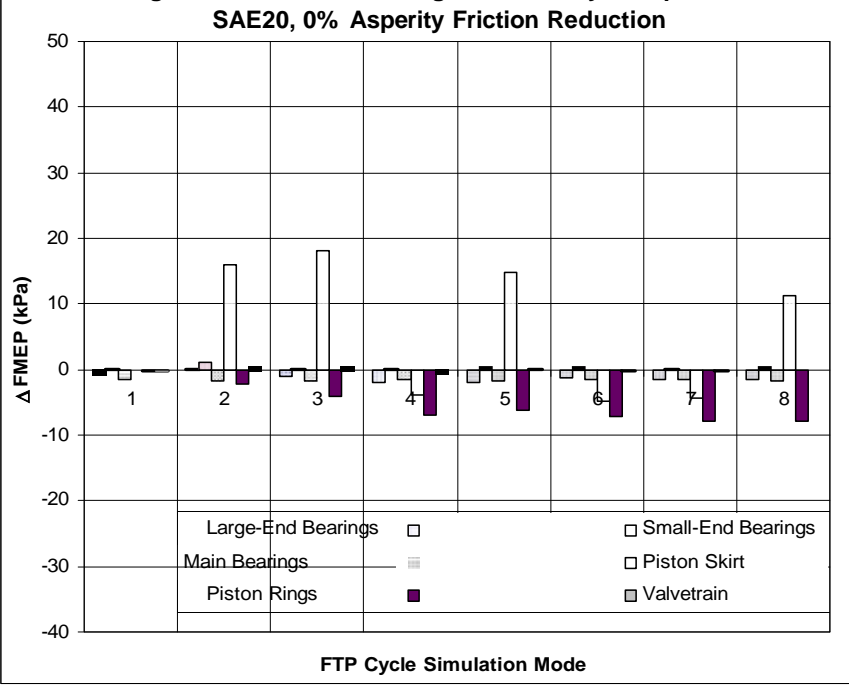

Figure 53: Predicted Change in FMEP by Component, SAE50, 0\% Asperity Friction Reduction

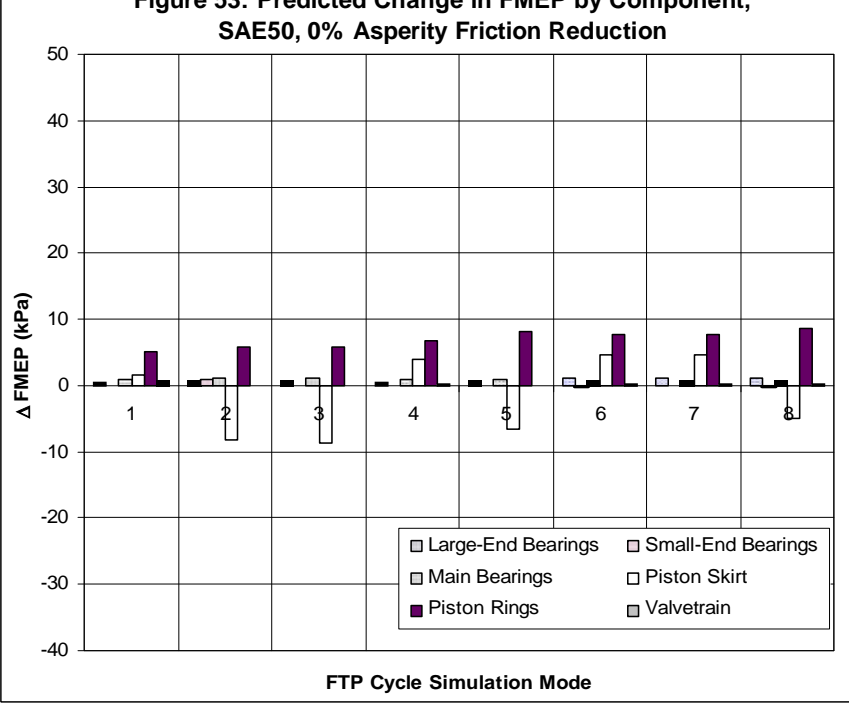


Figure 54: Predicted Change in FMEP by Component SAE05, 30\% Asperity Friction Reduction

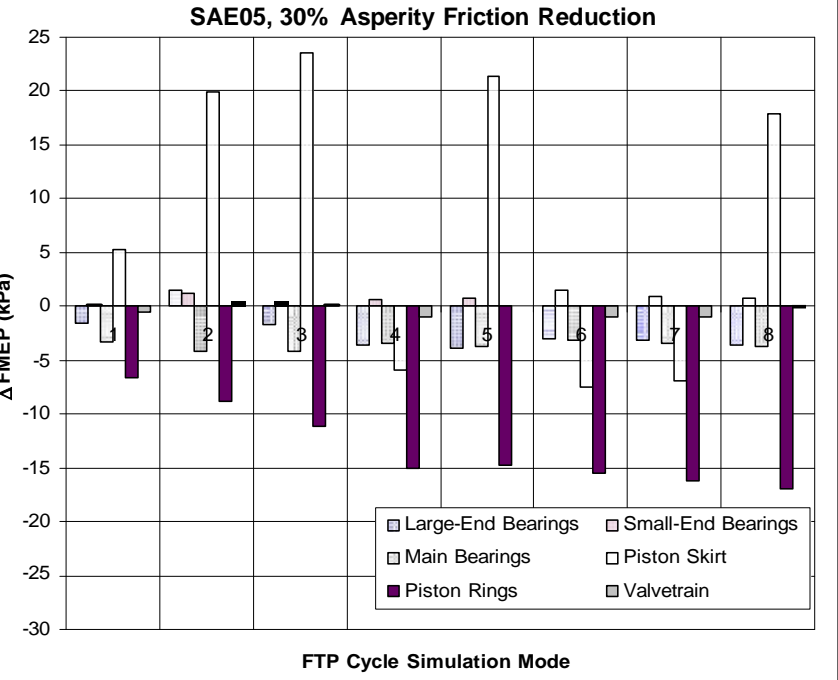

Figure 57: Predicted Change in FMEP by Component SAE30, 30\% Asperity Friction Reduction

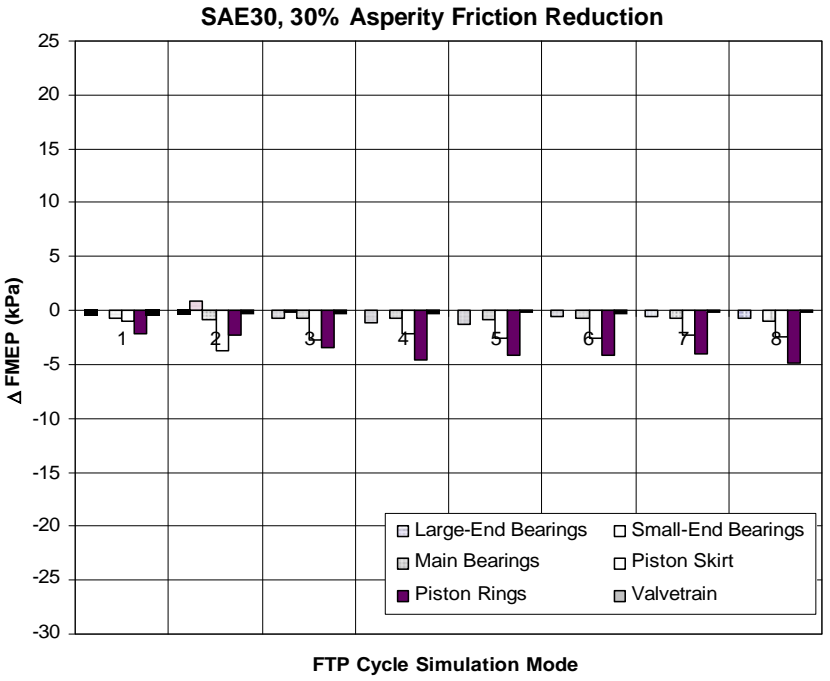

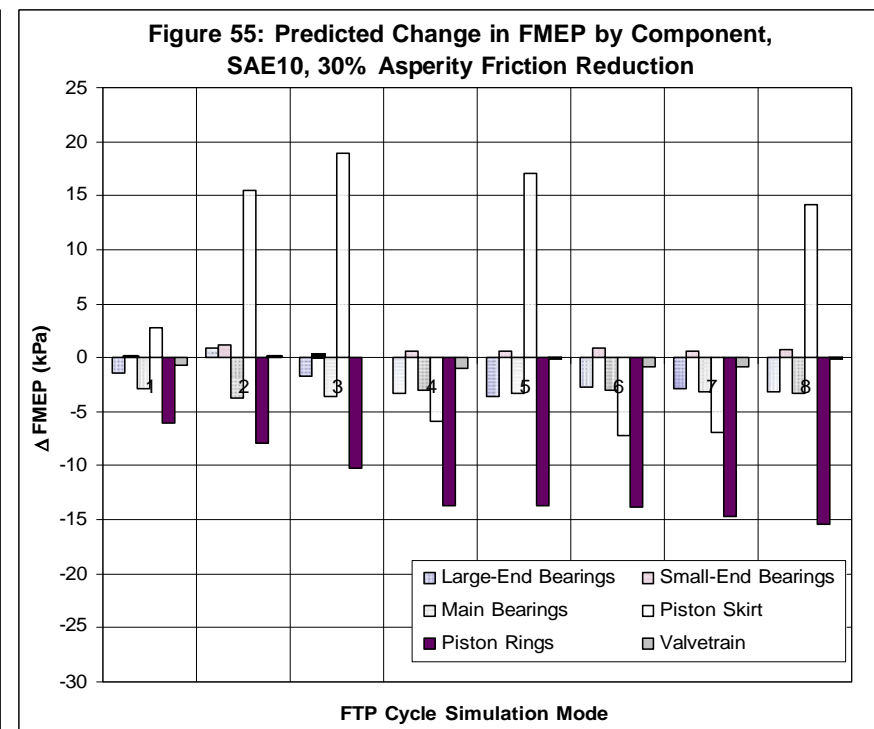
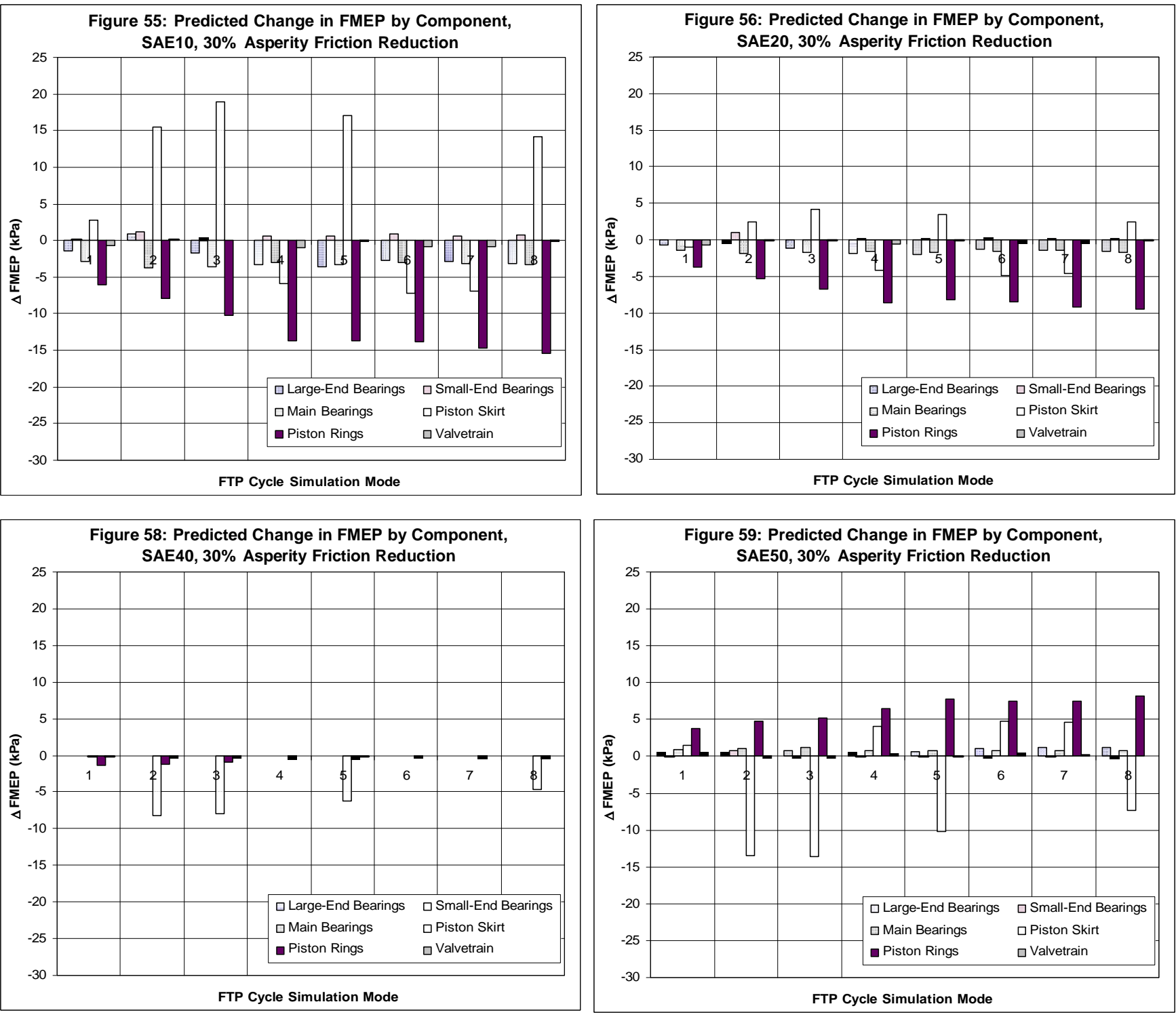
Client Name: Argonne National Laboratory

Project No: $\quad$ G0908
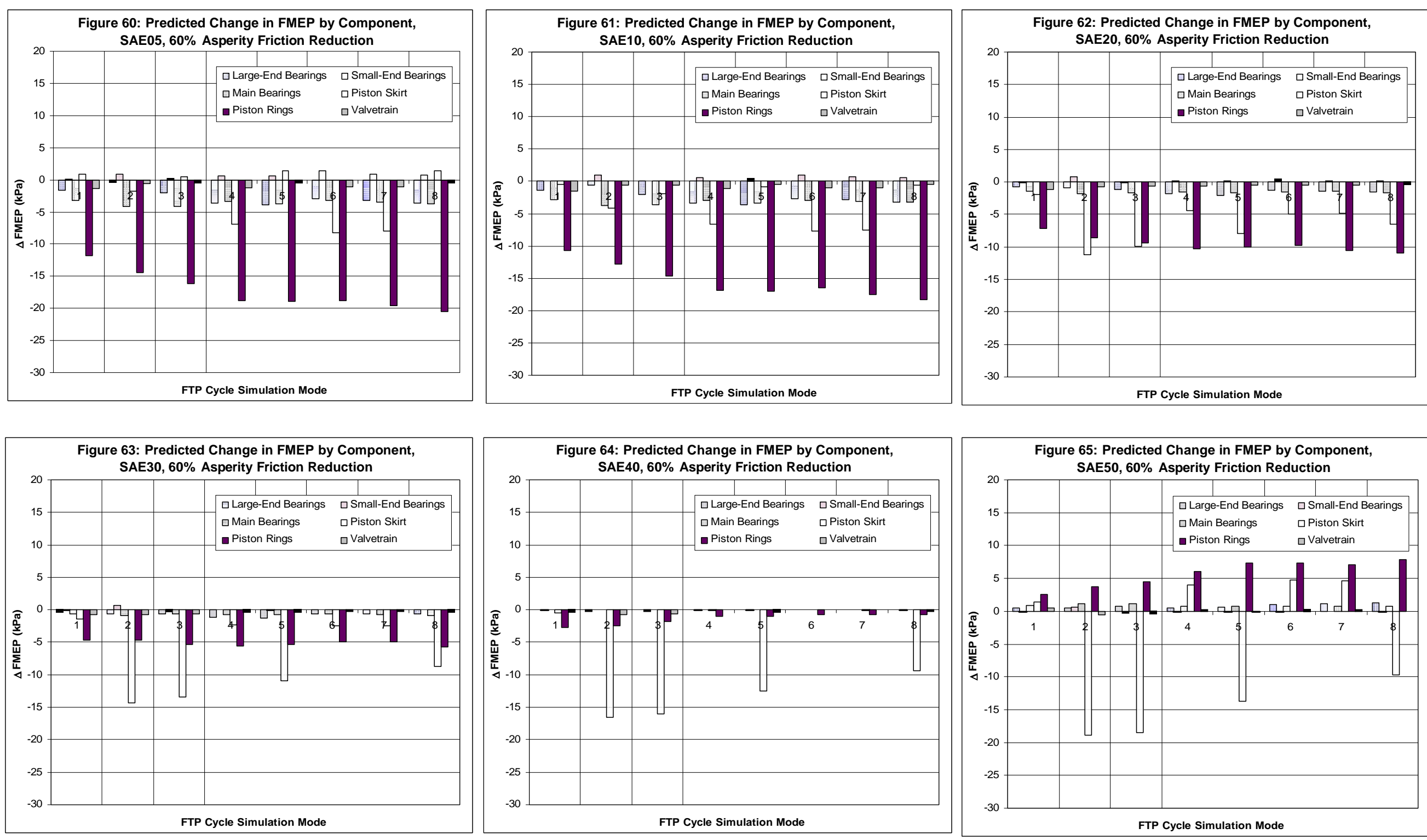
Client Name: Argonne National Laboratory

Project No: $\quad$ G0908

Figure 66: Predicted Change in FMEP by Component, SAE05, 90\% Asperity Friction Reduction

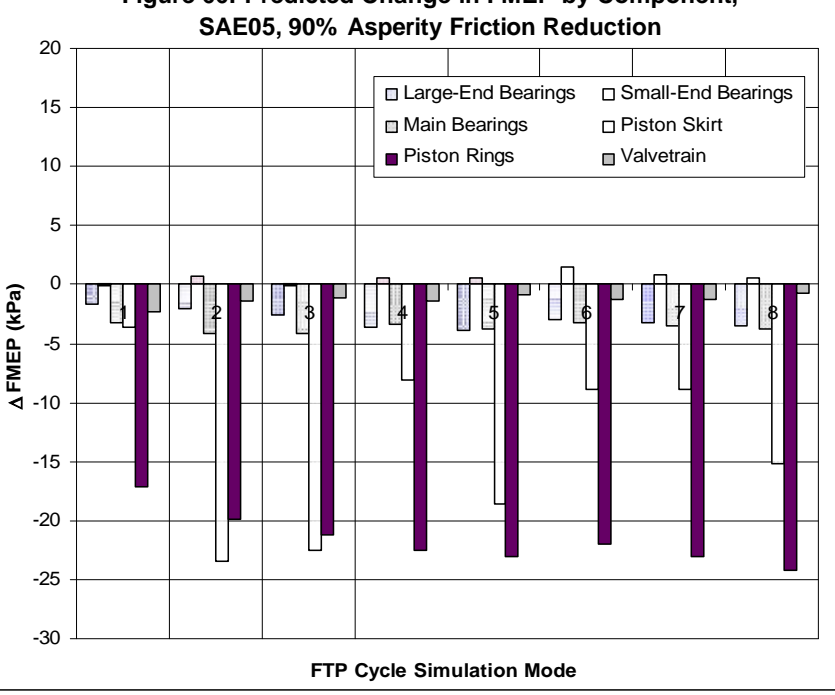

FTP Cycle Simulation Mode

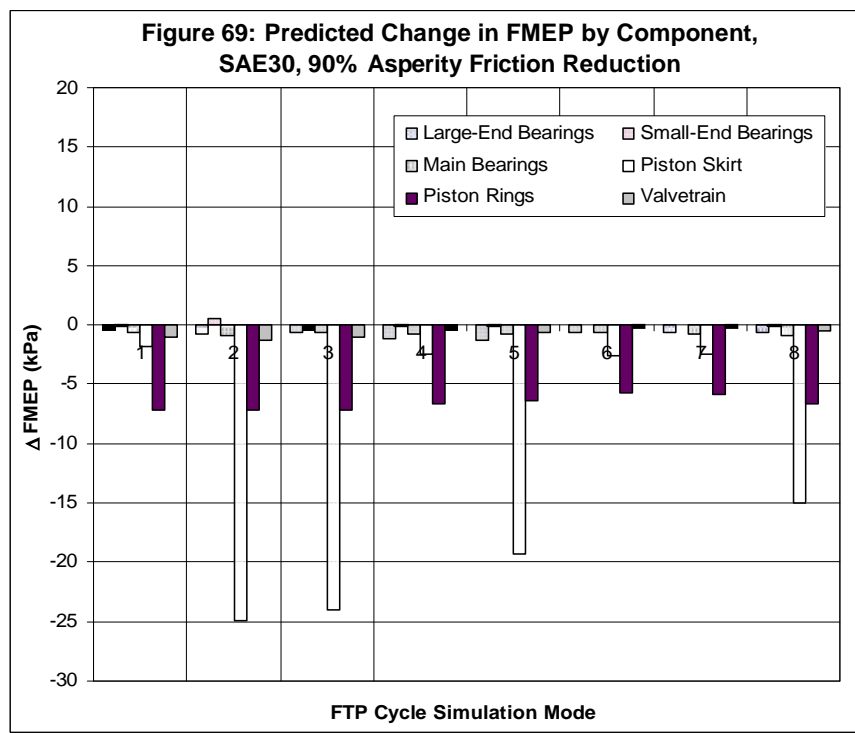

10-Jul-2003
Figure 67: Predicted Change in FMEP by Component SAE10, 90\% Asperity Friction Reduction
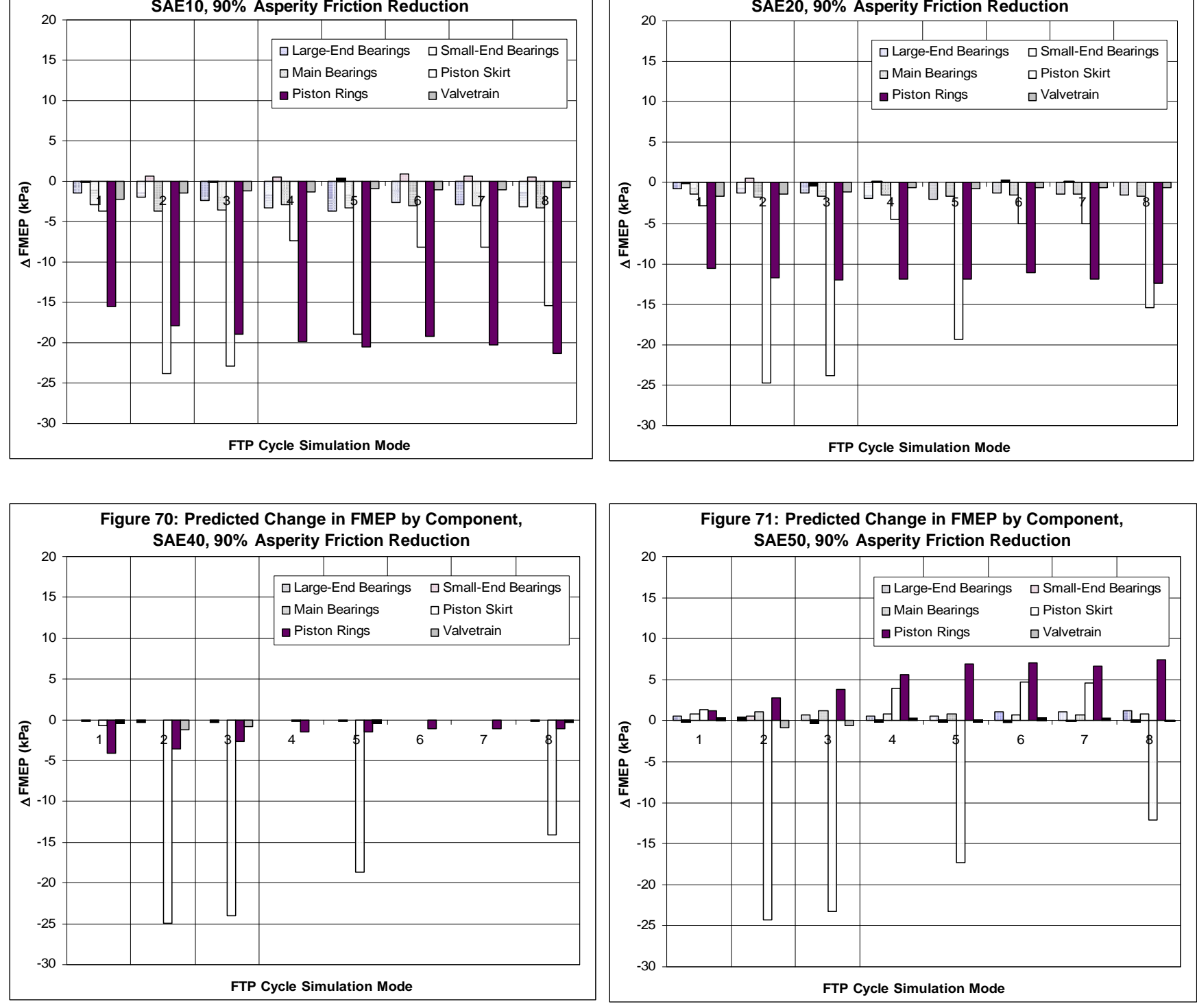

FTP Cycle Simulation Mode

Figure 68: Predicted Change in FMEP by Component,

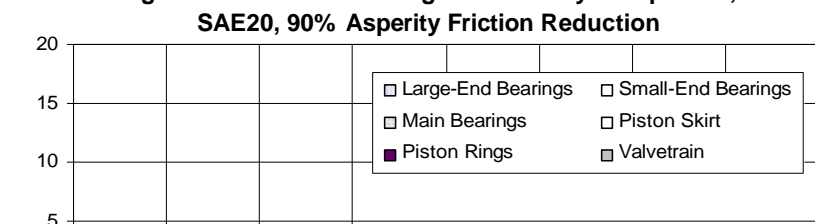

C) 2002 by Ricardo, Inc 
Client Name: Argonne National Laboratory

Project No.: G0908

Archive:

Figure 72: Predicted Changes in Average FMEP

Over FTP Cycle for Various Levels of Asperity

Friction Coefficient Reduction

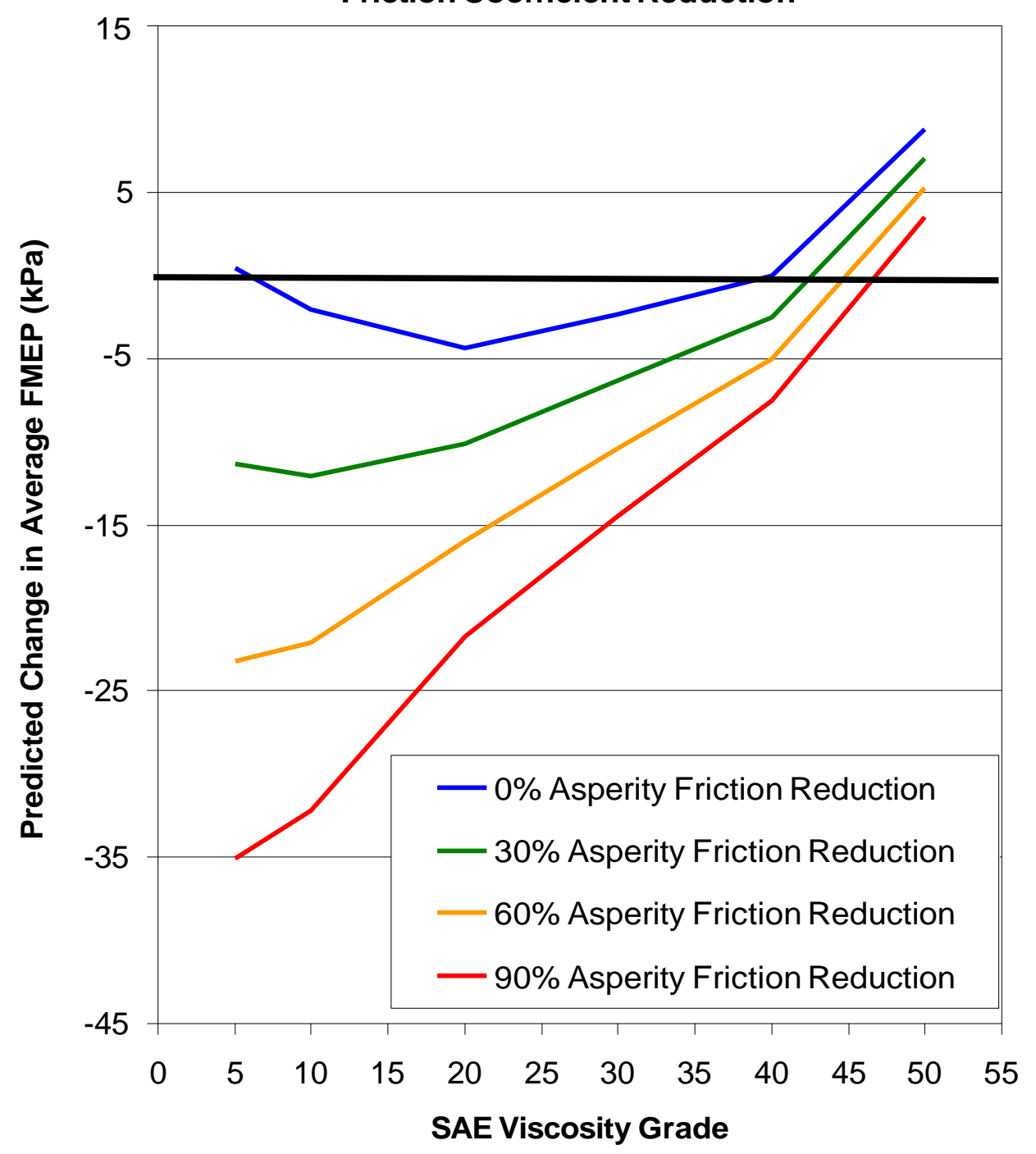
Consumption Over FTP Cycle for Various Levels of Asperity Friction Coefficient Reduction

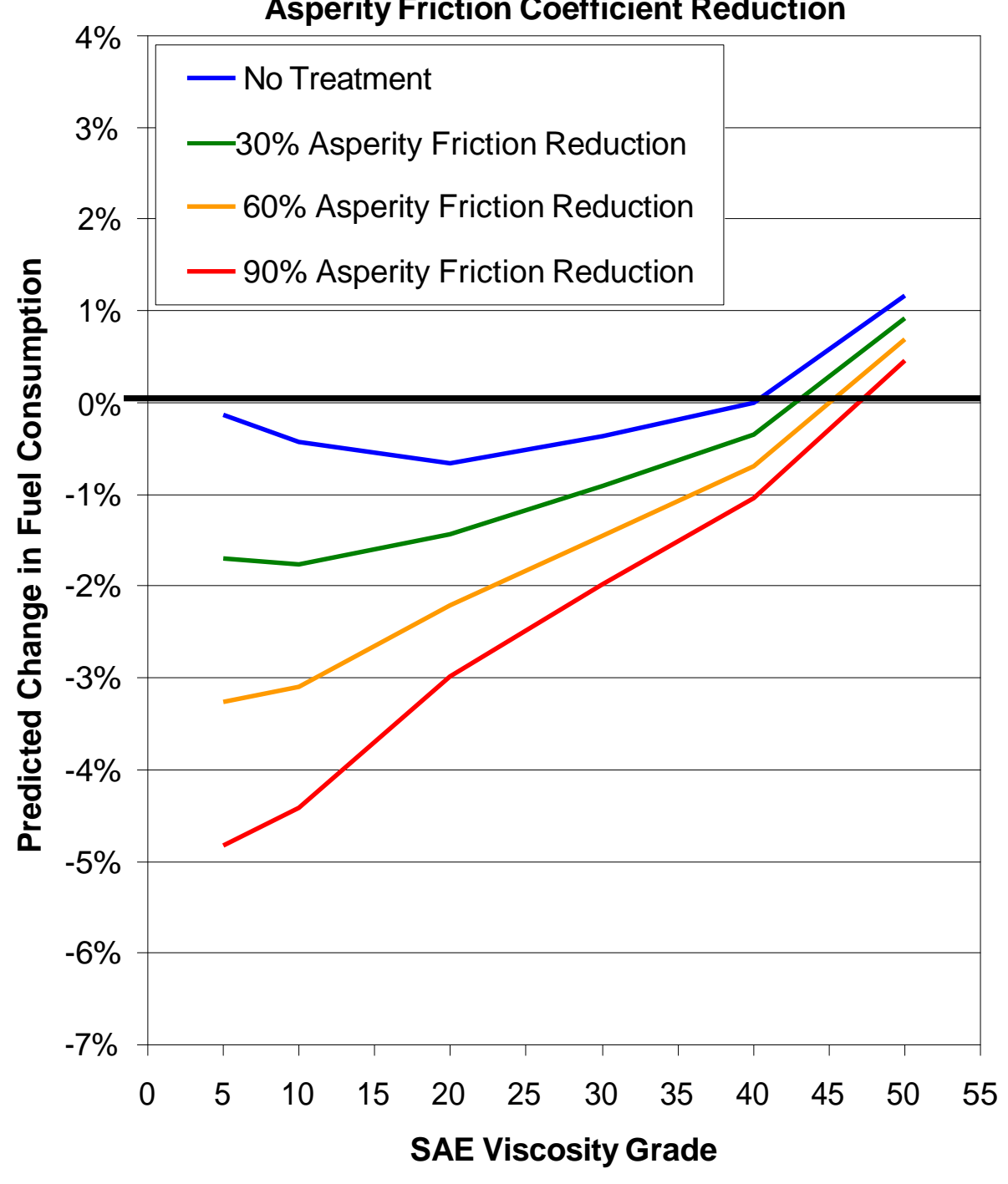




\section{Argonne}

\section{Energy Systems Division}

Argonne National Laboratory

9700 South Cass Avenue, Bldg. 212

Argonne, IL 60439

www.anl.gov 